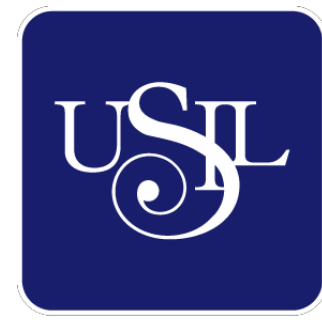

UNIVERSIDAD

SAN IGNACIO

DE LOYOLA

ESCUELA DE POSTGRADO

Maestría en Educación con Mención en Psicopedagogía de la infancia

\title{
INTELIGENCIA EMOCIONAL Y CLIMA DEL AULA EN ESTUDIANTES DEL SEXTO CICLO DE UNA INSTITUCIÓN EDUCATIVA PÚBLICA DEL DISTRITO DE CHORRILLOS
}

Tesis para optar el grado de Maestro en Educación con Mención en Psicopedagogía de la infancia

\section{ALINA ALIANO PIÑAS}

Asesora:

Elisa Beatriz Yanac Reynoso

Lima - Perú

2020 
Página del Jurado

Dra.Yvonne Cruz Castañeda

Presidente

Mg. Victoria Jimenez Chumacero

Secretaria

Mg. Elisa Beatriz Yanac Reynoso

Vocal 
Dedicatoria

A mis hijos Diego, Claudia y mi nieto Caleb por ser la fuerza para mi superación, a mis padres y familia por su apoyo incondicional. 


\section{Agradecimiento}

A Dios que es la fuente de mi fortaleza.

A la asesora de la maestría Elisa Beatriz Yánac

Reynoso. A la directora Pilar América Ladines

Espinoza y colegas de la I.E 7038 Corazón de Jesús de Armatambo- Chorrillos, pero por sobre todo a mis estudiantes que sin ellos no habría podido realizar la presente investigación. 


\section{INDICE}

\section{CARÁtULA}

\section{PÁGINAS PRELIMINARES}

Página del jurado

Dedicatoria

Agradecimiento

Índice

Resumen

Abstract

\section{INTRODUCCIÓN}

1.1. Problema de investigación

1.2. Justificación.

1.3. Antecedentes Internacionales.

1.4. Antecedentes Nacionales.

II. MARCO TEÓRICO

2.1. Variable Independiente.

2.2. Definición de emoción.

2.3. Definición Inteligencia Emocional. 28

2.4. Características de la persona emocionalmente inteligente. 29

2.5. Componentes de la inteligencia emocional. 31

2.5.1. Autoconocimiento emocional. 
2.5.3. Automotivación.

2.5.4. Relaciones interpersonales.

2.6. Modelos de Inteligencia Emocional.

2.6.1. Modelo de Goleman.

2.6.2. Modelo de Bar-On.

2.6.3. Modelo de Salovey y Mayer.

2.7. Variable Dependiente: Clima del aula.

2.7.1. Definición del clima del aula.

2.7.2. Elementos del clima del aula.

2.7.3. Rol del docente en el aula.

2.8. Objetivos e Hipótesis.

2.8.1. Objetivo General.

3.9.1. Hipótesis General.

\section{III.METODOLOGÍA DE LA INVESTIGACIÓN.}

3.1. Enfoque de investigación. 42

3.2. Tipo de Investigación.

3.3. Diseño de investigación. $\quad 42$

3.4. Variables. 43

3.4.1. Variable Independiente: Inteligencia Emocional 44

3.4.2. Variable Dependiente: Clima del aula. 44

3.4.3. Variables Intervinientes. 44

3.5. Población. 44

3.6. Muestra. $\quad 45$ 
3.7. Instrumentos.

3.8. Validez

IV. RESULTADOS

4.1. Validación y confiabilidad de los instrumentos.

4.2. Confiabilidad.

4.3. Tratamiento estadístico e interpretación de tablas Análisis descriptivo

V. DISCUSIÓN.

VI. CONCLUSIONES.

VII. SUGERENCIAS.

VIII. REFERENCIAS BIBLIOGRAFICAS

ANEXOS

Instrumentos Bar On

Cuestionario 
Índice de Tablas

Tabla 1. Nivel de validez de las encuestas, según al juicio de expertos $\quad 50$

$\begin{array}{lll}\text { Tabla } 2 \quad \text { Valores de los niveles de validez } & 50\end{array}$

Tabla 3. Procesamiento de datos 52

Tabla 4. Estadísticas de fiabilidad $\quad 52$

Tabla 5. Nivel de confiabilidad del coeficiente alfa de Cronbach 52

Tabla 6. Inteligencia Emocional $\quad 53$

Tabla 7. Componente Intrapersonal $\quad 54$

Tabla 8. Componente Interpersonal 55

Tabla 9. Componente de manejo del estrés 59

Tabla 10. Componente adaptabilidad 57

Tabla 11. Componente Estado de ánimo general 58

Tabla 12. Clima del aula $\quad 59$

Tabla 13. Inteligencia intrapersonal* clima en el aula tabulación cruzada $\quad 60$

Tabla 14. Inteligencia intrapersonal * inteligencia emocional 61

Tabla 15. Inteligencia interpersonal * inteligencia emocional tabulación cruzada 62

Tabla 16. Componente Adaptabilidad*Clima del aula tabulación cruzada 63

Tabla 17. Componente manejo del estrés * Clima del aula tabulación cruzada $\quad 65$

Tabla 18. Componente manejo de Estrés*Inteligencia Emocional tabulación cruzada 66

Tabla 19. Componente Adaptabilidad*Inteligencia Emocional tabulación cruzada 67

Tabla 20. Componente Estado de Animo General*Clima del aula tabulación cruzada 68

Tabla 21. Componente Estado de Animo General*Inteligencia Emocional tabulación $\begin{array}{ll}\text { Cruzada } & 70\end{array}$

Tabla 22. Prueba de Kolmogorov-Smirnov para una muestra. 71

Tabla 23. Correlaciones entre la inteligencia emocional y el clima del aula de los 
estudiantes del sexto ciclo de una Institución Pública del distrito de Chorrillos. 72

Tabla 24. Correlaciones entre la inteligencia interpersonal y el clima del aula de los estudiantes del sexto ciclo de una institución pública de Chorrillos

Tabla 25. Correlaciones entre la inteligencia interpersonal y el clima del aula de los estudiantes del sexto ciclo de una institución pública de Chorrillos.

Tabla 26. Correlaciones entre el componente manejo del estrés de la inteligencia emocional y el clima del aula de los estudiantes del sexto ciclo de una institución pública de Chorrillos.

Tabla 27. Correlaciones entre el componente adaptabilidad de la inteligencia emocional y el clima del aula de los estudiantes del sexto ciclo de una institución pública del distrito de Chorrillos

Tabla 28: Correlaciones entre el componente estado de ánimo de la inteligencia emocional y el clima del aula de los estudiantes del sexto ciclo de una institución pública del distrito de Chorrillos. 
Índice de Figuras

Figura 1. Inteligencia emocional

Figura 2 Inteligencia Intrapersonal

Figura 3. Inteligencia Interpersonal

Figura 4. Componente manejo del estrés

Figura 5. Componente adaptabilidad

Figura 6. Componente estado de ánimo general

Figura 7 Clima del aula

Figura 8. Inteligencia intrapersonal * Clima en el aula tabulación cruzada

Figura 9. Inteligencia intrapersonal * Inteligencia Emocional

Figura 10. Inteligencia interpersonal * Inteligencia Emocional tabulación cruzada

Figura 11. Componente Adaptabilidad*Clima del aula tabulación cruzada

Figura 12 Componente manejo de Estrés * Clima del aula tabulación cruzada

Figura 13. Componente manejo de Estrés*Inteligencia Emocional tabulación cruzada

Figura 14. Componente Adaptabilidad*Inteligencia Emocional tabulación cruzada

Figura 15. Componente Estado de Animo General*Clima en el aula tabulación cruzada 69

Figura 16. Componente Estado de Animo General*Inteligencia Emocional tabulación 


\section{Resumen}

La presente investigación tiene como objetivo fundamental establecer la relación entre inteligencia emocional y clima del aula de los estudiantes del sexto ciclo de una Institución Educativa Pública del distrito de Chorrillos, para la cual se realizará una investigación de tipo descriptivo correlacional con una población de 197 estudiantes y una muestra final de 135 alumnos del sexto ciclo de la I.E. en mención. La variable independiente Inteligencia emocional se medirá aplicando el instrumento del Inventario de Cociente Emocional de BarOn ICE, adaptación por Nelly Ugarriza Chávez, mientras que para la variable dependiente Clima del aula se utilizó el instrumento denominado Ficha técnica del cuestionario Escala SES, cuyo autor es Kevin Marjoribanks, y adaptado por Aurelio Villa en España. Para determinar la validez de ambos instrumentos se utilizó el Alpha de Cronbach, la misma que se encarga de determinar la media ponderada de las correlaciones entre las variables que forman parte de la encuesta.

De las conclusiones se puede determinar que, con respecto al objetivo general: Existe relación directa y alta $($ Rho de Spearman $=0.745)$, entre la inteligencia intrapersonal y el Clima de aula. Asimismo, se halló una relación directa y moderada (Rho de Spearman $=0.650$ ), entre los niveles de relación entre la entre la inteligencia y clima del aula. Finalmente se estableció la relación directa y moderada $($ Rho de Spearman $=0.550)$ entre el componente manejo del estrés y el clima del aula, según la percepción de los estudiantes evaluados. 


\begin{abstract}
The main objective of this research is to establish the relationship between emotional intelligence and classroom climate of sixth cycle students of a Public Educational Institution in the district of Chorrillos, for which a descriptive correlational research will be carried out with a population of 197 students and a final sample of 135 students from the sixth cycle of IE In mention. The independent variable Emotional intelligence will be measured by applying the BarOn ICE Emotional Quotient Inventory instrument, adapted by Nelly Ugarriza Chávez, while for the dependent variable Climate of the classroom, the instrument called the SES Scale questionnaire technical data sheet, whose author is Kevin Marjoribanks, and adapted by Aurelio Villa in Spain. To determine the validity of both instruments, Cronbach's Alpha was used, which is responsible for determining the weighted average of the correlations between the variables that are part of the survey.
\end{abstract}

From the conclusions it can be determined that, with respect to the general objective: There is a direct and high relationship (Rho de Spearman $=0.745$ ), between intrapersonal intelligence and classroom Climate. Likewise, a direct and moderate relationship was found (Spearman's Rho $=0.650$ ), between the levels of relationship between intelligence and classroom climate. Finally, the direct and moderate relationship was established (Spearman's Rho $=0.550$ ) between the component management of stress and classroom climate, according to the perception of the students evaluated. 


\section{Introducción}

\subsection{Problema de investigación}

\section{Planteamiento}

Han pasado más de dos siglos y por tradición padres, docentes y estudiantes justificaban el éxito a la capacidad intelectual, sin embargo, la relación no se ve tan clara, sobre todo cuando observamos estudiantes que, con un nivel y rendimiento intelectual alto, no son capaces de resolver situaciones de la vida cotidiana. Por el contrario, personas con bajo nivel, resuelven satisfactoriamente situaciones cotidianas, siendo con frecuencia personas con éxito en la vida. Muchos de los problemas en el clima del aula, están referidos a una inadecuada educación de sus emociones. Por este motivo, es necesario incluir el desarrollo de la competencia emocional en el currículo escolar, dentro de las competencias para la vida que el MINEDU promueve.

Con los años, se ha descubierto que las personas con inteligencia emocional tienden a desempeñarse mejor en todos los aspectos de la vida que aquellas con habilidades más débiles. A menudo son personas con personalidades más saludables, mayor productividad y que establecen relaciones más estables. Por lo tanto, es razonable suponer que, si desea construir organizaciones, comunidades y sociedades más efectivas, productivas y humanizadas, debe formar individuos con sabiduría social y emocional (Bar-On, Maree \& Elias, 2007). En vista de lo anterior, es cierto que cualquier esfuerzo dirigido al desarrollo completo de la humanidad debe prestar especial atención al manejo adecuado de las emociones, que es una habilidad básica que vale la pena moldear. Por ello, las instituciones educativas de nivel secundario están orientadas a brindar una formación integral a sus estudiantes necesitan implementarse para dicho fin. Además de que en países como México la Secretaría de Educación Pública en su actual Plan de Estudios 2011 exige que en todos los 
niveles de educación básica se desarrollen competencias para la vida, entre las cuales se encuentra el manejo de situaciones problemáticas, para lo cual las habilidades emocionales son imprescindibles. También hacen un acertado análisis de como en un currículo distinguimos la parte intencional u oficial, el que enseñamos los docentes, el que nuestros estudiantes aprenden y el currículo evaluado por las pruebas así que, aunque no coincidan, lo que todos esperamos es que tengan éxito en la vida y esto se logra cuando uno se conoce y aplica su inteligencia emocional,

En tal sentido, la presente investigación tratará de responder el siguiente problema:

\section{Problema General:}

¿Qué relación existe entre la inteligencia emocional y el clima del aula de los estudiantes del sexto ciclo de una Institución Educativa Pública del distrito de Chorrillos?

\section{Problemas específicos.}

Problema específico 1.

¿Qué relación existe entre la inteligencia intrapersonal y el clima del aula de los estudiantes del sexto ciclo de una Institución Pública del distrito de Chorrillos? Problema específico 2.

¿Qué relación existe entre la inteligencia interpersonal y el clima del aula de los estudiantes del sexto ciclo de una Institución Pública del distrito de Chorrillos?

Problema específico 3.

¿Qué relación existe entre el componente manejo del estrés de la inteligencia emocional y el clima del aula de los estudiantes del sexto ciclo de una Institución Pública del distrito de Chorrillos?

Problema específico 4. 
¿Qué relación existe entre el componente adaptabilidad de la inteligencia emocional y el clima del aula de los estudiantes del sexto ciclo de una Institución Pública del distrito de Chorrillos?

Problema específico 5.

¿Qué relación existe entre el componente estado de ánimo de la inteligencia emocional y el clima del aula de los estudiantes del sexto ciclo de una Institución Pública del distrito de Chorrillos?

\subsection{Justificación}

Según una investigación de Ascorra, Arias y Graff (2003), la inteligencia emocional y el clima en el aula son temas de actualidad, y se han realizado varios estudios sobre ellos, señalando que la falta de capacidad emocional tiene un impacto negativo en los estudiantes y maestros ,porque no se les permite un buen ambiente de aprendizaje, pero las personas estudiadas tienen características típicas de antecedentes sociales y culturales desfavorables, y estas características no se han estudiado completamente, por lo que este estudio compensará esta brecha teórica. Desde un punto de vista práctico, este estudio servirá como una herramienta para proporcionar las pautas de precaución necesarias para mejorar el entorno escolar en función de su comprensión de su EQ. En teoría, la lista de verificación ICE Bar On puede verificarse como una herramienta que puede describir la inteligencia emocional y puede aplicarse de la misma manera que la tabla de clima escolar, y puede verse como útil cuando se describe el comportamiento a través de sus resultados. Estudiantes y tomar medidas correctivas si su nivel es bajo. Con esto se pretende explicar las situaciones que se presentan y lograr en nuestros estudiantes mejorar las competencias para la vida que deben desarrollarse en el colegio. 


\subsection{Antecedentes internacionales:}

Colores (2015) en su tesis “Desarrollo de la competencia Inteligencia Emocional en una institución de educación básica del nivel de secundaria”, presentado en la Universidad Tecnológica de Monterrey-México, para optar el grado académico de Maestría en Educación, La investigación se basa en la importancia que tiene el manejo de las emociones en los diferentes ámbitos de la vida, y en este trabajo se explora cómo se desarrolla la inteligencia emocional al interior de una institución educativa de nivel medio del estado de Querétaro. Para ello se realizó un estudio de tipo cualitativo en el cual se aplicó un cuestionario a 18 alumnos y otro a 8 maestros de una institución de educación básica de nivel secundaria, con la finalidad de conocer sus percepciones respecto a cómo se desarrollan las habilidades emocionales de los estudiantes al interior del centro educativo, si existen estrategias específicas para dicho fin y si las consideran eficaces. Entre los principales resultados obtenidos, se encontró que la institución tiene algunos programas que desarrollan la inteligencia emocional de los estudiantes, y la interacción entre estos programas y sus maestros en el aula es más importante. Esto resalta el papel de los maestros y la importancia de regular emocionalmente su capacidad para capacitar a los estudiantes en este campo; esto plantea una nueva pregunta sobre qué medidas pueden tomar las instituciones educativas para desarrollar su personal docente y el EQ de los estudiantes.

Escobedo (2015) en su tesis: “Relación entre Inteligencia Emocional y Rendimiento Académico de los alumnos del nivel básico de un colegio privado", presentado en la Universidad Rafael Landivar-Guatemala, para optar el título de Licenciada en Educación y Aprendizaje, manifiesta que existe relación entre inteligencia emocional y rendimiento académico de los estudiantes del nivel de básico de un colegio privado, ubicado en Santa Catarina Pinula. Se aplicó a 53 alumnos del nivel de básico, de ambos géneros entre los 14 y 16 años de edad. Fue una investigación cuantitativa, de tipo correlacional. Se aplicó la prueba 
TMSS, basada en Trait Meta-Mood Scale, para evaluar la Inteligencia Emocional, prueba desarrollada por Peter Salovey y Jack Mayer. El rendimiento académico se obtuvo del promedio de las notas finales. El estadístico que se utilizó fue el coeficiente de correlación de Pearson. Luego del análisis estadístico, se determinó que existe una correlación estadísticamente significativa a nivel de 0.05 entre estrategias para regular las emociones y rendimiento académico en los alumnos de 1ro y 2do básico. En lo que se refiere a la subescala de Atención a las Emociones, se determinó que no existe una correlación positiva, entre las dos variables. Por otro lado, se obtuvo una correlación positiva débil, en los alumnos de 1ro y 2do básico, entre la claridad en la Percepción Emocional y el rendimiento académico, entre el total de las subescalas de inteligencia emocional y el rendimiento académico de los alumnos, la correlación no fue estadísticamente significativa. Por lo que se recomienda aplicar la prueba TMMS a sujetos con diferentes características, para poder comparar los resultados.

Maldonado (2016) en su tesis: Clima de Aula Escolar y Estilos de Enseñanza. Asociación y Representaciones Expresados por Profesores de Educación Básica en la Comuna de Quilpué tiene como objetivo asociar el clima de aula escolar y los estilos de enseñanza expresados por los docentes de enseñanza básica de Quilpué y las representaciones sociales de los mismos. Desde un punto de vista metodológico, este es un tipo mixto de encuesta. Con este fin, además de desarrollar grupos de discusión como técnicas cualitativas, el formato Classrom Environmental Scale (CES) también es aplicable al acuerdo de estilo de enseñanza de los maestros, Honey y Alonso. La muestra de investigación se realizó en 13 instituciones básicas del sistema público de la comuna, y se realizó una muestra específica en la institución, con un total de 86 maestros participantes. Los resultados muestran que existen diferencias significativas en las relaciones subdimensionales de los estudiantes, la ciudad / rural de los 
docentes y las especialidades; en general, existe un alto grado de correlación entre el "ambiente de clase" y los docentes que demuestran estilos de enseñanza abiertos.

Porcayo (2015) en su tesis: “Inteligencia emocional en niños", presentada en la Universidad Autónoma de México, para optar el título de Licenciada en Psicología, se planteó describir la Inteligencia Emocional en niños de ambos sexos de la Escuela Primaria Guadalupe Victoria, San Mateo Atenco; Estado de México; aplicó el instrumento de Inteligencia Emocional construido por Rodríguez (2006), dicho instrumento mide cinco factores de la Inteligencia Emocional (IE): Expresividad Emocional, Autocontrol, Motivación, Autoconocimiento y Habilidades Sociales. Se aplicó a 100 niños, la muestra estuvo conformada por 54 mujeres y 46 niños; cuyas edades oscilaron entre los 10 y12 años asimismo se encontraban cursando quinto y sexto grado de primaria. Los resultados obtenidos fueron que los niños estudiados presentan puntajes medios en todos los factores de la Inteligencia Emocional (IE) a excepción de las Habilidades Sociales pues es el puntaje más bajo, en general los niños tienen más desarrollado el factor de motivación, en cuestión de género no hubo diferencia por el contrario en cuestión de edades si se encontraron diferencias estadísticamente significativas ya que los niños de 10 años son quienes presentan las medias más altas en los factores de la Inteligencia Emocional mientras que los de 12 años son quienes presentan las medias más bajas en dichos factores. En resumen, se puede determinar que los niños estudiados tienen un buen EQ; sin embargo, las habilidades sociales deben desarrollarse más porque obtienen calificaciones más bajas en habilidades sociales

\subsection{Antecedentes Nacionales:}

Blondet (2014) en su tesis: “Clima del aula y motivación académica de alumnos del 5to. año de secundaria de las Instituciones Educativas Públicas de Huacho, 2014”, presentado en la Universidad Cesar Vallejo, para optar el grado de maestro en Administración de la Educación, refiere: que buscaba conocer la relación entre las variables en estudio, Clima de 
aula que es el estado psico emocional de los que comparten un espacio en el aula de clase y que relación podemos encontrar con la motivación que reciben del orientador como de ellos mismos para su desarrollo intelectual, partiendo de la siguiente formulación del problema general, ¿Cuál es la relación entre el clima de aula y la motivación académica de los alumnos del 5to de secundaria de las instituciones educativas públicas de Huacho - 2014.?

Investigación cuantitativa no experimental; descriptiva correlacional. La muestra es probabilística aleatoria simple, con una población de 313 alumnos, quedando una muestra de 171 alumnos del 5to de secundaria de 06 instituciones educativas públicas - 2014. Se administró dos cuestionarios de 24 preguntas para cada variable.

Para ver la fiabilidad de los instrumentos de las variables se hizo uso del estadístico de coeficiente de correlación de Conbrach, en la variable Clima de aula se obtuvo un resultado de $\mathrm{Rho}=, 0,902$; y la variable Motivación académica un resultado de Rho $=0,801$, llegando a la conclusión que existe fiabilidad en los instrumentos de las variables Clima de aula y motivación académica.

Guerrero (2014) en su tesis "Clima social familiar, inteligencia emocional y rendimiento académico de los alumnos de quinto de secundaria de las instituciones educativas públicas de Ventanilla", presentado en la UNMSM, para optar el grado académico de Magister en Psicología con mención en Psicología Educativa, nos dice:

El propósito de esta investigación es establecer la relación entre el ambiente social familiar, la inteligencia emocional y el rendimiento académico de los estudiantes de quinto grado de secundaria de Ventanilla. La muestra incluyó a 600 estudiantes masculinos y femeninos de secundaria de quinto grado de quienes obtuvieron la escala del clima social de las familias Moros y Trickett, la lista de verificación de inteligencia emocional Bar-On y el rendimiento académico. Comunicación y matemática. Los resultados mostraron que existe relación entre las dimensiones del clima social familiar, la inteligencia emocional con el 
rendimiento académico en el curso de comunicación. Se encontró que había diferencias en la escala de manejo del estrés de inteligencia emocional entre hombres y mujeres. Finalmente, el rendimiento académico está relacionado con la gestión de la presión y la escala de adaptabilidad de la inteligencia emocional y la dimensión de relación y desarrollo del ambiente social familiar.

Medina (2017) en su tesis "Inteligencia emocional de los docentes y clima de aula en la Escuela Profesional de Administración de Negocios de la Universidad de San Juan Bautista, Filial Chincha”, presentado en la UNE, para optar el grado de Maestría en Gestión Educacional, nos dice:

La investigación titulada "Inteligencia emocional de los docentes y clima de aula en la Escuela Profesional de Administración de Negocios de la Universidad San Juan Bautista, filial Chincha”, aplicó el diseño descriptivo correlacional. El tipo de investigación descriptiva y el método, analítico-sintético. Se trabajó con una muestra de 46 docentes. El estudio concluye que existe correlación estadísticamente significativa de 0,823 entre la inteligencia emocional y el clima de aula existente en la Escuela Profesional de Administración de Negocios de la Universidad San Juan Bautista, filial Chincha, cuya dependencia entre las variables es del 82,3\%. Tomando en consideración el coeficiente de variabilidad $(\mathrm{r} 2=0,677)$ se infiere que el clima de aula está determinado en $67,7 \%$ por la inteligencia emocional, con lo cual se evidencia que los docentes tienen conocimiento y control de sus emociones y reconocen que el tipo de relaciones interpersonales y nivel de trabajo en equipo con el cual el clima de aula es muy positivo.

Palomino (2015) en su tesis "Estudio de correlación entre la inteligencia emocional y el rendimiento académico de los estudiantes de la Facultad de Educación - UNMSM 2012-II', presentado en la UNMSM, para optar el grado académico de Magister en Educación con mención en Docencia en el Nivel Superior, nos muestra la correlación entre la Inteligencia 
Emocional y el Rendimiento Académico de los estudiantes de la Facultad de Educación UNMSM, 2012-II. La metodología empleada es de una investigación correlacional, que se trabajó en 992 alumnos del nivel universitario, siendo la muestra de 278 estudiantes para el ICE de BarOn. Para el análisis estadístico de las variables se utilizó la correlación R de Spearman confirmándose la hipótesis general, de que existe correlación significativa, entre la variable independiente inteligencia emocional y la variable dependiente rendimiento académico, en la muestra estudiada. Contrariamente a ciertos supuestos, se ha confirmado que existe una relación significativa entre los diversos componentes de la inteligencia emocional y el rendimiento académico. Y según el género y la especialidad del alumno. La conclusión es que cuanto más conocimiento de la inteligencia emocional, el desarrollo y el uso de las emociones, más infame va más allá del uso cognitivo de un mayor rendimiento académico.

Tovar (2019) en su tesis: "Relacion entre la inteligencia emocinal y el rendimiento academico de los estudiantes del segundo año de la Escuela de Oficiales de la Policia Nacional del Perú”, presentado en la UNMSM, para optar el grado academico de Magister en Educacion con mencion en Docencia Universitaria, nos dice:

La investigación que se presenta tiene como objeto "Determinar la relación entre la inteligencia emocional y el rendimiento académico de los estudiantes del segundo año de la Escuela de Oficiales de la Policía Nacional del Perú - 2017’. El diseño en la investigación fue descriptivo correlacional. La presente investigación tiene un enfoque cuantitativo con una población de estudio de 180 alumnos; variable "Inteligencia Emocional” se utilizó un mecanismo de preguntas y respuestas, es decir, un cuestionario y de instrumento una encuesta de una escala politómica y su confiabilidad de Cronbach que indica una muy ingente confiabilidad. Para la variable "rendimiento académico" se utilizó la técnica de observación y de instrumento una lista de cotejo que se aplicó con una escala dicotómica y el instrumento 
fue KR20, lo que indicó una alta confiabilidad. Fueron dos los elementos que otorgaron validez a los instrumentos, entre estos se tiene, uno denominado como temático y el otro denominado metodólogo. Estos se relacionan al determinar que son aplicables los instrumentos para medir la relación entre la "Inteligencia Emocional” y “el Rendimiento Académico" de los alumnos evaluados. Se concluye que "existe una relación importante entre la inteligencia emocional y el rendimiento académico de los estudiantes del segundo año de la Escuela de Oficiales de la Policía Nacional del Perú - 2017.

Silva (2018) en su tesis: "Inteligencia emocional y clima del aula de los estudiantes de la Institucion Educativa Maria Parado de Bellido del distrito del Rimacv, 2017”, presentado en la Uniuversidad Cesar Vallejo, para optar el grado académico de Maestro en Educacion, nos dice:

La investigación tuvo como objetivo fundamental establecer la relación entre inteligencia emocional y clima del aula en las estudiantes de la institución educativa María Parado de Bellido del Distrito del Rímac, 2017. Se realizó una investigación de tipo descriptivo correlacional con una población de 207 estudiantes y aplicada a una muestra final de 135 alumnas del 4to año de secundaria. La variable Inteligencia emocional fue medida a con el Inventario de Cociente Emocional de BarOn ICE, adaptación peruana hecha por Nelly Ugarriza Chavez y Liz Pajares, mientras que la variable Clima del aula se utilizó el instrumento denominado Ficha técnica del cuestionario (Escala SES), cuyo autor es Kevin Marjoribanks, de nacionalidad australiana y su adaptación fue hecha por Aurelio Villa de España.

Para determinar la validez de ambos instrumentos se utilizó el alpha de Cronbach, que se encarga de determinar la media ponderada de las correlaciones entre las variables (o ítems) que forman parte de la encuesta, así mismo se hizo la prueba de bondad de ajuste de Kolmogorov, la cual se usó debido a que la base de datos tuvo más de 50 componentes 
encontrando valores de $\mathrm{p}$ menores de 0.05 ; en tal sentido al demostrar que los datos no siguen una distribución normal, para contrastar las hipótesis, se empleó la estadísticas no paramétrica: Rho de Spearman.

De los resultados obtenidos se comprobó que existe una correlación directa, alta y significativa entre la inteligencia emocional y el clima del aula, es decir a mayor inteligencia emocional, mejor clima del aula; situación que también se repitió con las dimensiones de la inteligencia emocional: intrapersonal, interpersonal, manejo del estrés, adaptabilidad y estado de ánimo donde se encontró una correlación directa, alta y significativa con el clima del aula. Vega (2015) en su tesis “Clima del aula y su relación con los logros de aprendizajes en comunicación en los estudiantes del quinto grado de la I.E. San Juan-UGEL 01, 2016", presentado en la UNE-La cantuta, para optar el grado académico de Maestro en Docencia Universitaria, nos muestra una investigación de tipo descriptivo y diseño correlacional, tuvo el propósito de determinar el nivel de relación entre el clima de aula y los logros de aprendizaje en el área de comunicación de los estudiantes del quinto grado de primaria de la I.E. San Juan - UGEL 01, 2016. La muestra estuvo conformada por 81 alumnos. Se realizaron dos pruebas: el test de medición del clima de aula y una prueba escrita de comprensión y producción de textos. El primero, basado en el test de Marjoribanks (1980), adaptado por Cornejo y Redondo (2001), con 0.75 de coherencia interna según prueba Alpha de Cronbach; y, el segundo, es una prueba de comprensión y producción de textos desarrollado por la unidad de medición de la calidad del Ministerio de Educación en el año 2009. Se utilizó la prueba estadística r de Spearman, obteniéndose una correlación positiva media de $r=0,567$, entre ambas variables.

Vilchez (2015) en su tesis: "Influencia del programa de inteligencia emocional en el clima escolar de los estudiantes del tercer año "A" de secundaria de la I.E. 1283 Okinawa, 2015", presentado en la UNE-La cantuta, para optar el grado académico de Maestro con mención en 
Gestión Educacional, se planteó como objetivo establecer la relación que existe entre la inteligencia emocional y el clima escolar, para tal efecto se realizó una investigación de tipo aplicada con diseño pre experimental. La muestra estuvo conformada por 22 estudiantes de ambos sexos, que cursaban el tercer año de secundaria, a quienes se le aplicó un pre y pos test. Los principales hallazgos fueron: Existe una relación estadísticamente significativa entre la inteligencia emocional y el clima escolar, así como los componentes: normas de convivencia, comunicación asertiva, valores y la percepción de la Institución Educativa. En conclusión, la hipótesis fue confirmada. 


\section{Marco teórico}

\subsection{Variable Independiente: Inteligencia Emocional}

\section{Definición de Inteligencia:}

Hasta hace poco tiempo se pensó que los niños que más sabían o conocimientos tenianlos podían aplicar de mejor manera en la vida cotidiana, realidad que se contrasta con la aplicación de la inteligencia emocional. "El término Inteligencia procede del latín intelligere que significa comprender, entender a su vez derivado de legere que significa coger, escoger" (Martínez y Pérez, 2007).

Binet (1905) consideró la inteligencia como un conjunto de facultades: juicio, sentido común, iniciativa y habilidad personal para adaptarnos a las circunstancias.

Weschler (1958) definió la inteligencia como "la capacidad global o conjunto del individuo para actuar con un propósito determinado, pensar racionalmente y enfrentarse con su medio ambiente en forma efectiva".

La inteligencia según Piaget (Elkind, 1969) es una prolongación de la adaptación biológica constituida por los procesos de asimilación (procesos de respuesta a los estímulos internos) y procesos de acomodación (procesos de respuesta o reacción a las interferencias del medio ambiente) (citado en Sattler, 1977)

\subsection{Definición de Emoción:}

Cuando cada autor centró su investigación en una determinada variable, propuso una definición de sentimiento, que se separó de la idea de otro investigador interesado en otros componentes, Investigaciones de (Palmero, Guerrero, Gómez y Carpi, 2006). Por ejemplo, autores interesados en la cognición otorgan más importancia a la evaluación y la valoración para definir las emociones y centrarse en la capacidad de procesar información emocional basada en la percepción, la experiencia y las características subjetivas. Palmero, en relación a 
las definiciones de la emoción, cita a Lyons al decir que "las definiciones de la emoción no son más que modelos funcionales expresados en palabras... y es difícil concebir cómo alguien podría llegar muy lejos sin intentar formularlas" (citado en Palmero et al., 2006, p. 1).

Por su parte Izard considera que la "emoción consta de circuitos neuronales, sistemas de respuesta, y un estado/proceso de sentimiento que motiva y organiza la cognición y la acción. La emoción también proporciona información a la persona que lo experimenta, y puede incluir evaluaciones de antecedentes cognitivos y de la cognición en curso, incluyendo una interpretación de su estado emocional, expresiones o señales sociales y comunicativas, puede motivar un comportamiento de evitación o acercamiento, ejercer control/regulación de las respuestas..." (Izard, 2010, p. 367).

Gardner (1983, 1995, 1999) expresó en repetidas ocasiones su insatisfacción con la definición de la capacidad de pensamiento humano, que es la insatisfacción con el concepto ortodoxo de inteligencia única como lo define el coeficiente intelectual y se rebeló contra la visión general y estable de la inteligencia.

\subsection{Definición de Inteligencia Emocional:}

Daniel Goleman en 1995 escribió el libro Inteligencia Emocional para el conocimiento del público en general. Aunque el término parece cuestión de moda, no es adecuado pensar en ello como moda porque las modas son pasajeras y las emociones forman parte de los seres humanos (Rodríguez, 2000).

Según Meyer y Salovey (1997), la inteligencia emocional incluye la habilidad para percibir con precisión, valorar y expresar emoción; la habilidad de acceder y/o generar sentimientos cuando facilitan pensamientos; la habilidad de comprender la emoción y el conocimiento emocional, y la habilidad para regular las emociones, para promover crecimiento emocional e intelectual (citado en Bisquerra, 2010). 
La Inteligencia Emocional implica la habilidad para percibir, valorar y expresar emociones con exactitud; la habilidad para acceder y/o generar sentimientos que faciliten el pensamiento; la habilidad para comprender emociones y el conocimiento emocional y la habilidad para regular las emociones promoviendo un crecimiento emocional e intelectuall. (Mayer y Salovey, 1997, p. 10).

La inteligencia emocional es la capacidad o habilidad para controlar los impulsos emotivos ayudándonos a resolver los problemas de manera pacífica y proporcionándonos bienestar (Rodríguez, 2000).

La capacidad para controlar los impulsos es la inteligencia emocional ayudándonos a resolver los problemas de manera pacífica y proporcionándonos bienestar (Rodríguez, 2000). La inteligencia emocional se empleó para describir las cualidades emocionales que parecen tener importancia para el éxito. Estas pueden incluir:

- La empatía.

- La expresión y comprensión de los sentimientos.

- El control de nuestro genio.

- La independencia.

- La capacidad de adaptación.

- La simpatía.

- La capacidad de resolver los problemas en forma interpersonal.

- La persistencia.

- La cordialidad.

- La amabilidad.

- El respeto (Shapiro y Lawrence, 1997).

2.4 Características de la persona emocionalmente inteligente: 
Actitud positiva:

Resultado

Enfatizando los aspectos positivos sobre los negativos; valora el éxito sobre los errores, la calidad sobre los defectos, los logros sobre las deficiencias y el esfuerzo sobre los resultados, y busca equilibrar la tolerancia y la demanda

\section{Reconoce los propios sentimientos y emociones.}

Tiene la capacidad de expresar emociones y sentimientos: lo que se considera positivo y lo que se considera negativo, ambos deben transmitirse a través de alguna forma de expresión.

Las personas inteligentes saben cómo identificar el canal más adecuado y el momento adecuado. Puede controlar los sentimientos y las emociones: sabe cómo encontrar un equilibrio entre expresión y control. Sepa cómo esperar, soportar los contratiempos y poder retrasar la gratificación.

\section{Es empática:}

Se coloca con facilidad en la piel del otro, capta sus emociones, aunque no las exprese en palabras, sino a través de la comunicación no-verbal.

\section{Es capaz de tomar decisiones adecuadas:}

El proceso de toma de decisiones combina razón y emoción. Las emociones a veces dificultan la toma de decisiones. Es importante tener en cuenta los factores emocionales presentes en cada decisión para hacerla apropiada.

\section{Tiene motivación ilusión e interés:}

Por el contrario, pasivo, aburrido o perezoso. Esta persona tiene la capacidad de motivarse a sí mismo, estar entusiasmado con el logro de sus objetivos y estar interesado en las personas y las cosas que lo rodean. 


\section{Autoestima adecuada:}

Confianza en sus sentimientos positivos y su capacidad para enfrentar desafíos en la vida. Sabe dar y aceptar, y tiene valores que le dan sentido a la vida. Pudo superar dificultades y frustraciones, incluso si eran muy negativas. Tiene la capacidad de integrar la polaridad: cognición y emoción, hemisferio izquierdo y derecho, soledad y compañía, tolerancia y necesidad, derechos y obligaciones (Ibarrola, 2012).

\subsection{Componentes de la inteligencia emocional:}

\subsubsection{Autoconocimiento emocional:}

Se refiere al conocimiento de las propias emociones y cómo afectan. Es muy importante conocer el modo en el que el estado de ánimo influye en el comportamiento, cuáles son las propias virtudes y los propios puntos débiles. Sería sorprendente saber que poco se sabe de uno mismo (Ibarrola, 2012).

\subsubsection{Autocontrol emocional:}

El autocontrol consiste en manejarse correctamente en la dimensión, cuidándose, dominándose y organizándose bien en la vida. Esto implica, la capacidad de ordenarse en forma adecuada y ejercer el tipo de dominio propio que fomenta el bienestar del individuo y de manera complementaria, del grupo al que se pertenece (De Mezerville, 2004).

\subsubsection{Automotivación:}

Dentro del desarrollo en el niño, la automotivación es esencial para reforzar el comportamiento y dirigirse hacia los objetivos planteados que se tengan. Dirigir las emociones hacia un objetivo permite mantener la motivación y fijar la atención en las metas en lugar de los obstáculos. En esto es necesaria cierta dosis de optimismo e 
iniciativa, de forma que se logre ser emprendedor y se actué de forma positiva ante los contratiempos (Ibarrola, 2012).

\subsubsection{Relaciones interpersonales:}

Cualquiera puede darse cuenta de que una buena relación con los demás es una de las cosas más importantes para la vida y para el trabajo. Y no sólo tratar a los que nos parecen simpáticos, a nuestros amigos, a nuestra familia (Ibarrola, 2012).

\subsection{Modelos de Inteligencia Emocional:}

\subsubsection{Modelo de Goleman:}

Goleman establece la existencia de un Cociente Emocional (CE) que no se opone al Cociente Intelectual (CI) clásico, sino que ambos se complementan. Este complemento se manifiesta en las interrelaciones que se producen. Un ejemplo lo podemos observar entre las comparaciones de un individuo con un alto cociente intelectual, pero con poca capacidad de trabajo y otro individuo con un cociente intelectual medio y con alta capacidad de trabajo. Ambos pueden llegar al mismo fin, ya que ambos términos se complementan. Los componentes que constituyen la IE según Goleman (1995a) son:

- Conciencia de uno mismo.

- Autorregulación.

- Motivación.

- Empatía.

- Habilidades sociales.

\subsubsection{Modelo de Bar-On:}

El modelo está compuesto por diversos aspectos: componente intrapersonal, componente interpersonal, componente del estado de ánimo en general, componentes 
de adaptabilidad, componentes del manejo del estrés y, componente del estado de ánimo en general. Este Modelo, considera los siguientes componentes:

- Componente Intrapersonal.

- Componente Interpersonal.

- Componente de Adaptabilidad.

- Componente de manejo del estrés.

- Componente de estado de ánimo.

\subsubsection{Modelo de Salovey y Mayer:}

El modelo ha sido reformulado en sucesivas ocasiones desde que, en el 1990, Salovey y Mayer introdujeran la empatía como componente. En 1997 y en 2000, los autores realizan sus nuevas aportaciones, que han logrado una mejora del modelo hasta consolidarlo como uno de los modelos más utilizados y, por ende, uno de los más populares. Las habilidades incluidas en el modelo son las siguientes:

- Percepción emocional.

- Facilitación emocional del pensamiento.

- Comprensión emocional.

- Dirección emocional.

- Regularización reflexiva de las emociones para promover el crecimiento personal.

\subsection{Variable Dependiente: Clima del aula}

\subsubsection{Definición del clima del aula}

Clima de aula se relaciona con otros juicios, usados en la investigación actual, cómo la percepción de los estudiantes quienes piensan en las interacciones entre los compañeros, entre ellos y el maestro con el contenido o temas a desarrollar. Se puede decir 
que el clima del aula difiere mucho de lo que conocemos como realidad y que merece ser analizada.

El clima del aula es una dimensión bien diferenciada de la realidad escolar, que es digno de ser analizado, por cuanto es un facilitador u obstaculizador de los resultados, en la medida que contribuya efectivamente a los logros del centro.

Para Bethencourt y Báez, citados por Espinoza (2006): “el clima del aula o ambiente de aprendizaje es el conjunto de propiedades organizativas, tanto instructivas como psicosociales que permiten describir la vida del aula y las expectativas de los escolares se asocian significativamente a sus resultados de aprendizaje, a su atención y a su comportamiento". (p. 223)

Coll y Sole (2004), proponen que el clima de aula, es un sistema contextual constituido por diversos elementos que interactúan entre sí y que dan como resultado de estas interacciones, el aprendizaje. En estas interacciones intervienen los estudiantes, los profesores, los contenidos, las prácticas entre otros. (p, 361)

Desde otro ángulo, el clima de aula, se considera como: "El conjunto de actitudes, respuestas afectivas y percepciones relacionadas a los procesos del aula de parte de los alumnos". (Zahn, 1986, citado por Centeno, 2008, p, 19)

$\mathrm{Al}$ analizar las diversas teorías propuestas por los investigadores que mencionamos, la mayoría de ellas enfatizan una relación saludable. Esta relación debe existir entre los maestros y los estudiantes que se reúnen en el aula. Para esto, deben establecer La relación de confianza, respeto, empatía, especialmente la capacidad de ganar una atmósfera agradable en el desarrollo de la psicología, la emoción y el placer, entre ellos, se ha fortalecido el binomio de aprendizaje / enseñanza de cada componente del aula. El maestro actúa como una guía para marcar la distancia de las habilidades y el conocimiento de los estudiantes para generar admiración, respeto y confianza. 


\subsubsection{Elementos del clima del aula}

El clima del aula en las I.E. publicas de Perú, está conformada por los siguientes elementos que tienen relación con las necesidades emocionales de los estudiantes, para el logro afectivo de los aprendizajes, éstos son:

a) El respeto a sí mismo y los demás:

Se refiere a maestros y estudiantes que deben ser respetados y discriminados sin razón (religión, cultura, idioma, nivel socioeconómico). Cada uno tiene su propio valor de acuerdo con sus condiciones sociales; todos los seres humanos tienen la misma dignidad y los mismos derechos.

b) Crecimiento personal de cada miembro del grupo.

Cada miembro debe aumentar el conocimiento, aprender habilidades y destrezas para mejorar su calidad de vida, desarrollar valores y mejorar gradualmente su capacitación, porque no todos los miembros de la clase tienen las mismas necesidades e intereses. Y la misma velocidad de aprendizaje.

c) La identidad y autoestima

Son necesidades emocionales que tienen que ser promovidas por los docentes en el aula. Todo alumno, con alto grado de autoestima, es aquella que se siente orgullosa de ser quien es, y se su forma de ser. La identidad se adquiere en el seno de la familia, y de la sociedad, de manera que los estudiantes ya la poseen, al iniciar su vida escolar, de ahí, que la escuela juega un papel importante en el fortalecimiento de la identidad y de la autoestima del estudiante.

d) La convivencia satisfactoria.

Es otra necesidad afectiva que debe ser potenciada en el aula, y para lograrla, es fundamental el asertividad del docente, para con sus alumnos, hacer que estos tengan 
libertad para actuar y tomar decisiones; sin perder de vista los intereses del grupo. Los problemas que tengan deben ser resueltos, a través, del diálogo. Es necesario que docentes y estudiantes pongan en práctica la inteligencia emocional a la hora de solucionar conflictos, con el fin de lograr una convivencia en armonía.

e) Planificación de los aprendizajes:

Son cada de las secuencias, hacia dónde se dirigen los procesos de aprendizaje, cómo los va a realizar y si se ha alcanzado los objetivos, además debe tenerse presente que no todos los estudiantes tienen los mismos ritmos de aprendizaje, por lo que se debe crear espacios para atender casos particulares y de esta forma apoyarlos cuando tengan alguna dificultad en su aprendizaje.

f) Deben evitarse agresiones físicas o verbales

En el aula, tanto de parte del docente como entre estudiantes, porque esto puede afectar directa e indirecta, la autoestima e integridad de los estudiantes. Por lo que es fundamental hacer hincapié, sobre el valor del respeto como base de la disciplina y de la convivencia pacífica.

\subsubsection{Rol del docente en el aula}

Según la investigación realizada por Gómez y Mir (2011), el papel de los docentes en el proceso educativo tiene una alta prioridad y es la base para alcanzar los objetivos de enseñanza. Los educadores son aquellos que dan vida y significado a cada organización escolar. Es un instructor preparado que debe mantener un contacto oportuno con los estudiantes y esperar que el maestro brinde: comprensión, interés, simpatía, justicia y atención; por lo tanto, el papel del maestro juega un papel decisivo en la vida futura del estudiante, lo que lo convierte en Capacidad para superar el miedo, la inseguridad, los desequilibrios, las preocupaciones y las preocupaciones, y enfrentar el futuro con esperanza, optimismo, toma de decisiones y coraje. El profesor 
debe tener la habilidad de crear un ambiente de autoestima y seguridad en el aula para que el alumno asuma retos creativos y cognitivos.

El clima del aula debe de ser proporcionado por el docente, para permitir que el estudiante, asuma retos creativos, innovadores y cognitivos, tales como:

- Receptivo: proporciona al alumno seguridad y facilite la sincronía entre el pensamiento y la conducta.

- Abierto: genera confianza con el docente.

- Estimulante: motiva al alumno a encontrar soluciones y afrontar nuevos retos.

- Colaborador: facilita posibilidades, medios y recursos para desarrollar y profundizar en todos los temas que los motiven.

- Participativo: que le haga sentir miembro del grupo para poder aportar y recibir afecto, estímulo y compañía.

- Positivo y alegre: los juicios de valor y críticas serán positivas y optimistas. Según Voli (2004), citado por Cáceres, Gutiérrez, Briceño y Aranguren, considera para el estudio del clima en el aula, un conjunto de variables agrupadas en lo que denomina contextos del clima los cuales se presentan a continuación: (a) contexto interpersonal, (b) contexto regulativo, (c) contexto instruccional y (d) contexto imaginativo- creativo. Relaciones interpersonales. Se refiere a la percepción de los estudiantes de su relación íntima con sus maestros y su preocupación por los problemas. Todos estos factores nos hacen darnos cuenta claramente de que la relación interpersonal en la atmósfera del aula puede medir la percepción de los estudiantes sobre la cercanía y la preocupación de los maestros en cualquier nivel educativo (incluido el nivel universitario).

Contexto regulativo Se refiere a las opiniones de los estudiantes sobre las reglas y las relaciones de autoridad en las instituciones educativas; donde existen códigos o regulaciones 
implícita o explícitamente, estas regulaciones o regulaciones constituyen un documento que determina los criterios de coexistencia, qué se puede hacer y qué no Lo que debe hacerse, los derechos y obligaciones de los estudiantes, maestros y administradores.

De esta manera, es mejor tener un conjunto de reglas, y es mejor negociar con ellas para definir claramente los estándares de acción requeridos.

Contexto Instruccional Ambiente de enseñanza. Cubre las opiniones de los estudiantes sobre el interés o desinterés de los maestros por aprender de los estudiantes. Es decir, son conscientes del interés de los docentes en el aprendizaje, y debido a que utilizan estrategias para generar su motivación o financiación para objetos de aprendizaje, su propósito es provocar conflictos cognitivos y emocionales de los estudiantes. Esto despertó interés en el objeto de investigación. Por lo tanto, lo que es seguro es que la situación de enseñanza en la atmósfera del aula es un entorno para medir la percepción de los estudiantes en la situación de enseñanza desde la perspectiva académica. Por lo tanto, sienten que los maestros están interesados o no interesados en que aprendan.

Contexto Imaginativo-Creativo Entorno creativo imaginativo. Se dice que esto se refiere al aspecto de su entorno estimulante, porque mide la percepción de los estudiantes de un entorno imaginativo y creativo en el que se sienten inspirados para crear y experimentar el mundo a su manera, o viceversa. Sienten un clima rutinario, rígido y tradicional (páginas 3402-3403). Según Mena y Valdés (2008), citados por Hernández (2015):

El desarrollo del concepto clima escolar y de aula tiene como precedente el de clima organizacional, resultante del estudio de las organizaciones en el ámbito laboral. Este concepto surge como parte del esfuerzo de la psicología social por comprender el comportamiento de las personas en el contexto de las organizaciones. Desde un planteamiento ecológico, el clima representa un conjunto de condiciones, circunstancias 
e influencias que rodean y afectan el desarrollo de un organismo o de un grupo de organismos (p.38).

Estos autores han enfocado el ámbito escolar como una organización y tratan de comprender el comportamiento de los estudiantes, profesores y demás miembros de esta organización en las relaciones que se desarrollan en dicho ambiente.

Según Cid (2004) citado por López (2015), cree que, para investigar un aula, debe saber distinguir los elementos principales del aula de los factores ambientales o transitorios, y proponer tres aspectos principales del clima del aula:

Dimensión situación-situación: se refiere al entorno en el que se realiza el trabajo docente.

- Dimensión social-emocional o ambiente social del aula: se refiere al entorno emocional y emocional generado por la comunicación entre profesores y alumnos y entre ellos y sus compañeros en el proceso educativo.

- Comunicación: se refiere a la comunicación entre profesores y alumnos que utilizan diversos canales de información en el proceso de enseñanza. (Páginas 21-22).

Según La Paro y Pianta (2003) citados por Alves (2015), "Un clima óptimo en el aula se caracteriza por bajos niveles de conflicto y comportamiento perturbador, transiciones suaves de un tipo de actividad a otro, expresiones apropiadas de emoción, comunicación respetuosa y resolución de problemas, interés y concentración en la tarea y apoyo y la capacidad de respuesta a las diferencias individuales y a las necesidades de los estudiantes".

\subsection{Objetivos e Hipótesis}

\subsubsection{Objetivo General:}

Determinar el nivel de relación entre la inteligencia emocional y el clima del aula de los estudiantes del sexto ciclo de una Institución Pública del distrito de Chorrillos. 
Objetivos específicos.

\section{Objetivo específico 1.}

Determinar el nivel de relación entre la inteligencia intrapersonal y el clima del aula de los estudiantes del sexto ciclo de una Institución Pública del distrito de Chorrillos.

\section{Objetivo específico 2.}

Determinar el nivel de relación entre la inteligencia interpersonal y el clima del aula de los estudiantes del sexto ciclo de una Institución Pública del distrito de Chorrillos. Objetivo específico 3.

Determinar el nivel de relación entre el componente manejo del estrés de la inteligencia emocional y el clima del aula de los estudiantes del sexto ciclo de una Institución Pública del distrito de Chorrillos.

\section{Objetivo específico 4.}

Determinar el nivel de relación entre el componente adaptabilidad de la inteligencia emocional y el clima del aula de los estudiantes del sexto ciclo de una Institución Pública del distrito de Chorrillos.

\section{Objetivo específico 5.}

Determinar el nivel de relación entre el componente estado de ánimo de la inteligencia emocional y el clima del aula de los estudiantes del sexto ciclo de una Institución Pública del distrito de Chorrillos.

\subsection{Hipótesis}

\subsubsection{Hipótesis General:}

Existe una relación positiva y significativa entre la inteligencia emocional y el clima del aula de los estudiantes del sexto ciclo de una Institución Pública del distrito de Chorrillos. 
Hipótesis específicas.

\section{Hipótesis específica 1.}

Existe una relación positiva y significativa entre la inteligencia intrapersonal y el clima del aula de los estudiantes del sexto ciclo de una Institución Pública del distrito de Chorrillos.

\section{Hipótesis específica 2.}

Existe una relación positiva y significativa entre la inteligencia interpersonal y el clima del aula de los estudiantes del sexto ciclo de una Institución Pública del distrito de Chorrillos.

\section{Hipótesis específica 3.}

Existe una relación positiva y significativa entre el componente manejo del estrés de la inteligencia emocional y el clima del aula de los estudiantes del sexto ciclo de una Institución Pública del distrito de Chorrillos.

\section{Hipótesis específica 4.}

Existe una relación positiva y significativa entre el componente adaptabilidad de la inteligencia emocional y el clima del aula de los estudiantes del sexto ciclo de una Institución Educativa de Chorrillos.

\section{Hipótesis específica 5.}

Existe una relación positiva y significativa entre el componente estado de ánimo de la inteligencia emocional y el clima del aula de los estudiantes del sexto ciclo de una Institución Pública del distrito de Chorrillos. 


\section{METODOLOGÍA DE LA INVESTIGACIÓN}

\subsection{Enfoque de investigación:}

Este estudio responde al paradigma cuantitativo con enfoque metodológico hipotético deductivo. El enfoque cuantitativo de la investigación pone una concepción global positivista, hipotética-deductiva, objetiva, particularista y orientada a los resultados para explicar ciertos fenómenos.

Se desarrolla más directamente en la tarea de verificar y comprobar teorías por medio de estudios muéstrales representativos, que nos permite aplicar los instrumentos: los test, entrevistas, cuestionarios y escalas para medir actitudes, cuyas pruebas estadísticas de aplicación nos permiten validar y lograr mejores resultados de confiabilidad, en la aplicación de nuestros análisis de datos.

\subsection{Tipo de Investigación:}

La investigación es de tipo descriptiva ya que desarrolla un carácter evaluativo en el ámbito educativo escolar.

Con respecto a la investigación descriptiva, Bavaresco, A. (1994) señala que "el objetivo de la investigación descriptiva consiste en llegar a conocer las situaciones y actitudes predominantes a través de la descripción exacta de las actividades, objetos procesos y personas". En una investigación descriptiva no se establecen relaciones de causa-efecto.

\subsection{Diseño de investigación:}

El diseño correlacional busca señalar la correlación que existe entre la variable "Inteligencia emocional" y la variable "Clima de aula", apoyándonos en lo que sostiene Hernández et al. (2003).

"La investigación correlacional es un tipo de estudio que tiene como propósito evaluar la relación que exista entre dos o más conceptos, categorías o variables (en un contexto 
particular). Los estudios cuantitativos correlacionales miden el grado de relación entre esas dos o más variables. Es decir, miden cada variable presuntamente relacionada y después también miden y analizan la correlación. Tales correlaciones se expresan en hipótesis sometidas a prueba. Hernández et al. (2003).

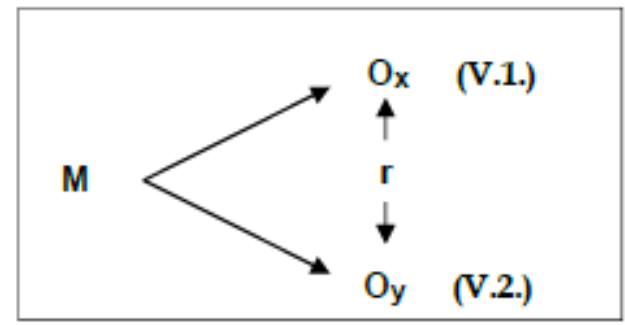

$M=$ muestra de investigación.

$\mathrm{O}_{\mathrm{x}}=$ Variable 1: Inteligencia emocional.

$\mathrm{O}_{\mathrm{y}}=$ Variable 2: Clima en el aula

$\mathrm{r}=$ relación entre variables

\subsection{Variables}

Sobre la clasificación de las variables, Bernal (2006, p. 140) sustenta "en las hipótesis causales, es decir, aquellas que plantean relación entre efectos y causas, se identifican tres tipos de variables: independientes, dependientes e intervinientes. Estos mismos tipos de variables pueden estar presentes en las hipótesis correlacionales cuando se explica la correlación”. Otra clasificación la presentan Ángel et al. (2011, p. 9): “variables cualitativas o categóricas, variables cuantitativas o numéricas". Las variables cuantitativas, según Ángel et al. (2011, p. 9), pueden ser: "variable cuantitativa discreta y variable cuantitativa continua". Las variables cuantitativas discretas pueden tomar un número contable de valores distintos; en cambio, las variables cuantitativas continuas, un número infinito de valores. La variable estilos de liderazgo es una variable cualitativa nominal y la variable calidad educativa es una variable cualitativa ordinal. 
Esta investigación al presentar hipótesis correlacionales considera una variable 1 y una variable 2, que presentamos en la siguiente forma:

\subsubsection{Variable Independiente: Inteligencia Emocional}

\section{Definición conceptual.}

Es la capacidad para reconocer sentimientos propios y ajenos, y la habilidad para manejarlos. Goleman (1995) estima que la inteligencia emocional se puede organizar en torno a cinco capacidades: conocer las emociones y sentimientos propios, manejarlos, reconocerlos, crear la propia motivación, y gestionar las relaciones.

\subsubsection{Variable Dependiente: Clima del aula}

\section{Definición conceptual.}

En concordancia con los objetivos de la investigación, la definición de Bethencourt y Báez (1999) en que menciona que: "El clima del aula o ambiente de aprendizaje es el conjunto de propiedades organizativas, tanto instructivas como psicosociales que permiten describir la vida del aula; y las expectativas de los escolares se asocian significativamente a sus resultados de aprendizaje, a su atención y a su comportamiento" (p. 551), es la pertinente y la que se emplea en este trabajo.

\subsubsection{Variables Intervinientes:}

- Sexo.

- Edad.

- Nivel socio-económico.

- Calidad de vida familiar.

- Rendimiento académico.

\subsection{Población:}

Población estará constituida por 197 estudiantes del sexto ciclo de educación secundaria de la Institución Educativa No. 7038 “Corazón de Jesús” de Armatambo, una de las más antiguas 
en Chorrillos, con muchas urbanizaciones y asentamientos humanos distrito, que trata de salir adelante de acuerdo con las exigencias modernas, pero sin perder sus lugares turísticos que datan desde la colonia.

\subsection{Muestra}

Para el presente estudio la muestra estuvo constituida por 135 estudiantes sexto ciclo de la institución educativa y se utilizará el método no probabilístico por conveniencia por ser la muestra poblacional accesible a la investigación.

\subsection{Instrumentos:}

- El inventario de inteligencia emocional creado por Bar On, mide las dimensiones Intrapersonal, Interpersonal, manejo del estrés, adaptabilidad y componente del estado de ánimo general.

- Instrumento inventario de inteligencia emocional de Bar On

\section{Descripción del instrumento}

\section{Instrumento Inteligencia Emocional}

Ficha técnica

Nombre Original: EQi-YV Bar On Emocional Quotient Inventory

Autor: Reuven Bar-On

Procedencia: Toronto - Canadá

Adaptación Peruana: Nelly Ugarriza Chávez y Liz Pajares

Administración: Individual o Colectiva.

Formas: Formas Completa y Abreviada

Duración: Sin límite de tiempo (forma completa 20 a 25 minutos, aproximadamente y abreviada de 10 a 15 minutos.)

Aplicación: Niños y adolescentes entre 7 y 18.

Puntuación: Calificación computarizada 
Significación: Evaluación de las habilidades emocionales y sociales.

Tipificación: Baremos peruanos

Usos: Educacional, clínico, jurídico, médico y en la investigación. Son usuarios potenciales los profesionales que se desempeñan como psicólogos, psiquiatras, médicos, trabajadores sociales, consejeros, tutores y orientadores vocacionales.

\section{Instrumento clima del aula}

Escala de SES Ficha técnica del cuestionario - escala SES:

Nombre: Escala SES (School Environment Scale).

Autor: Kevin Marjoribanks.

Procedencia: Australia (1980).

Adaptación: España, Aurelio Villa. Administración: para el presente caso grupal.

Duración: no se puso límite, pero fue de 15 minutos, aproximadamente.

Aplicación: para estudiantes del VI ciclo.

Significación: Busca determinar la percepción que tienen los estudiantes del sexto ciclo respecto de los cuatro contextos que componen el clima del aula

\subsection{Validez:}

Cuenta con una validez convergente trabajada en Perú (Ugarriza, 2001) en una muestra de Lima Metropolitana, conformada por 114 escolares.

\section{Confiabilidad:}

Ugarriza (2001) a través del método de coeficientes de Alfa Cron Bach para la muestra, obtuvo una consistencia interna para el inventario total de 0.93 . Para la presente investigación se sometió, el Inventario de Inteligencia Emocional de Bar-On, al coeficiente de Alfa Cron Bach en una muestra de 135 sujetos con características similares a la muestra hallando una confiabilidad de 0.875 . 


\section{Procesamiento estadístico de datos.}

Acopiada la información relacionada a las variables de la hipótesis se procederá a ordenar la información a fin de proceder a su procesamiento estadístico mediante el programa SPSS 19. Se aplicará la estadística descriptiva.

- Medidas de tendencia central media aritmética.

- Medidas de variabilidad: Varianza la desviación típica y el cociente de variabilidad.

- La estadística inferencial: $\mathrm{t}$ de student, $\mathrm{Z}$ de Gauss, prueba binomial.

Para el procesamiento de los datos de inteligencia emocional y clima del aula, y el estudio de la influencia entre ellos, se utilizó las estadísticas descriptivas referidas a las distribuciones de frecuencias bidimensionales y sus respectivos gráficos de barras. Para el estudio de la correlación entre la inteligencia emocional y el clima del aula se utilizó los gráficos de diagrama de dispersión que define el tipo de relación entre las variables inteligencia emocional y clima del aula y para analizar el grado de correlación entre las dos variables en estudio se utilizó el estadígrafo coeficiente de correlación de Pearson con sus interpretaciones correspondientes. Para el procesamiento de los datos se utilizó los programas estadísticos Excel y SPSS.

Un coeficiente de correlación expresa de manera cuantitativa la magnitud y dirección de una relación.

El índice de correlación lineal de Pearson o simplemente índice de correlación entre X , Y, para una variable de intervalo o de razón ( datos originales) es:

$$
\mathrm{r}=\frac{\operatorname{Cov}(X ; Y)}{S_{x} S_{y}}=\frac{n \sum X Y-\sum X \sum Y}{\sqrt{n \sum X^{2}-\left(\sum X\right)^{2}} \sqrt{n \sum Y^{2}-\left(\sum Y\right)^{2}}}
$$


Dónde: Sx , Sy son las desviaciones estándar de las variables X, Y respectivamente. $\mathrm{r}$

mide la estrechez del ajuste de las coordenadas X,Y alrededor de la recta de regresión.

Interpretación clásica del valor de r:

$0,70 \leq \mathrm{r}<1$, alto grado de correlación

$0,40 \leq \mathrm{r}<0,70$, correlación significativa

$0,20 \leq \mathrm{r}<0,40$ correlación baja

$0,00 \leq \mathrm{r}<0,20$ correlación no significativa. 


\section{Resultados:}

\subsection{Validación y confiabilidad de los instrumentos}

Se eligieron dos instrumentos de investigación para ambas variables:

Inteligencia emocional y clima del aula.

\section{Validación de los instrumentos}

La validación de los instrumentos de recolección de datos se realizó a través de los siguientes procedimientos: Validez externa y confiabilidad interna. Sabino, C. (1992, p. 154), con respecto a la Validez, sostiene: "Para que una escala pueda considerarse como capaz de aportar información objetiva debe reunir los siguientes requisitos básicos: validez y confiabilidad".

Validez de los instrumentos de recolección de datos:

Este procedimiento se realizó a través de la evaluación de juicio de expertos, para ello recurrimos a la opinión de docentes doctores de reconocida trayectoria en la Cátedra de Postgrado de la Universidad Nacional de Educación Enrique Guzmán y Valle y la UNMSM, los cuales determinaron la validez de los ítems de los instrumentos aplicados en la presente investigación.

A los referidos expertos se les entregó la matriz de consistencia, los instrumentos y la ficha de validación donde se determinaron: la correspondencia de los criterios, objetivos e ítems, calidad técnica de representatividad y la calidad del lenguaje.

Sobre la base del procedimiento de validación descrita, los expertos consideraron que es pertinente la existencia de una estrecha relación entre los criterios y objetivos del estudio y los ítems constitutivos de los dos instrumentos de recopilación de la información.

La cuantificación de las calificaciones de los expertos se presenta a continuación en la siguiente tabla: 
Tabla 1 Nivel de validez de las encuestas, según el juicio de expertos

\begin{tabular}{lllll}
\hline Expertos & \multicolumn{2}{l}{ Inteligencia emocional } & \multicolumn{2}{l}{ Clima del } \\
& & \multicolumn{2}{l}{ Aula } \\
\cline { 2 - 5 } & Puntaje & $\%$ & Puntaje & $\%$ \\
& 95 & 95 & 95 & 95 \\
Dr. Fredy Jaimes Yábar & 95 & 95 & 95 & 95 \\
Dr. Wilber Montalvo Fleitas & 95 & 95 & 95 & 95 \\
Dr. Salomón Berrocal Villegas & 95 & 95 & 95 & 95 \\
Dr. Alfonso Cornejo Zúñiga & $\mathbf{9 5}$ & $\mathbf{9 5}$ & $\mathbf{9 5}$ & 95 \\
Promedio de valoración & & & &
\end{tabular}

Fuente: Instrumentos de opinión de expertos

Los valores resultantes después de tabular la calificación emitida por los expertos, están considerados a un nivel de validez muy bueno.

Los resultados pueden ser comprendidos mediante el siguiente cuadro que presentamos en la tabla:

Tabla 2 Valores de los niveles de validez

\begin{tabular}{ll}
\hline Valores & Niveles de validez \\
\hline $91-100$ & Excelente \\
$81-90$ & Muy bueno \\
$71-80$ & Bueno \\
$61-70$ & Regular \\
$51-60$ & Deficiente \\
\hline
\end{tabular}


Fuente: Cabanillas Alvarado, Gualberto (2004:76) Tesis “Influencia de la enseñanza directa en el mejoramiento de la comprensión lectora de los estudiantes de Ciencias de la Educación “. UNSCH

Dada la validez de los instrumentos por juicio de expertos, podemos deducir que ambos instrumentos tienen muy buena validez.

\section{2 . Confiabilidad}

\section{Confiabilidad de los instrumentos}

Se empleó el coeficiente alfa $(\alpha)$ para indicar la consistencia interna del instrumento.

Acerca de este coeficiente Muñiz (2003, p. 54) afirma que “ $\alpha$ es función directa de las covarianzas entre los ítems, indicando, por tanto, la consistencia interna del test”. Se empleará la fórmula del alfa de Cronbach porque la variable es de respuesta politómica:

Para establecer la confiabilidad de los instrumentos mediante el coeficiente del alfa de Cronbach se siguen los siguientes pasos.

a. Para determinar el grado de confiabilidad del cuestionario primero se determinó una muestra piloto de 10 estudiantes al azar, pertenecientes a la muestra. Posteriormente, se aplicó los instrumentos para determinar el grado de confiabilidad.

b. Luego, se estimó la confiabilidad por la consistencia interna de Cronbach, mediante el software SPSS versión 24, el cual analiza y determina el resultado con exactitud. c. Se aplicó la sumatoria de varianza, la suma de ítems y el Alpha de Cronbach.

El instrumento cuestionario para Inteligencia emocional y clima del aula, evaluada por el método estadístico de alfa de Cronbach mediante el software SPSS versión 24 arroja: 
Tabla 3 : Procesamiento de casos

\section{Resumen del procesamiento de los casos}

\begin{tabular}{llll}
\hline & & $\mathrm{N}$ & $\%$ \\
Casos & Válidos & 80 & 100,0 \\
& Excluidos $^{\mathrm{a}}$ & 0 &, 0 \\
& Total & 80 & 100,0 \\
& & \\
\hline a. Eliminación por lista basada en todas las variables del procedimiento.
\end{tabular}

\section{Tabla 4: Estadísticos de fiabilidad}

\begin{tabular}{lll}
\hline Variables & Alfa de Cronbach & N de elementos \\
\hline Inteligencia emocional & 0,85 & 10 \\
Clima del aula & 0,87 & 10
\end{tabular}

Se obtiene un coeficiente promedio de 0,86 que determina que los instrumentos tienen muy buena confiabilidad.

Tabla 5 Nivel de confiabilidad del coeficiente alfa de Cronbach

\begin{tabular}{ll} 
Rango & Nivel \\
\cline { 1 - 1 } 0.9- 1.0 & Excelente \\
$\mathbf{0 . 8 - 0 . 9}$ & Muy bueno \\
$\mathbf{0 . 7 - 0 . 8}$ & Aceptable \\
$\mathbf{0 . 6 - 0 . 7}$ & Cuestionable \\
$\mathbf{0 . 5 - 0 . 6}$ & Pobre \\
$\mathbf{0 . 0 - 0 . 5}$ & No aceptable \\
\hline
\end{tabular}

Fuente: George y Mallery (1995) 
4.3 Tratamiento estadístico e interpretación de tablas Análisis descriptivo

Tabla 6: Inteligencia Emocional

\section{Inteligencia Emocional}

\begin{tabular}{llcccc}
\hline \hline & & Frecuencia & Porcentaje & $\begin{array}{c}\text { Porcentaje } \\
\text { válido }\end{array}$ & $\begin{array}{c}\text { Porcentaje } \\
\text { acumulado }\end{array}$ \\
\hline Válido & Bajo & 11 & 8,1 & 8,1 & 8,1 \\
& Regular & 34 & 25,2 & 25,2 & 33,3 \\
& Bueno & 90 & 66,7 & 66,7 & 100,0 \\
& Total & 135 & 100,0 & 100,0 & \\
\hline \hline
\end{tabular}

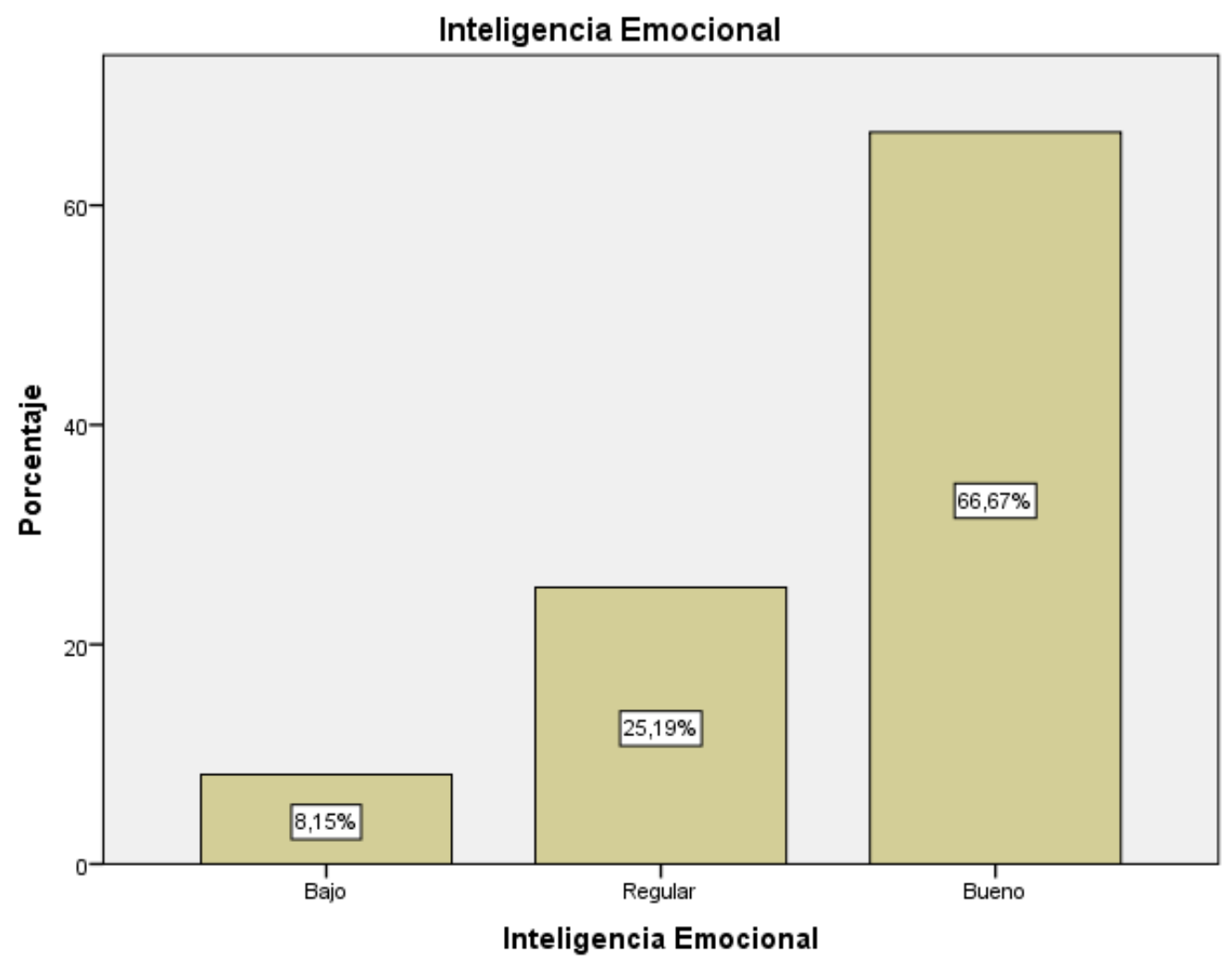

Figura 1: Inteligencia Emocional 
Comentario: Se evidencia en la tabla y figura que del 100\% de los estudiantes

evaluados el $66.67 \%$ se encuentra en un nivel de inteligencia emocional bueno. Acto seguido el $25.19 \%$ se encuentra en un nivel regular y por último el $8.15 \%$ se encuentra en un nivel bajo.

Tabla 7: Inteligencia intrapersonal

Inteligencia intrapersonal

\begin{tabular}{llcccc}
\hline \hline & & Frecuencia & Porcentaje & $\begin{array}{c}\text { Porcentaje } \\
\text { válido }\end{array}$ & $\begin{array}{c}\text { Porcentaje } \\
\text { acumulado }\end{array}$ \\
\hline Válido & Bajo & 2 & 1,5 & 1,5 & 1,5 \\
& Regular & 36 & 26,7 & 26,7 & 28,1 \\
& & & & & \\
& Bueno & 97 & 71,9 & 71,9 & 100,0 \\
& & & & & \\
& Total & 135 & 100,0 & 100,0 & \\
& & & & & \\
\hline \hline
\end{tabular}




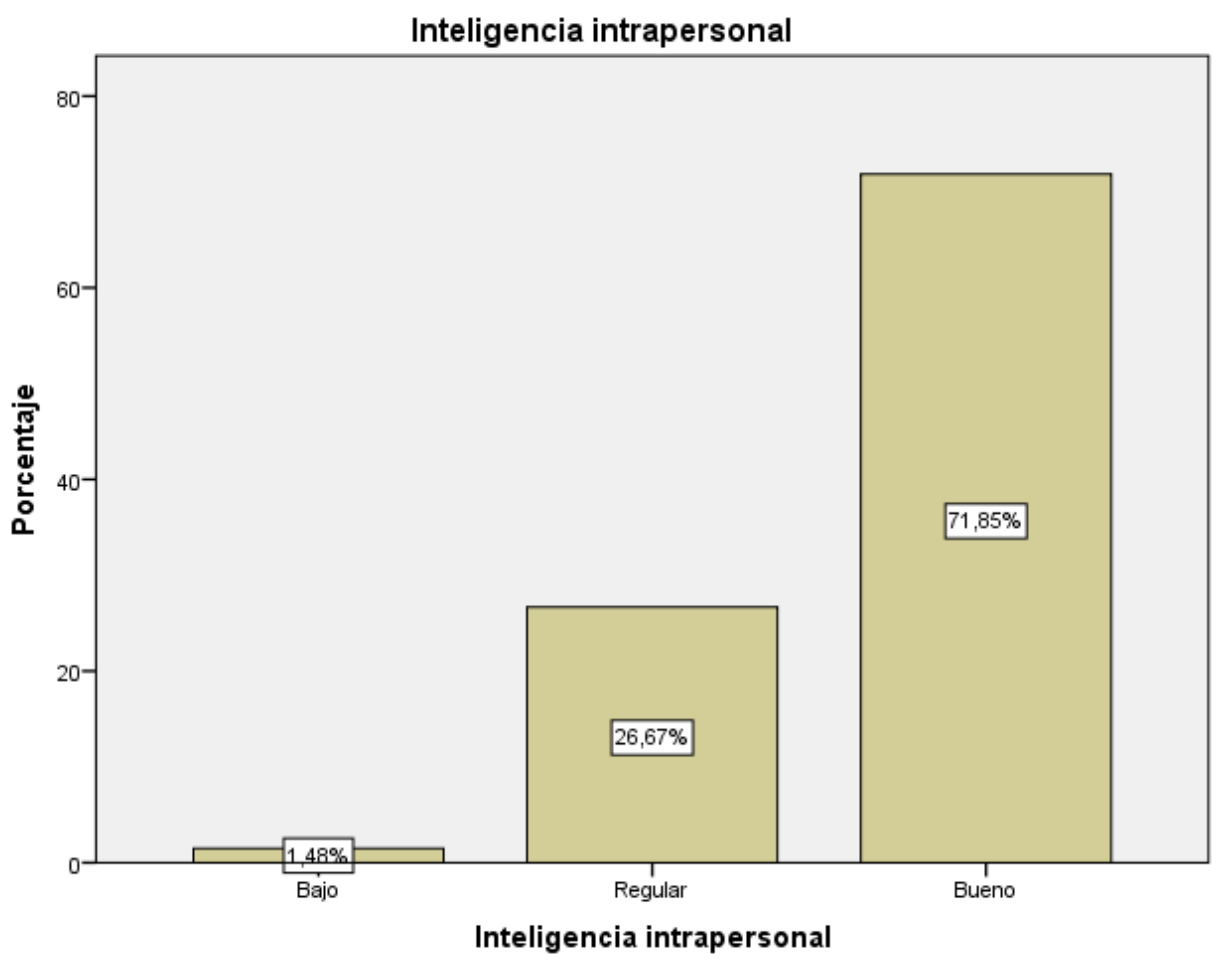

Figura 2: Inteligencia intrapersonal

Comentario: Se evidencia en la tabla y figura que del 100\% de los estudiantes evaluados, el $71.85 \%$ se encuentra en su inteligencia intrapersonal en u nivel bueno, seguidamente el $26.67 \%$ se encuentra en un nivel regular y el $1.48 \%$ se encuentra en un nivel bajo.

Tabla 8: Inteligencia interpersonal

\section{Inteligencia interpersonal}

\begin{tabular}{lccccc}
\hline \hline & & Frecuencia & Porcentaje & $\begin{array}{c}\text { Porcentaje } \\
\text { válido }\end{array}$ & $\begin{array}{c}\text { Porcentaje } \\
\text { acumulado }\end{array}$ \\
\hline Válido & Regular & 21 & 15,6 & 15,6 & 15,6 \\
& Bueno & 114 & 84,4 & 84,4 & 100,0 \\
& Total & 135 & 100,0 & 100,0 & \\
\hline \hline
\end{tabular}




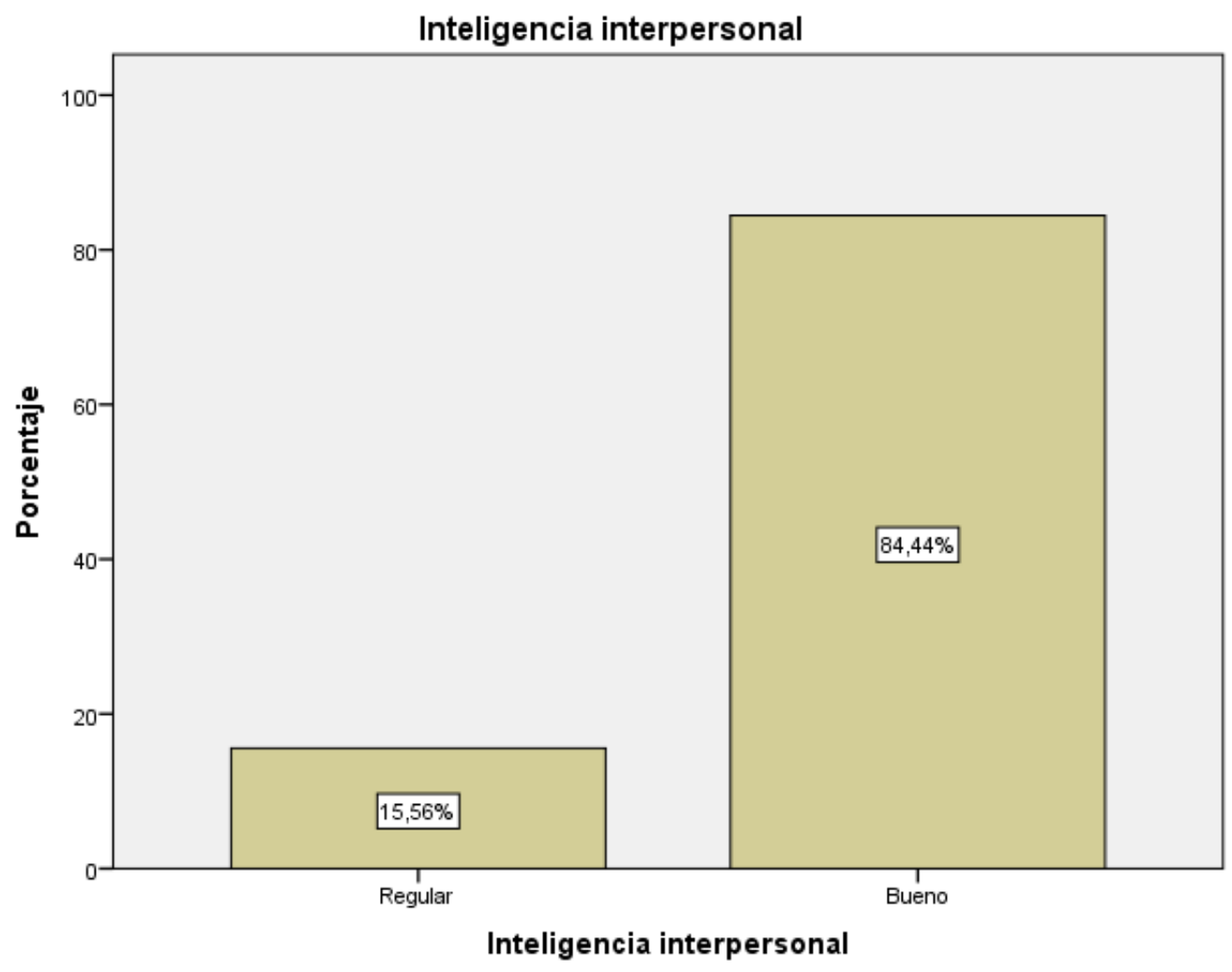

\section{Figura 3: Inteligencia interpersonal}

Comentario: Se evidencia en la tabla y figura que del $100 \%$ de los estudiantes evaluados, en relación a su inteligencia interpersonal, el $84.44 \%$ se encuentra en un nivel bueno y el $15.56 \%$ en un nivel regular.

Tabla 9: Componente manejo de Estrés

\begin{tabular}{llcccc}
\hline \hline & & Frecuencia & Porcentaje & $\begin{array}{c}\text { Porcentaje } \\
\text { válido }\end{array}$ & $\begin{array}{c}\text { Porcentaje } \\
\text { acumulado }\end{array}$ \\
\hline Válido & Bajo & 16 & 11,9 & 11,9 & 11,9 \\
& Regular & 55 & 40,7 & 40,7 & 52,6 \\
& Bueno & 64 & 47,4 & 47,4 & 100,0 \\
& Total & 135 & 100,0 & 100,0 & \\
\hline \hline
\end{tabular}




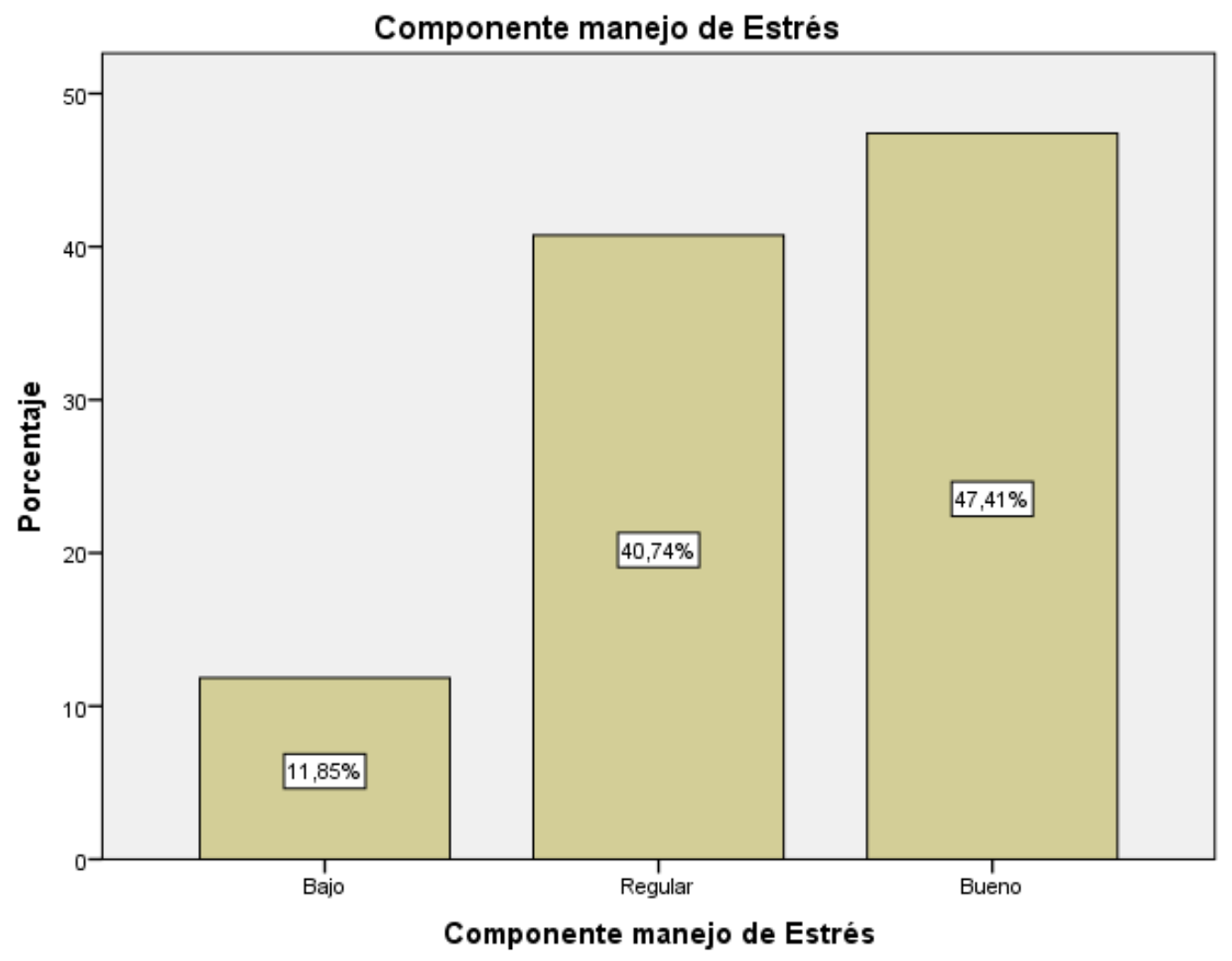

Figura 4: Componente manejo de Estrés

Comentario: Se evidencia en la tabla y figura que del $100 \%$, un $11.85 \%$ se encuentra en un nivel bajo, en relación al manejo del estrés, el $40.74 \%$ se encuentra un nivel regular y por último e impactante que solo $47.41 \%$ se encuentre en un nivel bueno con relación a su manejo de estrés.

Tabla 10: Componente Adaptabilidad

\begin{tabular}{llcccc}
\hline \hline & & Frecuencia & Porcentaje & $\begin{array}{c}\text { Porcentaje } \\
\text { válido }\end{array}$ & $\begin{array}{c}\text { Porcentaje } \\
\text { acumulado }\end{array}$ \\
\hline Válido & Bajo & 1 &, 7 &, 7 &, 7 \\
& Regular & 80 & 59,3 & 59,3 & 60,0 \\
& Bueno & 54 & 40,0 & 40,0 & 100,0 \\
& Total & 135 & 100,0 & 100,0 & \\
\hline \hline
\end{tabular}




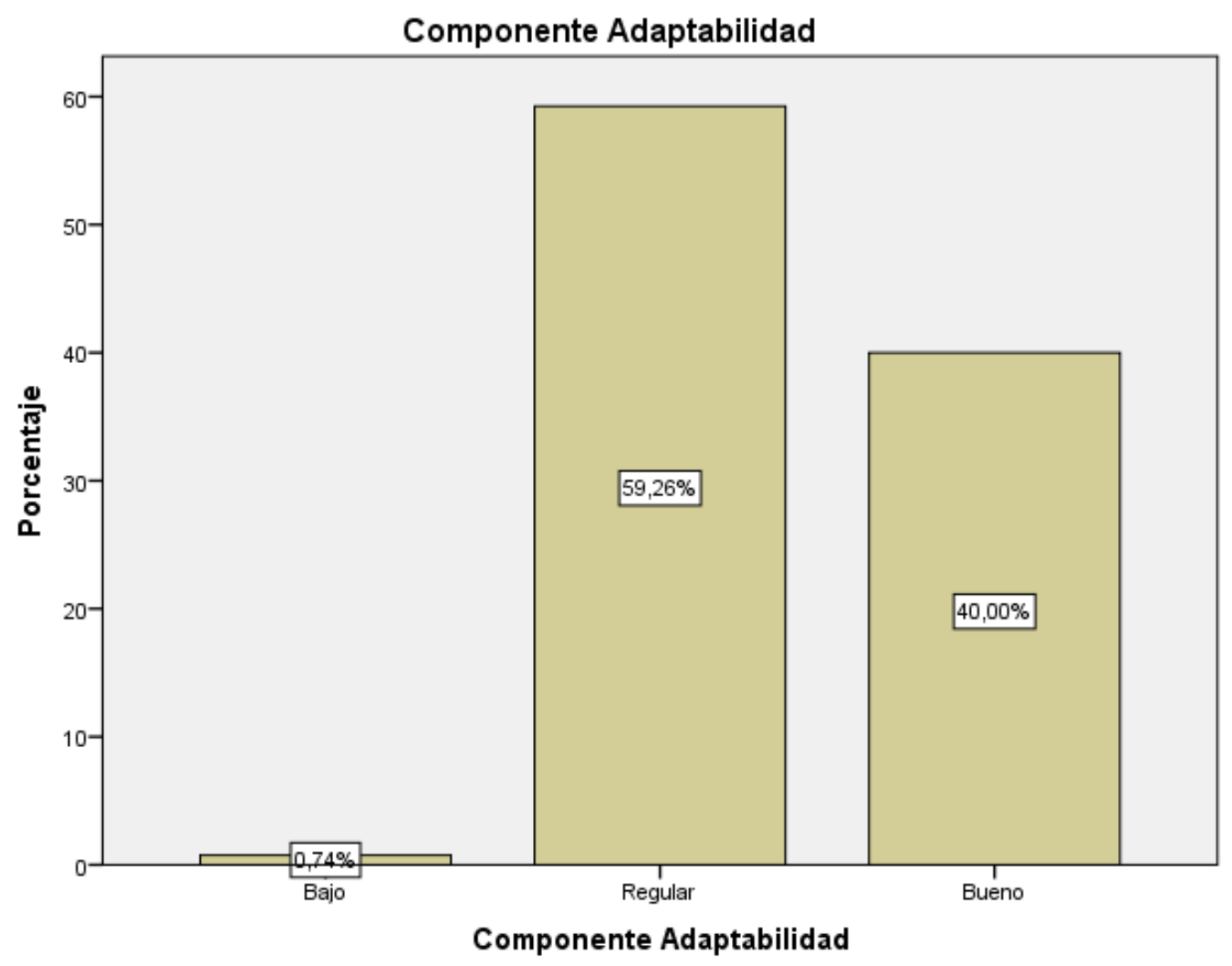

Figura 5: Componente Adaptabilidad

Comentario: Se evidencia en la tabla y figura en donde el $59.26 \%$ se encuentra en un nivel regular, el $1 \%$ en un nivel bajo y por último solo $40 \%$ se encuentra en buen clima de adaptabilidad.

Tabla 11: Componente Estado de Animo General

\begin{tabular}{llcccc}
\hline \hline & & Frecuencia & Porcentaje & $\begin{array}{c}\text { Porcentaje } \\
\text { válido }\end{array}$ & $\begin{array}{c}\text { Porcentaje } \\
\text { acumulado }\end{array}$ \\
\hline Válido & Bajo & 4 & 3,0 & 3,0 & 3,0 \\
& Regular & 39 & 28,9 & 28,9 & 31,9 \\
& Bueno & 92 & 68,1 & 68,1 & 100,0 \\
& Total & 135 & 100,0 & 100,0 & \\
\hline \hline
\end{tabular}




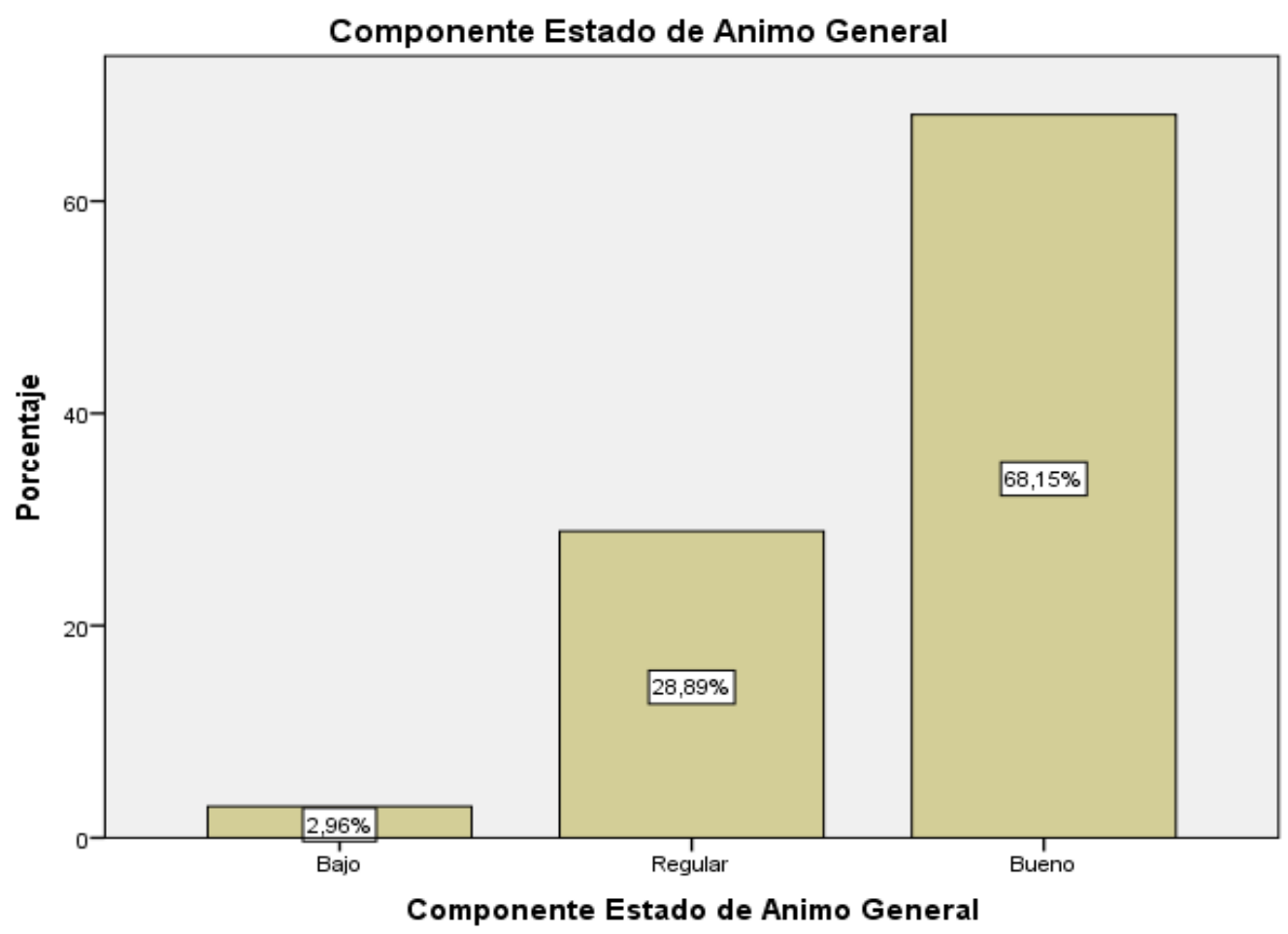

Figura 6: Componente Estado de Animo General

Comentario: Se evidencia en la tabla y figura que del 100\% de los estudiantes

evaluados, el $68.15 \%$ se encuentra en un nivel bueno en relación al componente del Estado de Animo General, un $28.89 \%$ se encuentra en un nivel regular y por último el $2.96 \%$ se encuentra en un nivel bajo.

Tabla 12: Clima del aula

\begin{tabular}{llcccc}
\hline \hline & & Frecuencia & Porcentaje & $\begin{array}{c}\text { Porcentaje } \\
\text { válido }\end{array}$ & $\begin{array}{c}\text { Porcentaje } \\
\text { acumulado }\end{array}$ \\
\hline Válido & Malo & 3 & 2,2 & 2,2 & 2,2 \\
& Regular & 35 & 25,9 & 25,9 & 28,1 \\
& Excelente & 97 & 71,9 & 71,9 & 100,0 \\
& Total & 135 & 100,0 & 100,0 & \\
\hline \hline
\end{tabular}




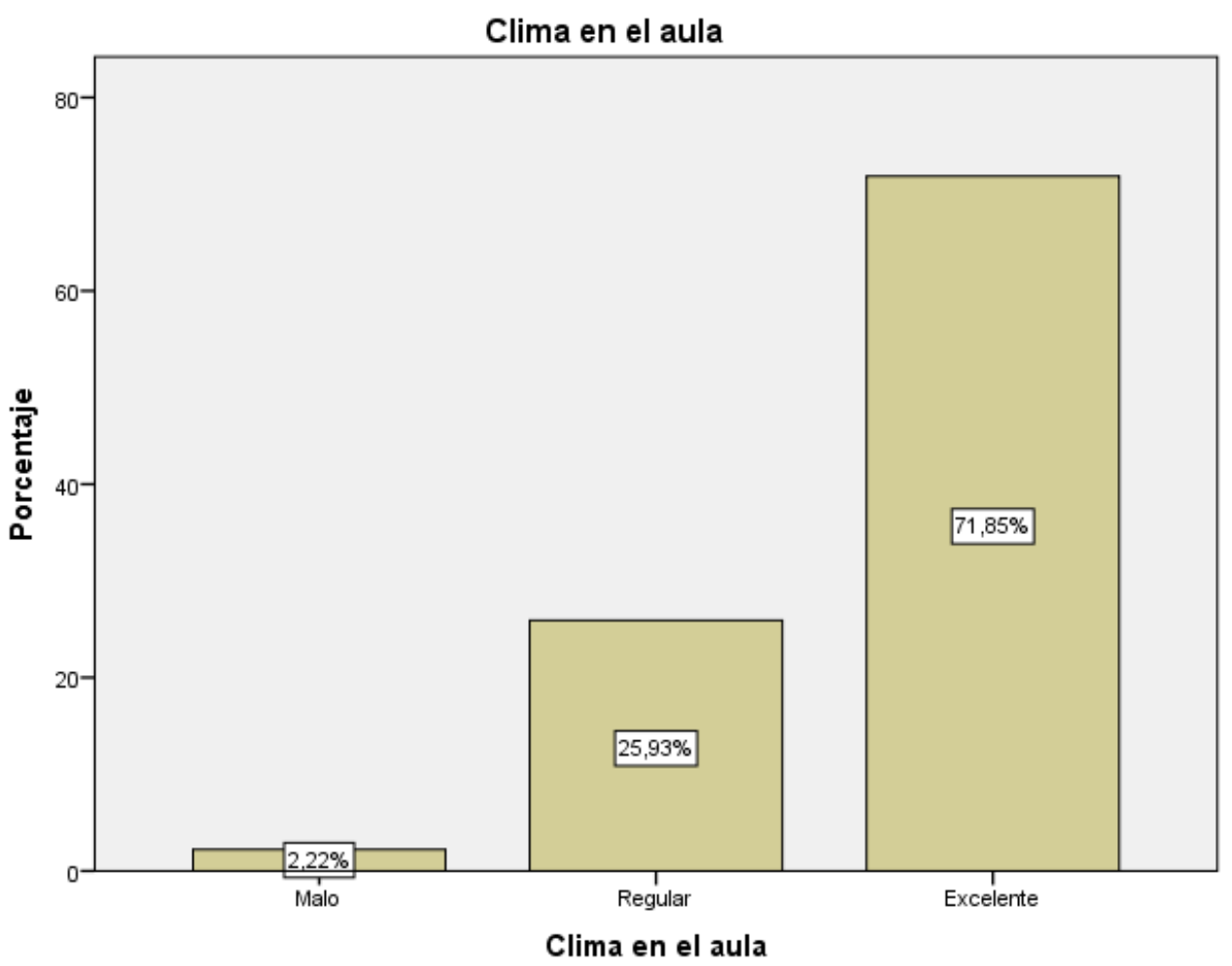

Figura 7: Clima del aula

Comentario: Se evidencia en la tabla y figura que del 100\% de los resultados se observa a un $71.85 \%$ con excelente clima en el aula, el $25.93 \%$ con regular clima y por último el $2.22 \%$ con mal clima en el aula.

Tabla 13: Inteligencia intrapersonal*Clima en el aula tabulación cruzada

\begin{tabular}{|c|c|c|c|c|c|c|}
\hline & & & \multicolumn{3}{|c|}{ Clima en el aula } & \multirow[b]{2}{*}{ Total } \\
\hline & & & Malo & Regular & Excelente & \\
\hline \multirow{5}{*}{$\begin{array}{l}\text { Inteligencia } \\
\text { intrapersonal }\end{array}$} & & Recuento & 2 & 0 & 0 & 2 \\
\hline & Bajo & $\begin{array}{l}\% \text { dentro de Clima el } \\
\text { aula }\end{array}$ & $1 \%$ & $0 \%$ & $0 \%$ & $1,5 \%$ \\
\hline & & Recuento & 1 & 35 & 0 & 36 \\
\hline & Regular & $\begin{array}{l}\% \text { dentro de Clima en } \\
\text { el aula }\end{array}$ & $1 \%$ & $26 \%$ & $0 \%$ & $26,7 \%$ \\
\hline & Bueno & Recuento & 0 & 0 & 97 & 97 \\
\hline
\end{tabular}




\begin{tabular}{llcccc}
\hline & & & & \\
& $\begin{array}{l}\text { \% dentro de Clima en } \\
\text { el aula }\end{array}$ & $0 \%$ & $0 \%$ & $72 \%$ & $71,9 \%$ \\
\hline \multirow{2}{*}{ Total } & 3 & 35 & 97 & 135 \\
$\begin{array}{l}\text { Recuento dentro de Clima en } \\
\text { el aula }\end{array}$ & $2 \%$ & $26 \%$ & $72 \%$ & $100,0 \%$ \\
\hline
\end{tabular}

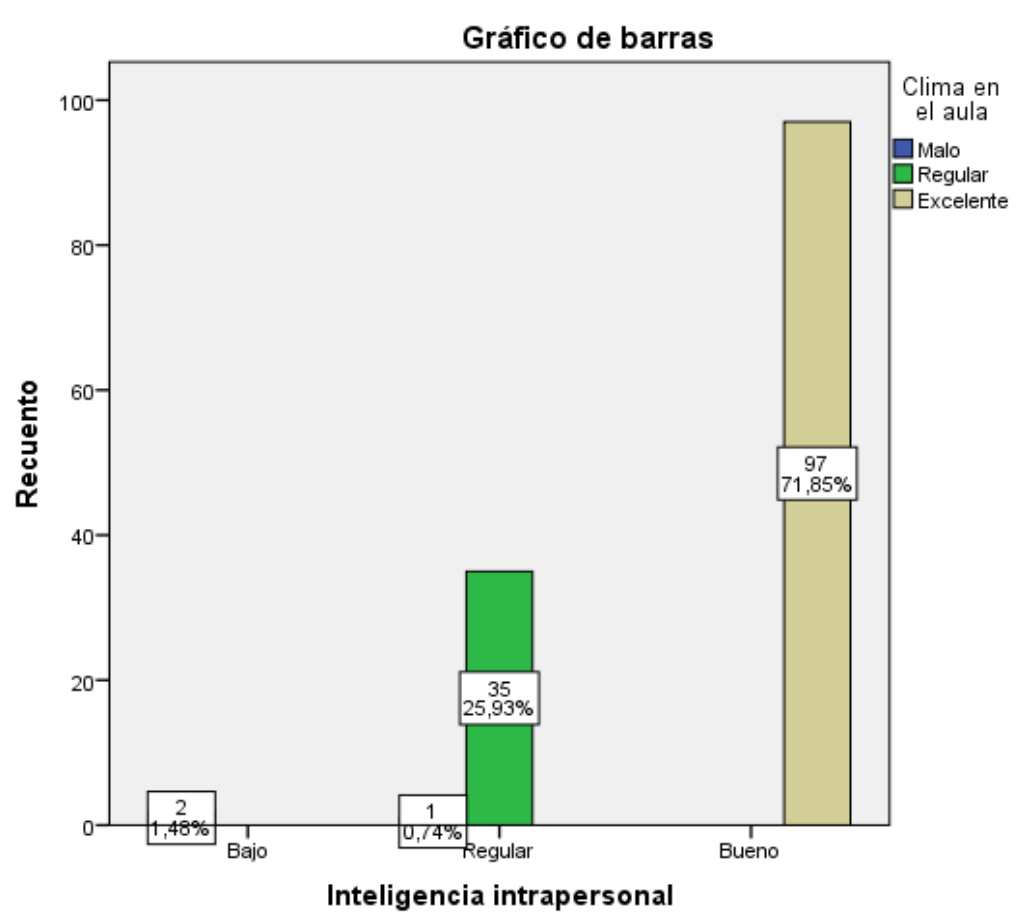

Figura 1: Inteligencia intrapersonal*Clima del aula tabulación cruzada.

Comentario: Se evidencia en la tabla cruzada el grado de asociación entre las variables clima en el aula e inteligencia intrapersonal, en donde nos permite observar que del 71.9\% (97) de los estudiantes que tienen un nivel bueno en relación a su inteligencia interpersonal, evidencia a un $72 \%$ con un nivel excelente en el clima de aula; el resto se encuentra en un nivel regular y bajo.

Tabla 14: Inteligencia intrapersonal * Inteligencia Emocional

\begin{tabular}{lllcccc}
\hline & & \multicolumn{3}{c}{ Inteligencia Emocional } & Total \\
\cline { 3 - 7 } & & & Bajo & Regular & Bueno & \\
\hline \multirow{3}{*}{ Inteligencia } & \multirow{2}{*}{ Bajo } & Recuento & 2 & 0 & 0 & 2 \\
\cline { 2 - 7 } & $\%$ & $1 \%$ & $0 \%$ & $0 \%$ & $1,5 \%$ \\
\cline { 2 - 7 } & \multirow{2}{*}{ Regular } & Recuento & 2 & 34 & 0 & 36 \\
& $\%$ & $1 \%$ & $25 \%$ & $0 \%$ & $26,7 \%$ \\
\hline
\end{tabular}




\begin{tabular}{|c|c|c|c|c|c|c|}
\hline US & $\begin{array}{l}\text { ESCUELA DE } \\
\text { POSTGRADO } \\
\end{array}$ & & & & & 62 \\
\hline & \multirow{2}{*}{ Bueno } & Recuento & 7 & 0 & 90 & 97 \\
\hline & & $\%$ & $5 \%$ & $0 \%$ & $67 \%$ & $71,9 \%$ \\
\hline \multirow{2}{*}{ Total } & & Recuento & 11 & 34 & 90 & 135 \\
\hline & & $\%$ & $8 \%$ & $25 \%$ & $67 \%$ & $100,0 \%$ \\
\hline
\end{tabular}

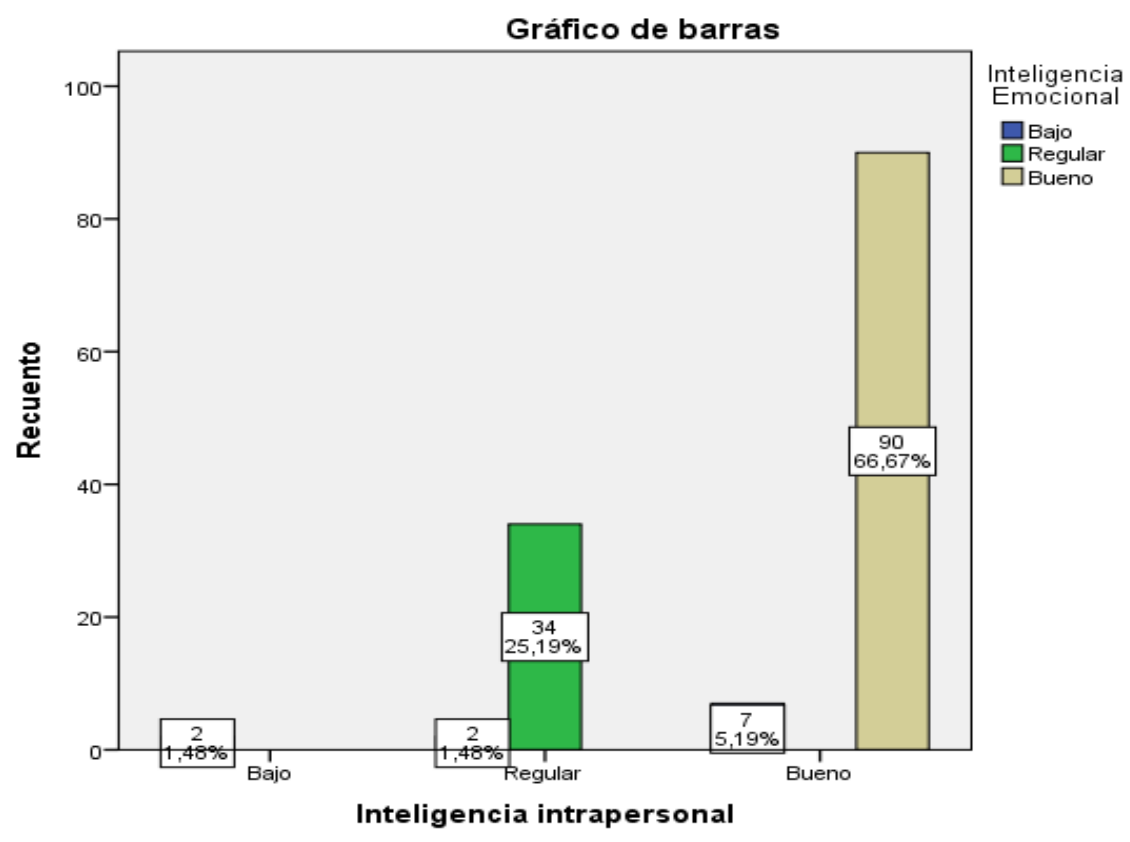

Figura 2: Inteligencia intrapersonal * Inteligencia Emocional

Comentario: Se evidencia en la tabla cruzada el grado de asociación entre las variables Inteligencia Emocional e inteligencia intrapersonal, en donde nos permite observar que del 66.67\% (97) de los estudiantes que tienen un nivel bueno en relación a su inteligencia intrapersonal, se evidencia a un 67\% (90) con un nivel excelente en el clima de aula; el resto se encuentra en nivel regular y bajo.

Tabla 15 Inteligencia interpersonal * Inteligencia Emocional tabulación cruzada

\begin{tabular}{llcccc}
\hline & & \multicolumn{3}{c}{ Clima en el aula } & Total \\
& & Malo & Regular Excelente & \\
\hline $\begin{array}{l}\text { Inteligencia } \\
\text { interpersonal }\end{array}$ & $\begin{array}{l}\text { Recuento } \\
\text { Regular dentro de }\end{array}$ & 3 & 16 & 2 & 21 \\
$\begin{array}{l}\text { Clima en el } \\
\text { aula }\end{array}$ & $2 \%$ & $12 \%$ & $1 \%$ & $15,6 \%$
\end{tabular}




\begin{tabular}{cccccc}
\hline & & 0 & 19 & 95 & 114 \\
Bueno & $\begin{array}{l}\text { Recuento } \\
\% \text { dentro de } \\
\text { Clima en el }\end{array}$ & $0 \%$ & $14 \%$ & $70 \%$ & $84,4 \%$ \\
$\begin{array}{l}\text { aula } \\
\text { Recuento }\end{array}$ & 3 & 35 & 97 & 135 \\
$\begin{array}{l}\% \text { dentro de } \\
\text { Clima en el } \\
\text { aula }\end{array}$ & $2 \%$ & $26 \%$ & $72 \%$ & $100,0 \%$ \\
\hline
\end{tabular}

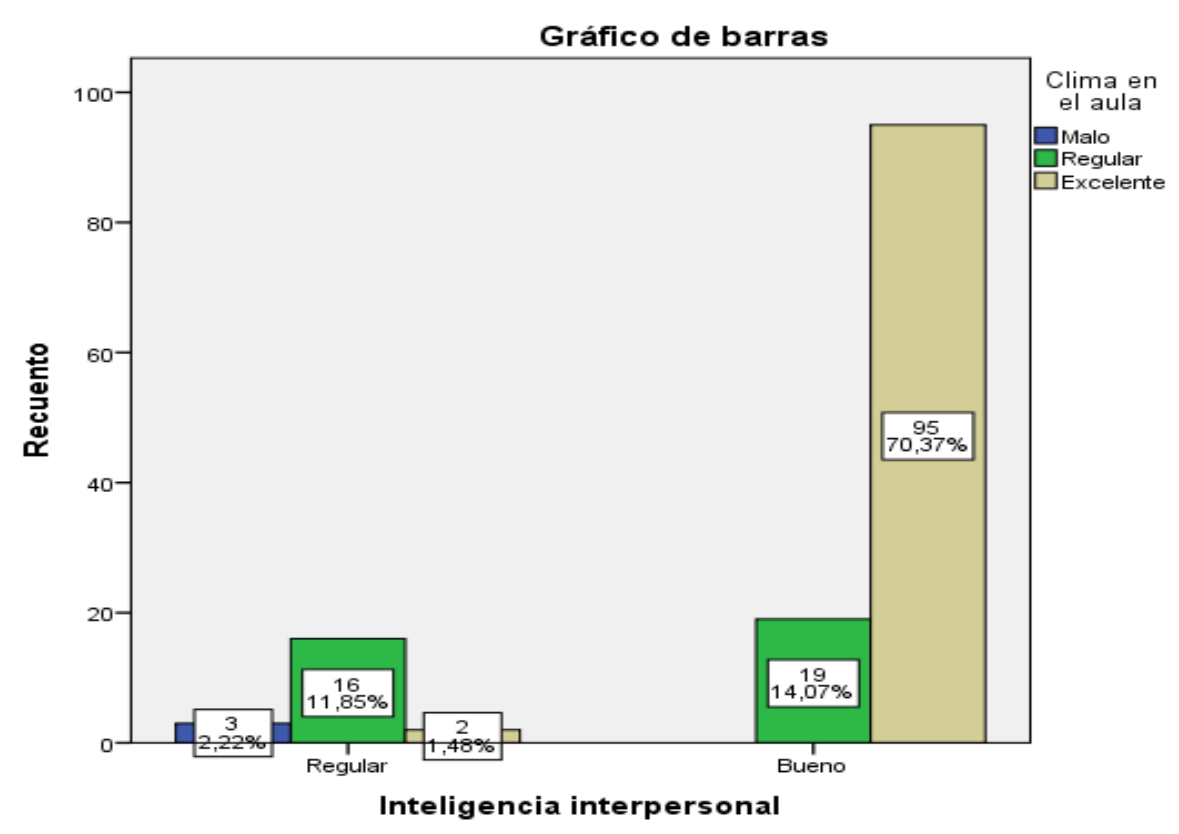

Figura 3: Inteligencia interpersonal * Clima del aula tabulación cruzada

Comentario: Se evidencia que del 14,07 \% (19) que presentan un nivel de inteligencia interpersonal bueno. Sin embargo, el 70,37 \% (95) se encuentran con un clima en el aula excelente, los demás estudiantes se ubican entre un nivel regular y bajo.

Tabla 161: Componente Adaptabilidad*Clima del aula tabulación cruzada

Clima en el aula

\section{Excelent}

Malo Regular e Total


Componente

$\%$ dentro de Clima en $\quad 0,0 \% \quad 0,0 \% \quad 1,0 \% \quad 0,7 \%$

Adaptabilidad el aula

\begin{tabular}{|c|c|c|c|c|c|}
\hline \multirow[t]{2}{*}{ Regular } & Recuento & 3 & 34 & 43 & 80 \\
\hline & $\%$ dentro de Clima en & $100,0 \%$ & $97,1 \%$ & $44,3 \%$ & $59,3 \%$ \\
\hline
\end{tabular}

Bueno Recuento

0

53

54

$\%$ dentro de Clima en $\quad 0,0 \% \quad 2,9 \% \quad 54,6 \% \quad 40,0 \%$

el aula

\begin{tabular}{llrrrc}
\hline Total & Recuento & 3 & 35 & 97 & 135 \\
& $\begin{array}{l}\text { \% dentro de Clima en } \\
\text { el aula }\end{array}$
\end{tabular}

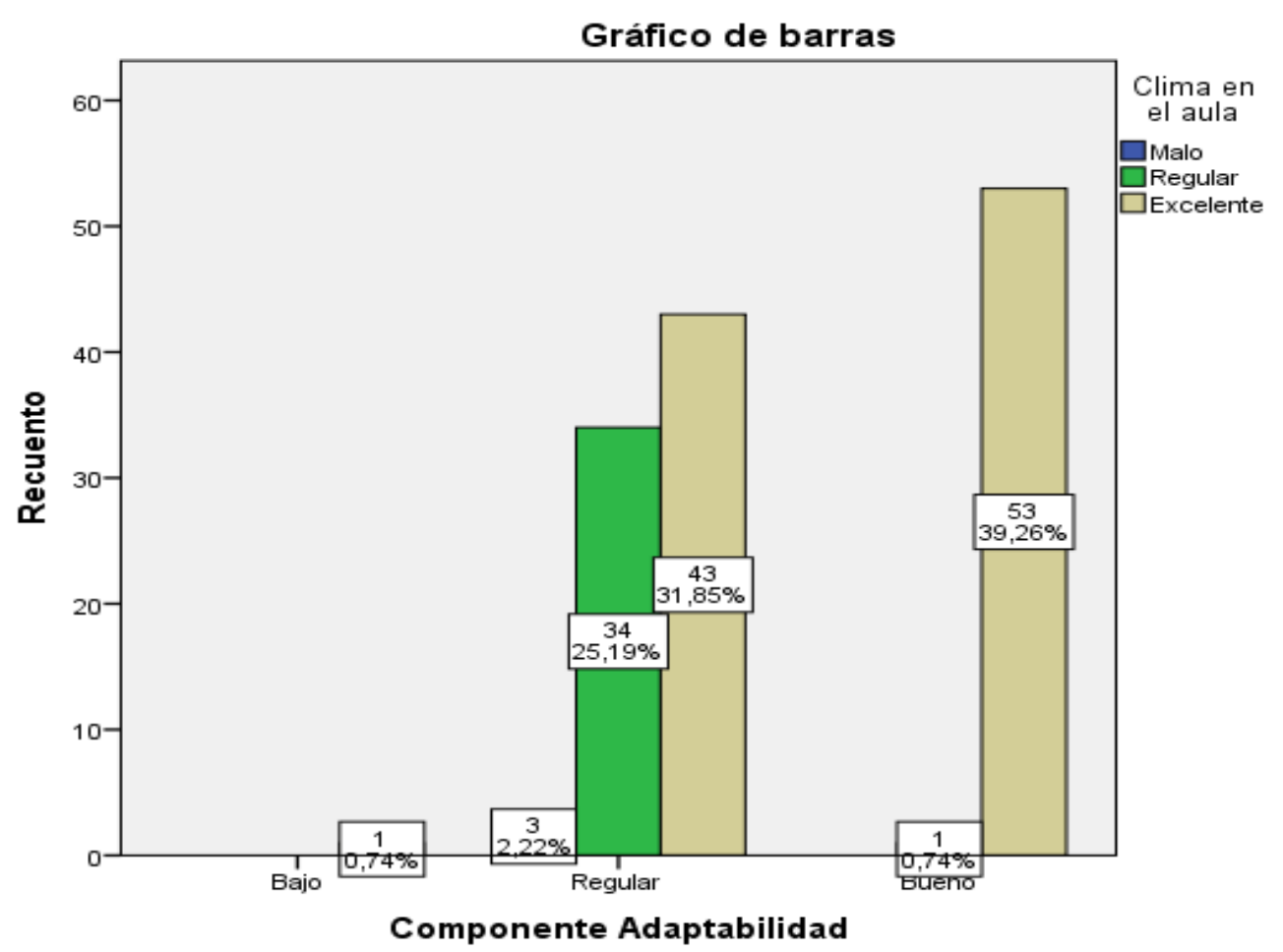

Figura 11: Componente Adaptabilidad*Clima del aula tabulación cruzada 
Tabla 17: Componente manejo de Estrés * Clima del aula tabulación cruzada

\begin{tabular}{|c|c|c|c|c|c|c|}
\hline & & & \multicolumn{3}{|c|}{ Clima en el aula } & \multirow[t]{2}{*}{ Total } \\
\hline & & & Malo & Regular & Excelente & \\
\hline \multirow{6}{*}{$\begin{array}{l}\text { Componente } \\
\text { manejo de } \\
\text { Estrés }\end{array}$} & \multirow[b]{2}{*}{ Bajo } & Recuento & 3 & 9 & 4 & 16 \\
\hline & & $\begin{array}{l}\% \text { dentro } \\
\text { de Clima } \\
\text { en el aula }\end{array}$ & $2 \%$ & $7 \%$ & $3 \%$ & $11,9 \%$ \\
\hline & \multirow[b]{2}{*}{ Regular } & Recuento & 0 & 26 & 29 & 55 \\
\hline & & $\begin{array}{l}\% \text { dentro } \\
\text { de Clima } \\
\text { en el aula }\end{array}$ & $0 \%$ & $19 \%$ & $21 \%$ & $40,7 \%$ \\
\hline & \multirow{4}{*}{ Bueno } & Recuento & 0 & 0 & 64 & 64 \\
\hline & & $\begin{array}{l}\% \text { dentro } \\
\text { de Clima } \\
\text { en el aula }\end{array}$ & $0 \%$ & $0 \%$ & $47 \%$ & $47,4 \%$ \\
\hline \multirow[b]{2}{*}{ Total } & & Recuento & 3 & 35 & 97 & 135 \\
\hline & & $\begin{array}{l}\% \text { dentro } \\
\text { de Clima } \\
\text { en el aula }\end{array}$ & $2 \%$ & $26 \%$ & $72 \%$ & $100,0 \%$ \\
\hline
\end{tabular}

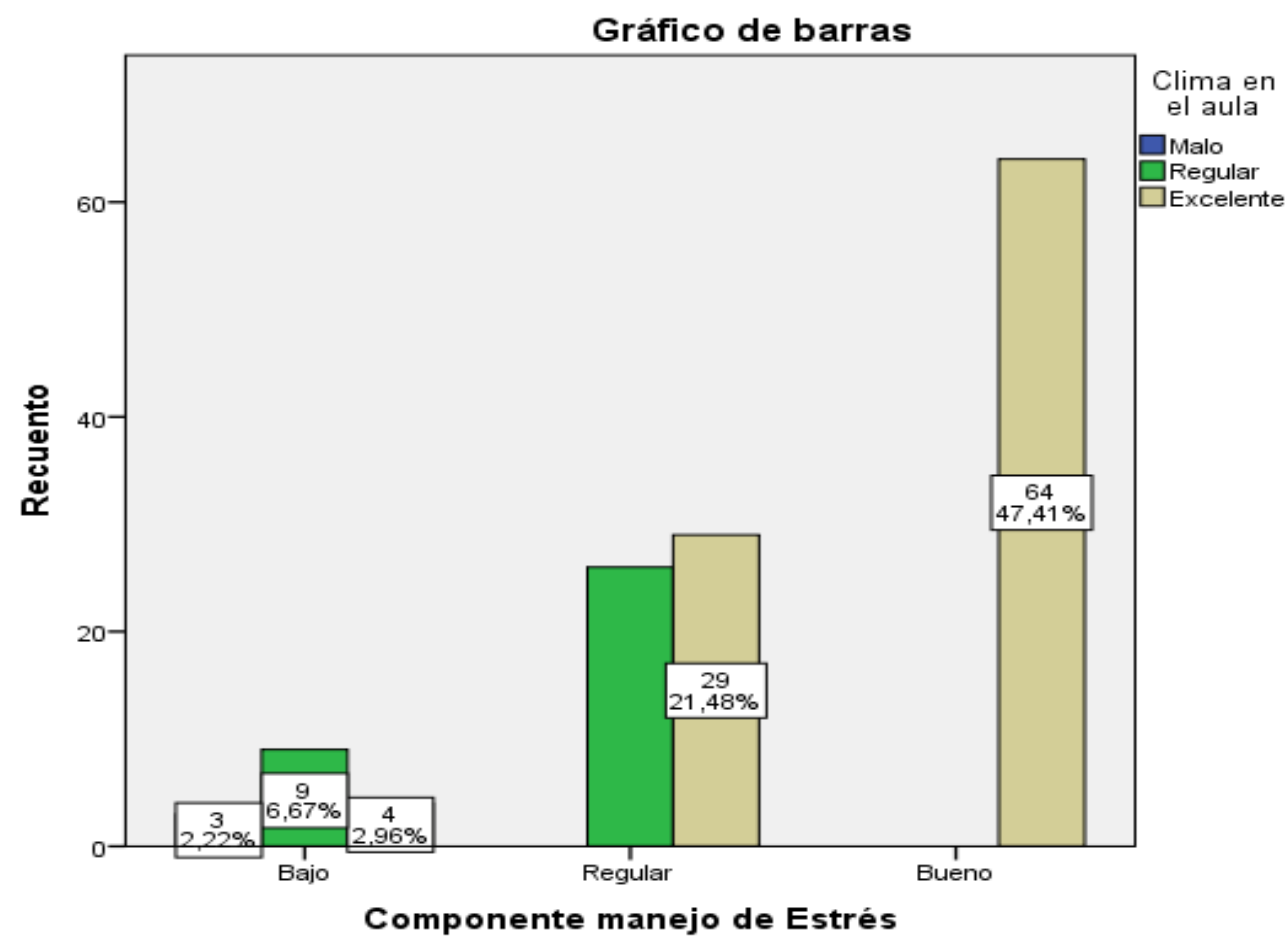

Figura 12: Componente manejo de Estrés * Clima del aula tabulación cruzada

Comentario: Se evidencia en la tabla y figura que del $47 \%$ (64) que presentan un nivel bueno en el manejo de estrés, también están en un con un clima en el aula excelente. 
Seguidamente del $40.7 \%$ se encuentra en un nivel regular con su manejo de estrés se evidencia a un $21 \%$ con un clima en el aula excelente y un $19 \%$ con un clima regular.

Tabla 18: Componente manejo de Estrés*Inteligencia Emocional tabulación cruzada

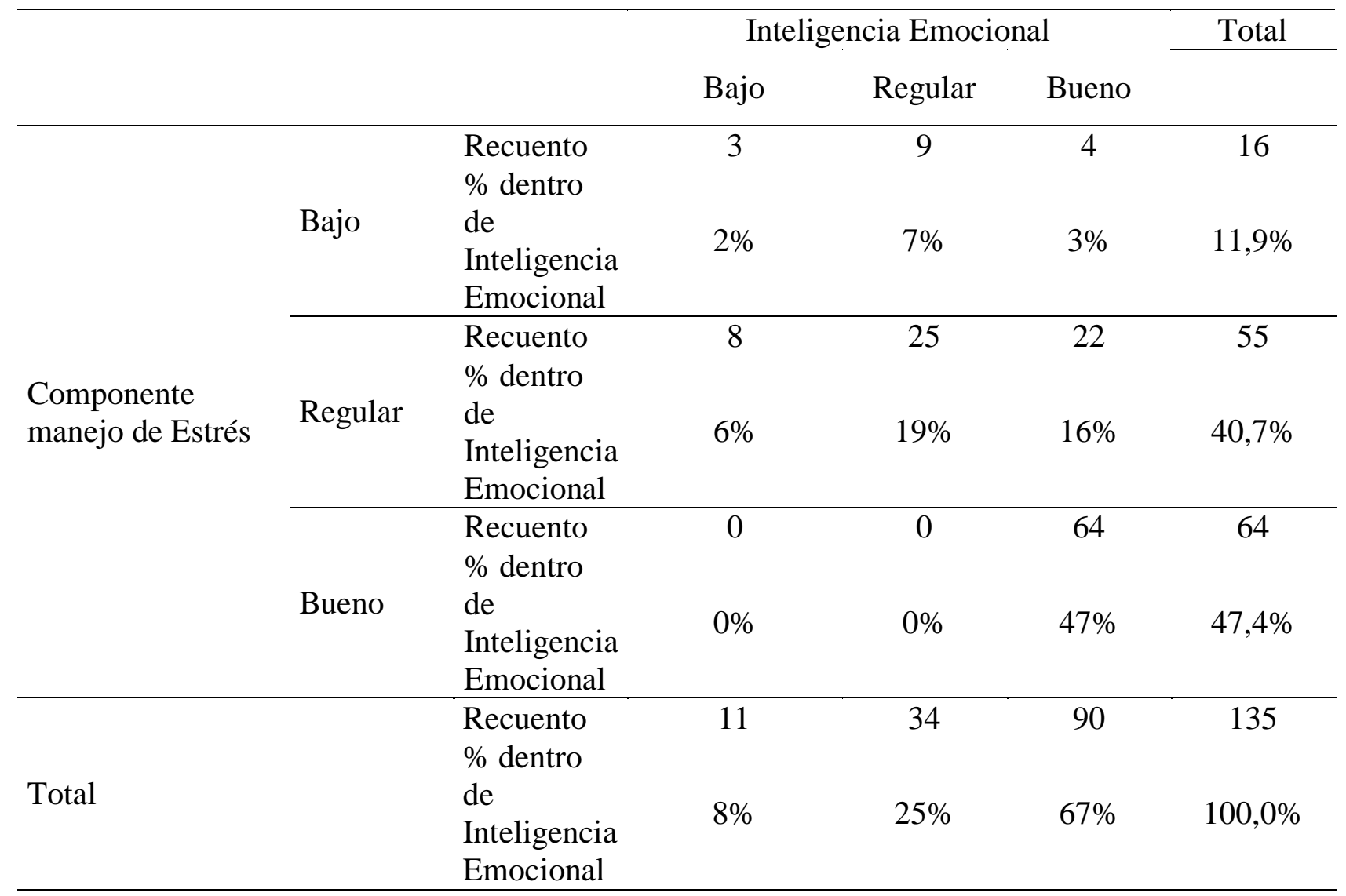




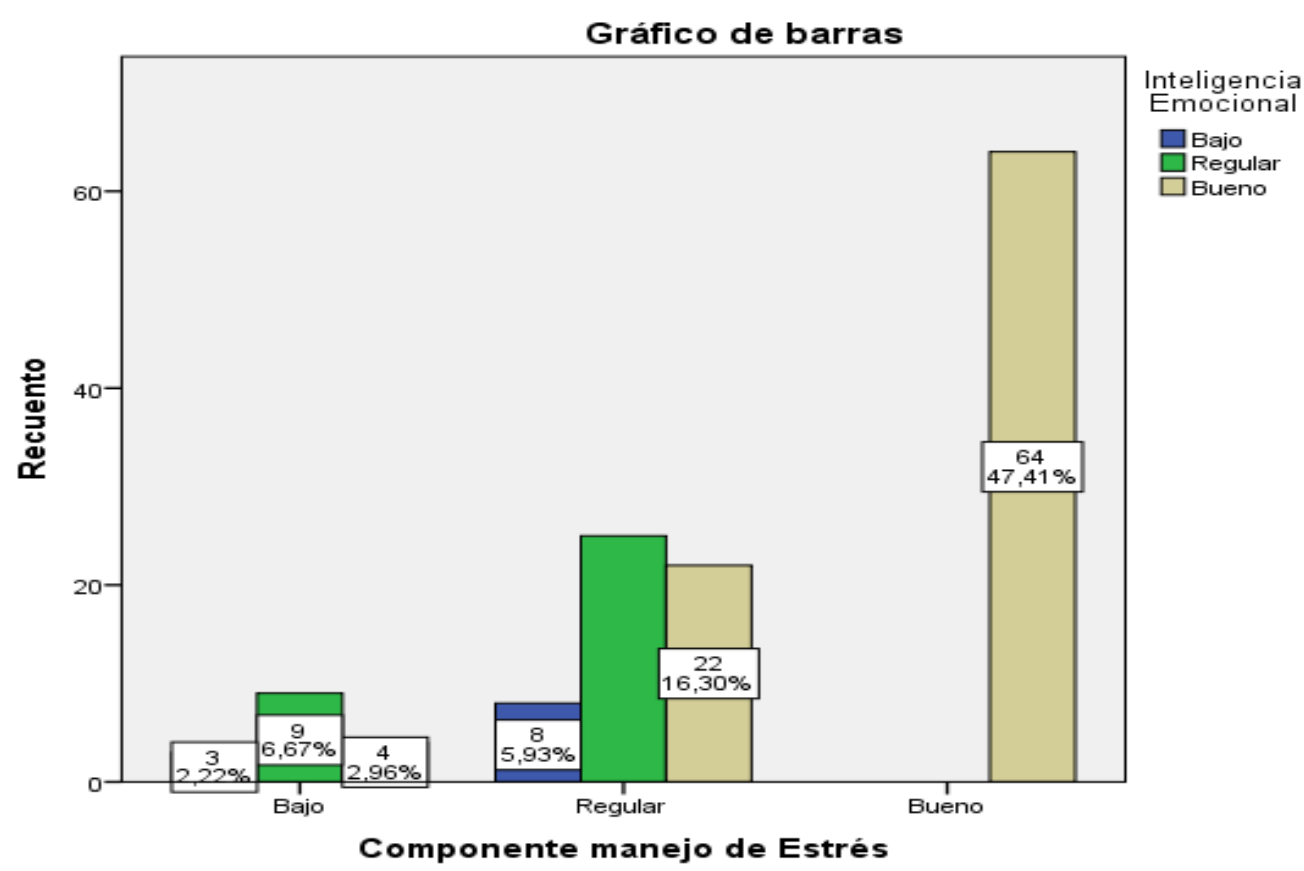

Figura 13: Componente manejo de Estrés*Inteligencia Emocional tabulación cruzada

Comentario: Se evidencia en la tabla y figura que del $47.4 \%$ (64) que tienen un manejo de estrés bueno, se encuentra con una inteligencia emocional bueno; seguidamente del 40.7\% que tienen un manejo de estrés regular; un grupo tienen un nivel de inteligencia emocional regular siendo el $19 \%$ y un $16 \%$ con un nivel bueno. El resto se encuentra en un bajo.

Tabla 19: Componente Adaptabilidad*Inteligencia Emocional tabulación cruzada

\begin{tabular}{|c|c|c|c|c|c|c|}
\hline & & & \multicolumn{3}{|c|}{ Inteligencia Emocional } & \multirow[t]{2}{*}{ Total } \\
\hline & & & Bajo & Regular & Bueno & \\
\hline \multirow{6}{*}{$\begin{array}{l}\text { Componente } \\
\text { Adaptabilidad }\end{array}$} & \multirow{2}{*}{ Bajo } & Recuento & 0 & 0 & 1 & 1 \\
\hline & & $\%$ & $0 \%$ & $0 \%$ & $1 \%$ & $0,7 \%$ \\
\hline & \multirow{2}{*}{ Regular } & Recuento & 10 & 34 & 36 & 80 \\
\hline & & $\%$ & $7 \%$ & $25 \%$ & $27 \%$ & $59,3 \%$ \\
\hline & \multirow{2}{*}{ Bueno } & Recuento & 1 & 0 & 53 & 54 \\
\hline & & $\%$ & $1 \%$ & $0 \%$ & $39 \%$ & $40,0 \%$ \\
\hline \multirow{2}{*}{ Total } & & Recuento & 11 & 34 & 90 & 135 \\
\hline & & $\%$ & $8 \%$ & $25 \%$ & $67 \%$ & $100,0 \%$ \\
\hline
\end{tabular}




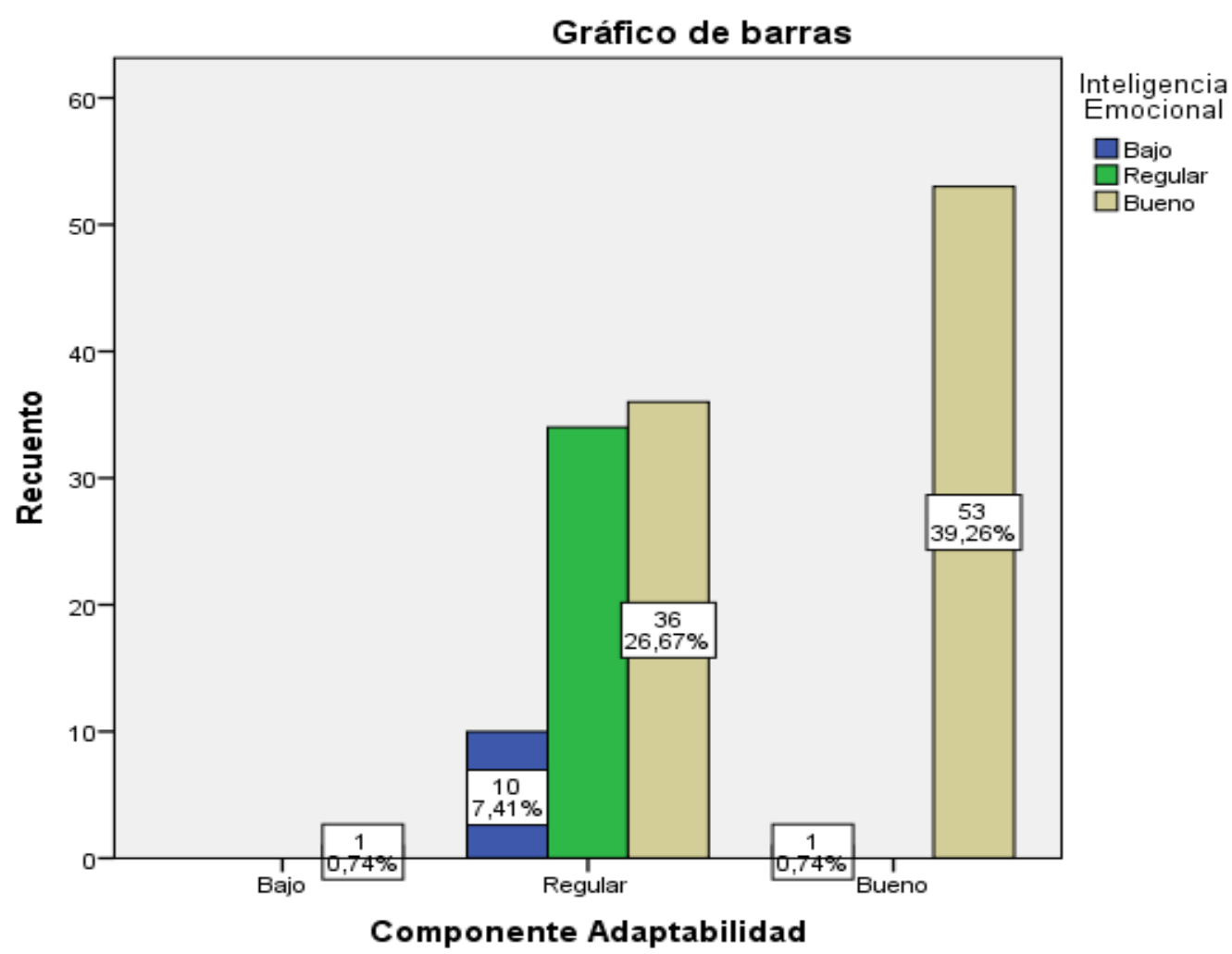

Figura 14: Componente Adaptabilidad*Inteligencia Emocional tabulación cruzada

Comentario: Se evidencia que del 59.3\% de estudiantes evaluados que se encuentran en un nivel de adaptabilidad regular, se evidencia a un grupo con un nivel de inteligencia regular siendo el $25 \%$ y el $27 \%$ en un nivel bueno. Seguidamente del $40 \%$ que se encuentra en un nivel bueno en relación a la adaptabilidad, se evidencia que el 39\% se encuentra en un nivel de inteligencia emocional bueno. Por último, el resto se encuentra en nivel bajo.

Tabla 20: Componente Estado de Animo General*Clima del aula tabulación cruzada

\begin{tabular}{cccccc}
\hline & & \multicolumn{3}{c}{ Clima en el aula } & Total \\
\cline { 3 - 6 } & & Malo & Regular & Excelente \\
& Recuento & 2 & 1 & 1 & 4 \\
\hline \multirow{2}{*}{ Bajo } & $\%$ & $1 \%$ & $1 \%$ & $1 \%$ & $3,0 \%$ \\
\hline
\end{tabular}




\begin{tabular}{|c|c|c|c|c|c|c|}
\hline \multirow[b]{2}{*}{ Componente } & & Recuento & 1 & 25 & 13 & 39 \\
\hline & Regular & $\%$ & $1 \%$ & $19 \%$ & $10 \%$ & $28,9 \%$ \\
\hline \multirow{2}{*}{ Animo General } & & Recuento & 0 & 9 & 83 & 92 \\
\hline & DUCHO & $\%$ & $0 \%$ & $7 \%$ & $61 \%$ & $68,1 \%$ \\
\hline \multirow[b]{2}{*}{ Total } & & Recuento & 3 & 35 & 97 & 135 \\
\hline & & $\%$ & $2 \%$ & $26 \%$ & $72 \%$ & $100,0 \%$ \\
\hline
\end{tabular}

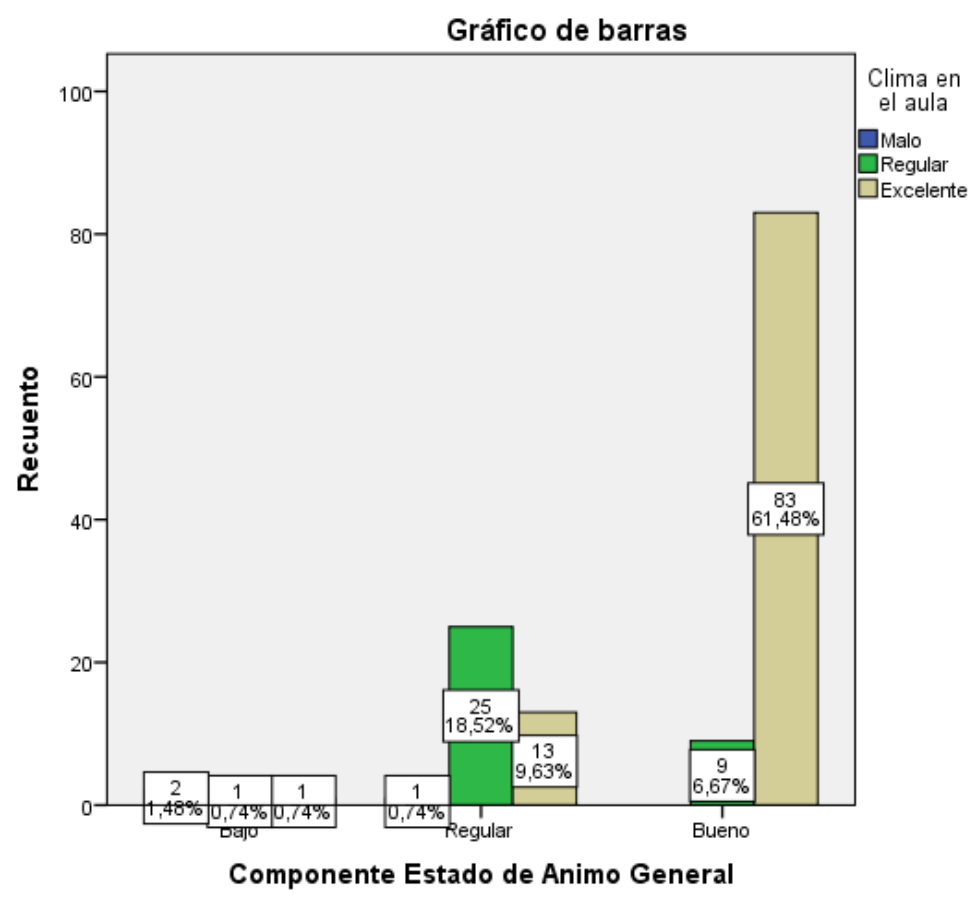

Figura 15: Componente Estado de Animo General*Clima en el aula tabulación cruzada

Comentario: Se evidencia que del $68.1 \%$ que se encuentra en un nivel bueno según su estado de ánimo general, solo el $61 \%$ se encuentra con un excelente clima en el aula. Seguidamente del $28 \%$ que se encuentran en un estado de ánimo general regular, el $25 \%$ se encuentra con un clima en el aula regular y el $10 \%$ en un nivel excelente. El resto se encuentra en un nivel bajo. 
Tabla 21: Componente Estado de Animo General*Inteligencia Emocional

tabulación cruzada

\begin{tabular}{|c|c|c|c|c|c|c|}
\hline & \multicolumn{3}{|c|}{ Inteligencia Emocional } & \multirow[t]{2}{*}{ Total } \\
\hline & & & Bajo & Regular & Bueno & \\
\hline \multirow{6}{*}{$\begin{array}{l}\text { Componente } \\
\text { Estado de } \\
\text { Animo } \\
\text { General }\end{array}$} & & Recuento & 2 & 1 & 1 & 4 \\
\hline & Bajo & $\begin{array}{l}\text { de dentro } \\
\text { Inteligencia } \\
\text { Emocional }\end{array}$ & $1 \%$ & $1 \%$ & $1 \%$ & $3,0 \%$ \\
\hline & & Recuento & 4 & 25 & 10 & 39 \\
\hline & Regular & $\begin{array}{l}\text { de dentro } \\
\text { Inteligencia } \\
\text { Emocional }\end{array}$ & $3 \%$ & $19 \%$ & $7 \%$ & $28,9 \%$ \\
\hline & & $\begin{array}{l}\text { Recuento } \\
\% \text { dentro }\end{array}$ & 5 & 8 & 79 & 92 \\
\hline & Bueno & $\begin{array}{l}\text { de } \\
\text { Inteligencia } \\
\text { Emocional }\end{array}$ & $4 \%$ & $6 \%$ & $59 \%$ & $68,1 \%$ \\
\hline \multirow[b]{2}{*}{ Total } & & $\begin{array}{l}\text { Recuento } \\
\% \text { dentro }\end{array}$ & 11 & 34 & 90 & 135 \\
\hline & & $\begin{array}{l}\text { de } \\
\text { Inteligencia } \\
\text { Emocional }\end{array}$ & $8 \%$ & $25 \%$ & $67 \%$ & $100,0 \%$ \\
\hline
\end{tabular}

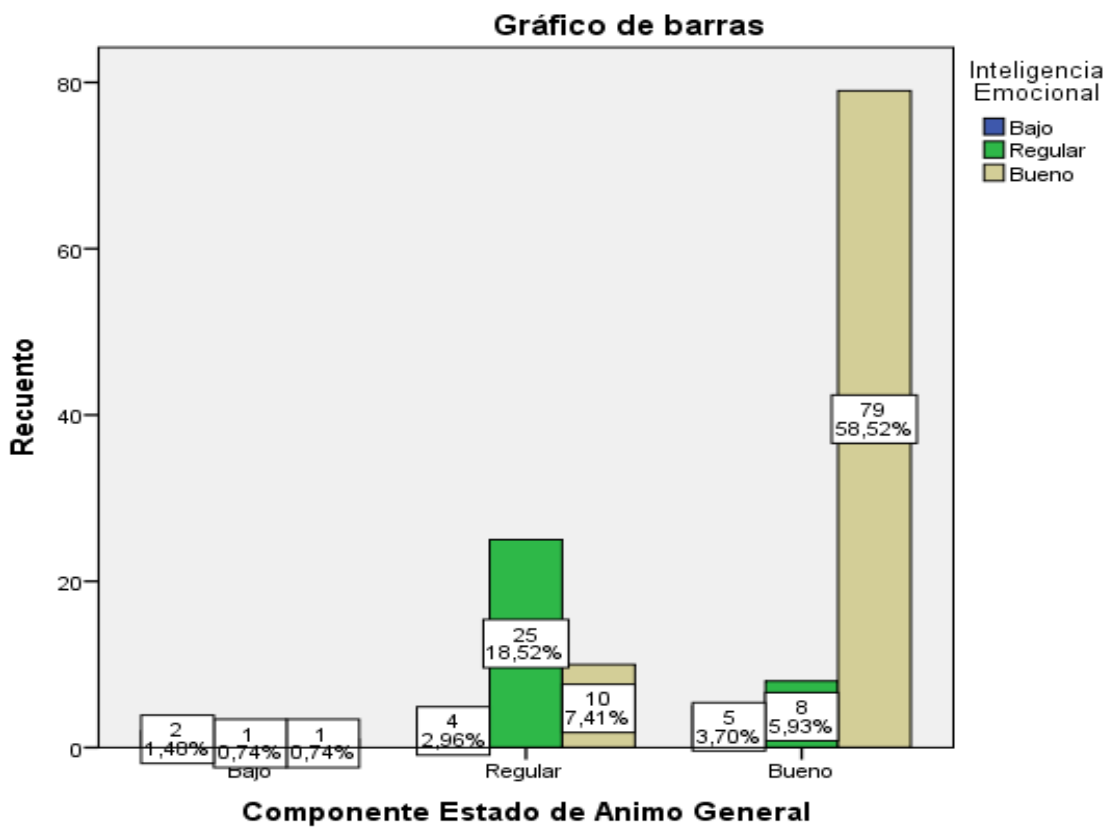

Figura 16: Componente Estado de Animo General*Inteligencia Emocional tabulación cruzada 
Se evidencia en la tabla que del $68 \%$ que se encuentran en un estado de ánimo general bueno, el $59 \%$ se encuentra con una inteligencia emocional bueno, seguidamente del $28.9 \%$ que se encuentra en un estado de ánimo general regular, el $7 \%$ se encuentra con un nivel de inteligencia emocional bueno y un $19 \%$ con un nivel regular. El resto se encuentra en un nivel bajo.

Antes de la prueba de hipótesis se realizó la siguiente prueba de normalidad.

Tabla 22: Prueba de Kolmogorov-Smirnov para una muestra

\begin{tabular}{|c|c|c|c|c|c|c|c|}
\hline & $\begin{array}{c}\text { Inteligen } \\
\text { cia } \\
\text { intrapers } \\
\text { onal } \\
\end{array}$ & $\begin{array}{l}\text { Inteligen } \\
\text { cia } \\
\text { interpers } \\
\text { onal } \\
\end{array}$ & $\begin{array}{l}\text { Inteligen } \\
\text { cia } \\
\text { Emocion } \\
\text { al } \\
\end{array}$ & $\begin{array}{c}\text { Clima en } \\
\text { el aula }\end{array}$ & $\begin{array}{l}\text { Compon } \\
\text { ente } \\
\text { Adaptabi } \\
\text { lidad } \\
\end{array}$ & $\begin{array}{l}\text { Compon } \\
\text { ente } \\
\text { manejo } \\
\text { de Estrés }\end{array}$ & $\begin{array}{c}\text { Compon } \\
\text { ente } \\
\text { Estado } \\
\text { de } \\
\text { Animo } \\
\text { General }\end{array}$ \\
\hline $\mathrm{N}$ & 135 & 135 & 135 & 135 & 135 & 135 & 135 \\
\hline Parámetr Media & 2,70 & 2,84 & 2,59 & 2,70 & 2,39 & 2,36 & 2,65 \\
\hline $\begin{array}{ll}\text { os } & \text { Desviaci } \\
\text { normale } & \text { ón } \\
\mathrm{s}^{\mathrm{a}, \mathrm{b}} & \text { estándar }\end{array}$ & ,490 & ,364 & 639 & ,508 &, 505 & ,685 &, 537 \\
\hline Máxima Absoluta & ,446 & ,510 & ,408 & ,444 & ,381 &, 301 & ,423 \\
\hline Positivo & ,273 & ,334 &, 258 & ,275 & ,381 &, 224 &, 258 \\
\hline $\begin{array}{l}\text { diferenci Negativo } \\
\text { as } \\
\text { extremas }\end{array}$ &,- 446 &,- 510 &,- 408 &,- 444 &,- 285 &,- 301 &,- 423 \\
\hline $\begin{array}{l}\text { Estadístico de } \\
\text { prueba }\end{array}$ & ,446 & ,510 & ,408 & ,444 &, 381 & ,301 & ,423 \\
\hline $\begin{array}{l}\text { Sig. asintótica } \\
\text { (bilateral) }\end{array}$ &, $000^{\mathrm{c}}$ &, $000^{\mathrm{c}}$ &, $000^{\mathrm{c}}$ &, $000^{c}$ &, $000^{\mathrm{c}}$ &, $000^{c}$ &, $000^{c}$ \\
\hline
\end{tabular}

a. La distribución de prueba es normal.

b. Se calcula a partir de datos.

c. Corrección de significación de Lilliefors. 


\section{Función de Prueba}

Se realizó por medio del coeficiente de correlación de Pearson, de manera que las variables presentarán normalidad en su información calculada.

\section{Regla de decisión}

Rechazar Ho cuando la significancia " $p$ " es menor que $\alpha=0,05$

No rechazar Ho cuando la significancia "p" es mayor que $\alpha=0,05$

\section{Nivel de significancia}

El nivel de significancia teórica es $\alpha=0,05$, que corresponde a un nivel de confiabilidad del 95\%.

\section{Hipótesis General:}

Existe una relación positiva y significativa entre la inteligencia emocional y el clima del aula de los estudiantes del sexto ciclo de una Institución Pública del distrito de Chorrillos.

Tabla 23: Correlaciones entre la inteligencia emocional y el clima del aula de los estudiantes del sexto ciclo de una Institución Pública del distrito de Chorrillos.

\begin{tabular}{llcc}
\hline \hline & & $\begin{array}{c}\text { Inteligencia } \\
\text { Emocional }\end{array}$ & $\begin{array}{c}\text { Clima en el } \\
\text { aula }\end{array}$ \\
\hline Inteligencia & Correlación de & 1 &, $712^{* *}$ \\
Emocional & Pearson & & \\
& Sig. (bilateral) & 135 & 135 \\
& $\mathrm{~N}$ &, $712^{* *}$ & 1 \\
\hline Clima en el aula & Correlación de & & \\
& Pearson &, 000 & \\
& Sig. (bilateral) & 135 & 135 \\
\hline \hline
\end{tabular}

***. La correlación es significativa en el nivel 0,01 (2 colas). 

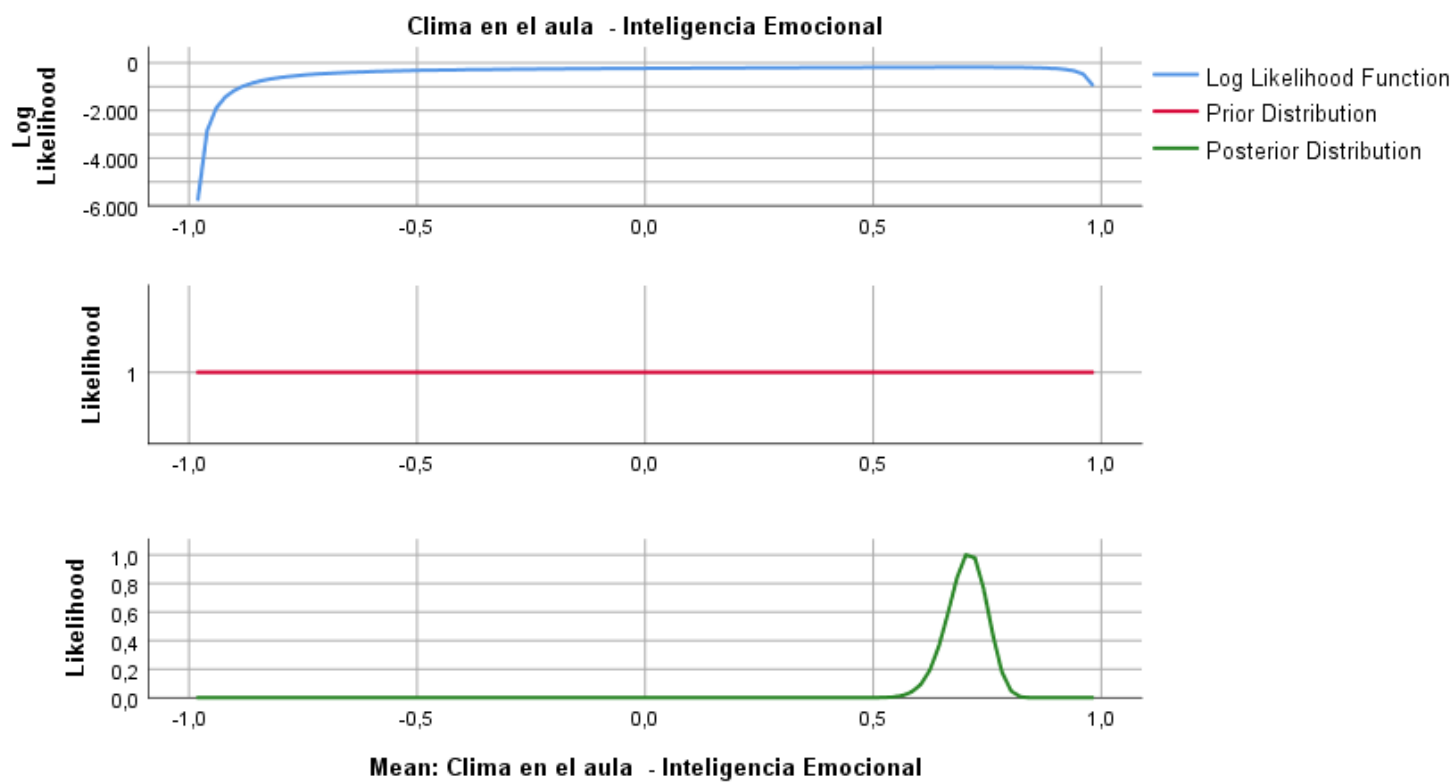

\section{Hipótesis específicas.}

Hipótesis específica 1.

Existe una relación positiva y significativa entre la inteligencia intrapersonal y el clima del aula de los estudiantes del sexto ciclo de una Institución Pública del distrito de Chorrillos.

Tabla 24: Correlaciones entre la inteligencia intrapersonal y el clima del aula de los estudiantes del sexto ciclo de una institución pública de Chorrillos.

\begin{tabular}{llrr}
\hline \hline & & $\begin{array}{c}\text { Inteligencia } \\
\text { intrapersonal }\end{array}$ & $\begin{array}{r}\text { Clima en el } \\
\text { aula }\end{array}$ \\
\hline Inteligencia & Correlación de & 1 &, $986^{* *}$ \\
intrapersonal & Pearson & &, 000 \\
& Sig. (bilateral) & 135 & 135 \\
& $\mathrm{~N}$ &, $986^{* *}$ & 1 \\
\hline Clima en el aula & Correlación de & & \\
& Pearson & 000 & \\
& Sig. (bilateral) & 135 & \\
& $\mathrm{~N}$ & & \\
& & & \\
& & & \\
& & & \\
& $* *$ La correlación es significativa en el nivel 0,01 (2 colas).
\end{tabular}

**. La correlación es significativa en el nivel 0,01 (2 colas). 

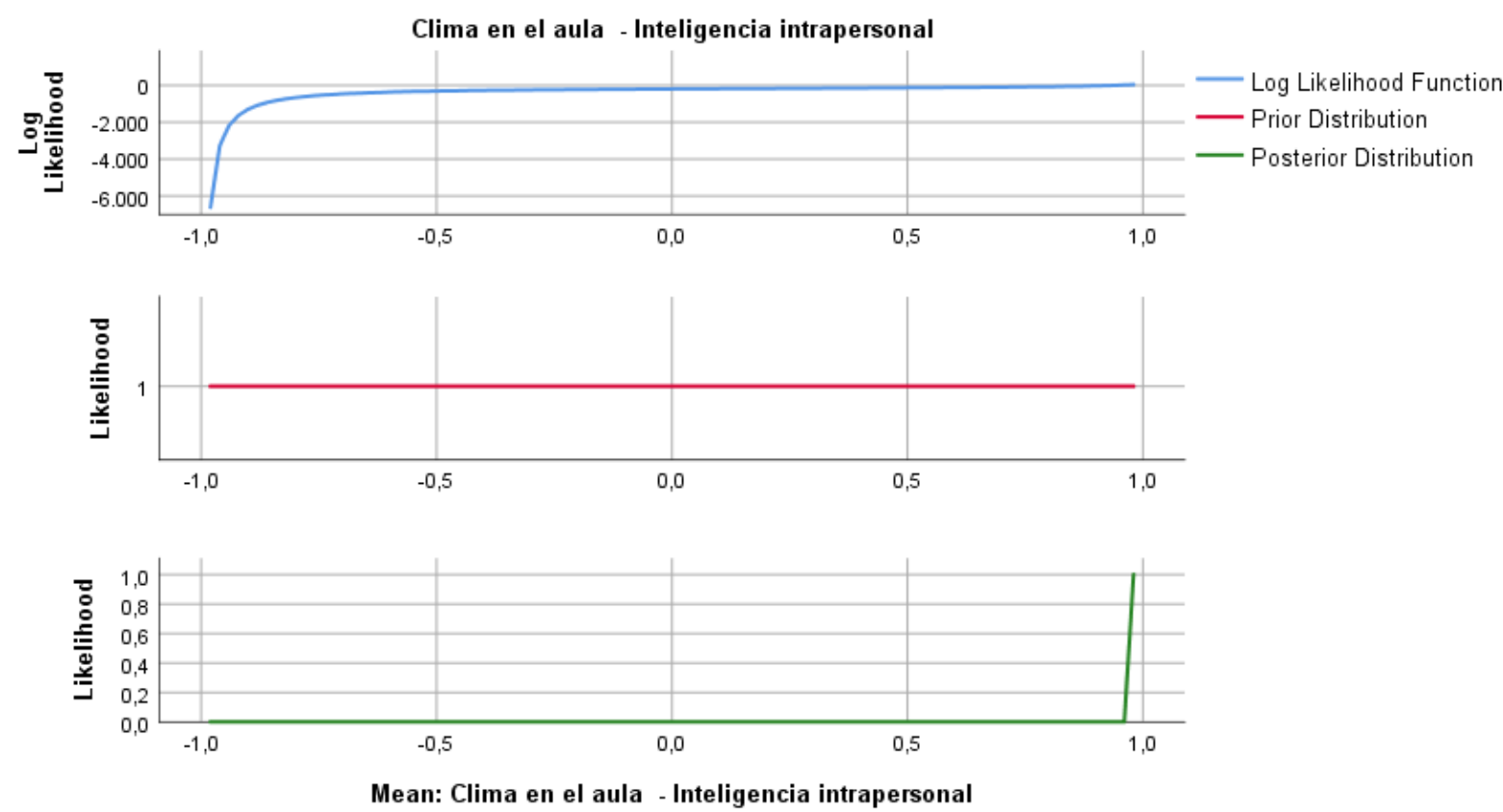

Hipótesis específica 2.

Existe una relación positiva y significativa entre la inteligencia interpersonal y el clima del aula de los estudiantes del sexto ciclo de una Institución Pública del distrito de Chorrillos.

Tabla 25: Correlaciones entre la inteligencia interpersonal y el clima del aula de los estudiantes del sexto ciclo de una institución pública de Chorrillos

\begin{tabular}{llcc}
\hline \hline & & $\begin{array}{c}\text { Inteligencia } \\
\text { interpersonal }\end{array}$ & $\begin{array}{c}\text { Clima en el } \\
\text { aula }\end{array}$ \\
\hline Inteligencia & Correlación de & 1 &, $631^{* *}$ \\
interpersonal & Pearson & & \\
& Sig. (bilateral) & 135 &, 000 \\
& $\mathrm{~N}$ &, $631^{* *}$ & 135 \\
\hline Clima en el aula & Correlación de & & \\
& Pearson &, 000 & \\
& Sig. (bilateral) & 135 & 135 \\
\hline \hline
\end{tabular}

**. La correlación es significativa en el nivel 0,01 (2 colas). 

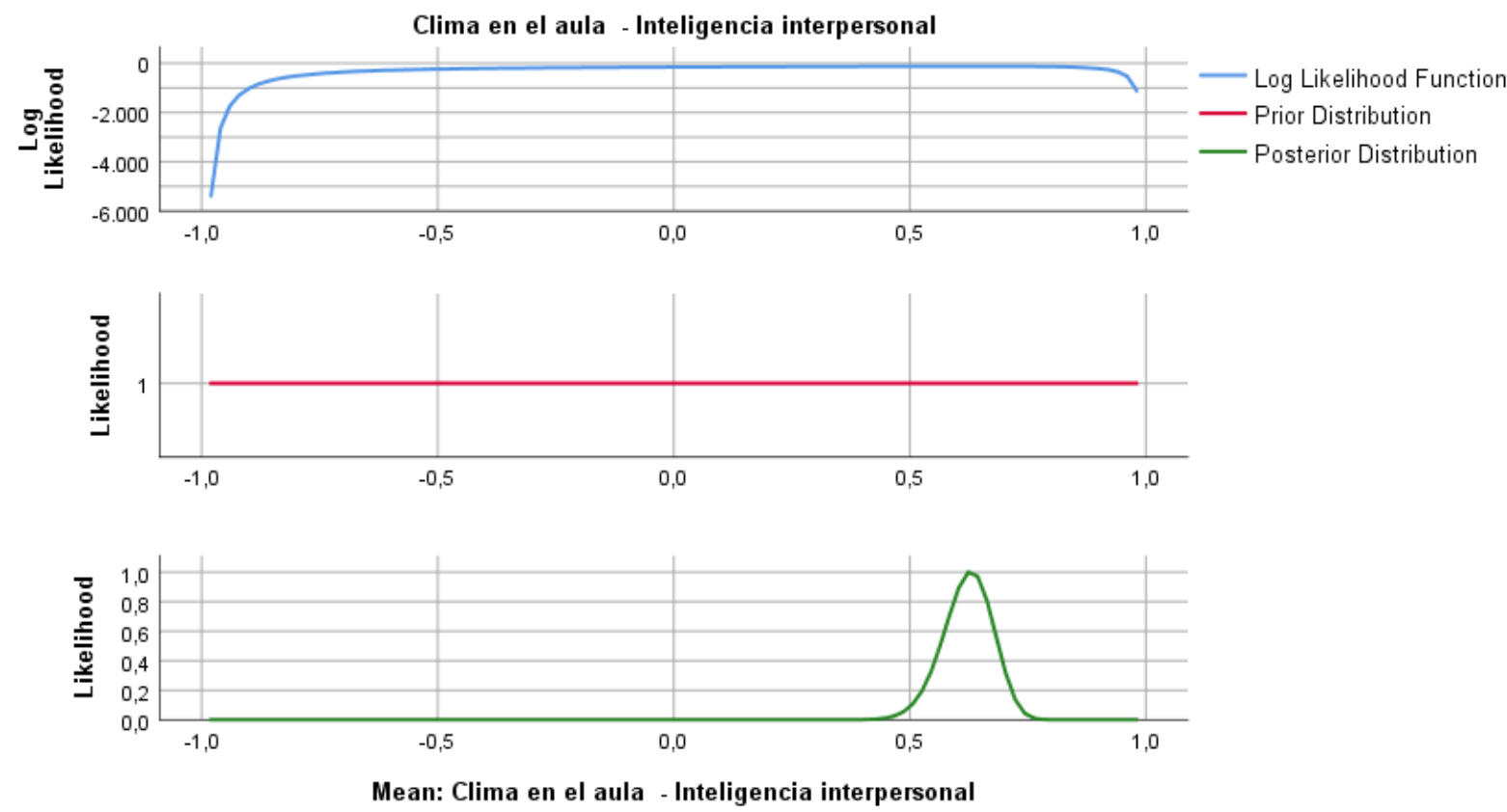

Hipótesis específica 3.

Existe una relación positiva y significativa entre el componente manejo del estrés de la inteligencia emocional y el clima del aula de los estudiantes del sexto ciclo de una Institución Pública del distrito de Chorrillos.

Tabla 26: Correlaciones entre el componente manejo del estrés de la inteligencia emocional y el clima del aula de los estudiantes del sexto ciclo de una institución pública de Chorrillos.

\begin{tabular}{llcc}
\hline \hline & & $\begin{array}{c}\text { Inteligencia } \\
\text { Emocional }\end{array}$ & $\begin{array}{c}\text { Clima en el } \\
\text { aula }\end{array}$ \\
\hline $\begin{array}{l}\text { Componente manejo de } \\
\text { Estrés }\end{array}$ & $\begin{array}{l}\text { Correlación de } \\
\text { Pearson }\end{array}$ &, $595^{* *}$ &, $634^{* *}$ \\
& Sig. (bilateral) &, 000 &, 000 \\
& $\mathrm{~N}$ & 135 & 135 \\
\hline
\end{tabular}

**. La correlación es significativa en el nivel 0,01 (2 colas). 

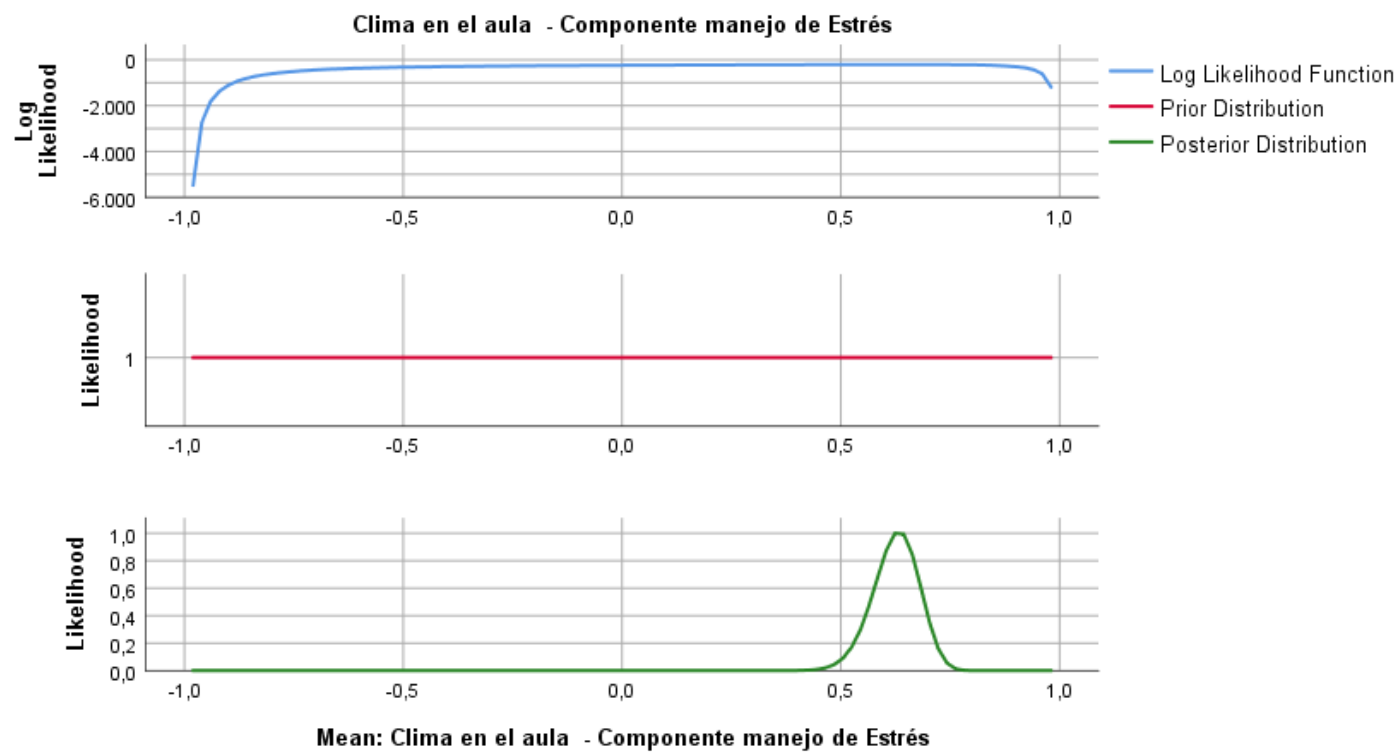

Hipótesis específica 4.

Existe una relación positiva y significativa entre el componente adaptabilidad de la inteligencia emocional y el clima del aula de los estudiantes del sexto ciclo de una Institución Pública del distrito de Chorrillos.

Tabla 27: Correlaciones entre el componente adaptabilidad de la inteligencia emocional y el clima del aula de los estudiantes del sexto ciclo de una institución pública del distrito de Chorrillos.

\section{Correlaciones}

\begin{tabular}{llcc}
\hline \hline & & $\begin{array}{c}\text { Inteligencia } \\
\text { Emocional }\end{array}$ & $\begin{array}{c}\text { Clima en el } \\
\text { aula }\end{array}$ \\
\hline Componente & Correlación de &, $462^{* *}$ &, $439^{* *}$ \\
Adaptabilidad & Pearson & & \\
& Sig. (bilateral) &, 000 &, 000 \\
& $\mathrm{~N}$ & 135 & 135 \\
\hline
\end{tabular}

**. La correlación es significativa en el nivel 0,01 ( 2 colas). 

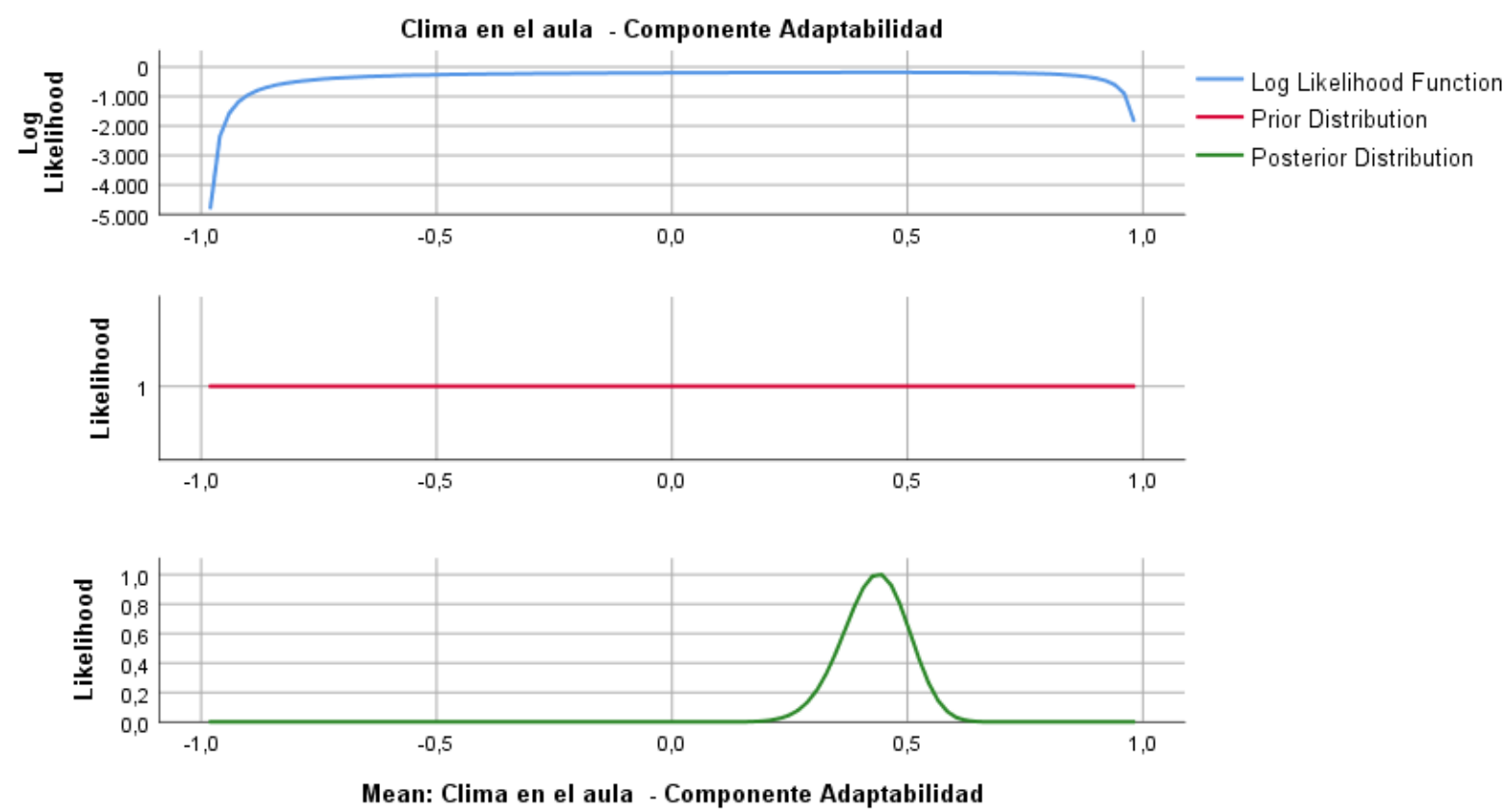

Hipótesis específica 5.

Existe una relación positiva y significativa entre el componente estado de ánimo de la inteligencia emocional y el clima del aula de los estudiantes del sexto ciclo de una Institución Pública del distrito de Chorrillos.

Tabla 28: Correlaciones entre el componente estado de ánimo de la inteligencia emocional y el clima del aula de los estudiantes del sexto ciclo de una institución pública del distrito de Chorrillos.

\begin{tabular}{llcc}
\hline \hline & & Inteligencia & Clima en el \\
& & Emocional & aula \\
\hline Componente Estado de & Correlación de &, $511^{* * *}$ &, $622^{* *}$ \\
Animo General & Pearson & & \\
& Sig. (bilateral) &, 000 &, 000
\end{tabular}


**. La correlación es significativa en el nivel 0,01 (2 colas).
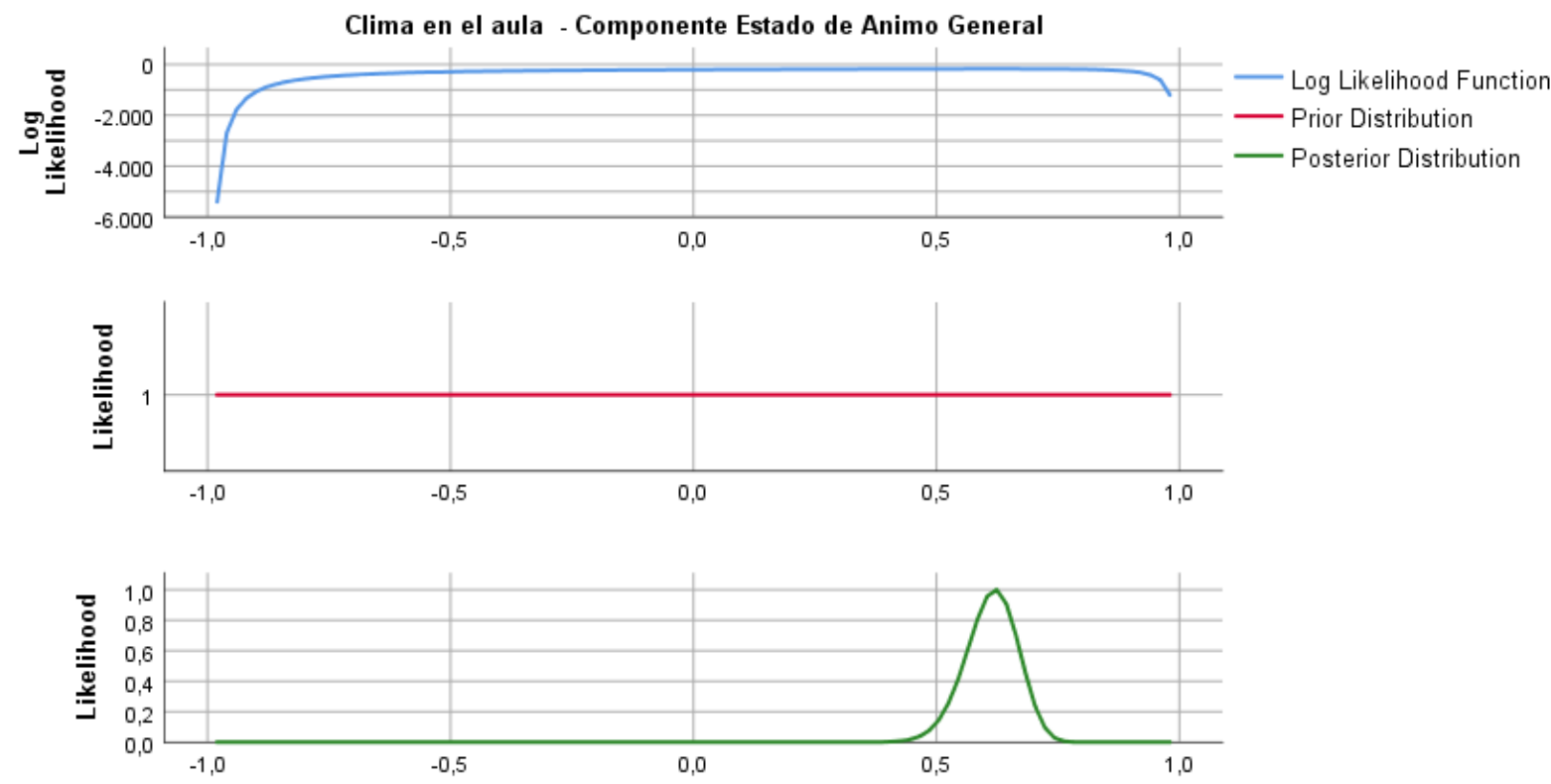

Mean: Clima en el aula - Componente Estado de Animo General
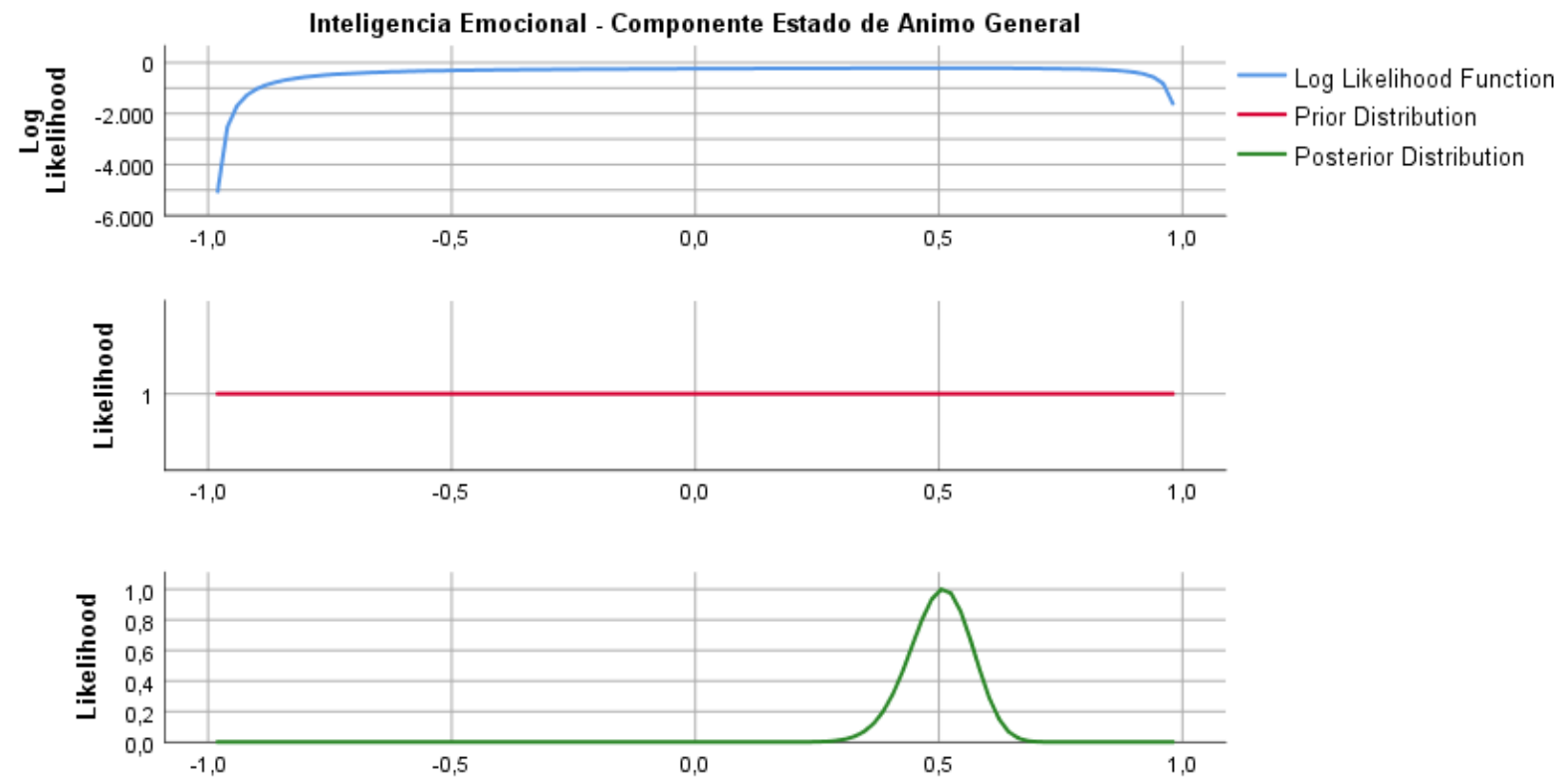

Mean: Inteligencia Emocional - Componente Estado de Animo General 


\section{Discusión}

- Entre los hallazgos de la investigación, se determinó los niveles adecuados y previstos referentes a la inteligencia emocional en relación al clima del aula, concluyéndose que a mayor inteligencia emocional mejor clima del aula. Lo cual concuerda con Ortiz (2015) quien explica que una de las ventajas educativas que presenta la inteligencia emocional y su aplicabilidad, es la mejora de la interrelación en toda la comunidad educativa. Basada en los postulados de Salovey y Mayer (1990) los resultados se relacionan con lo expresado en esta teoría. Dando por validada la hipótesis general.

- Con respecto a la hipótesis específica 1 , se obtuvo como resultado que existe relación significativa entre el clima de aula y la dimensión intrapersonal de la Inteligencia Emocional de los estudiantes del sexto ciclo de la institución pública 7038 Corazón de Jesús de Armatambo. Asimismo, La medición de Pearson es igual a $0,311 * *$ con un $67 \%$ esto indica que ambas variables están relacionadas significativamente, es decir a mayor clima intrapersonal, mejor clima del aula; en forma análoga Matassini (2012) en su trabajo de investigación sobre la inteligencia emocional de los docentes y el clima organizacional en una institución educativa del Callao determinó que el conocimiento y el control de sí mismo, son situaciones que forman parte de las habilidades que controlan nuestras emociones internas, suman en beneficio de un buen ambiente por ser una persona capaz de dominar sus sentimientos y poder mantener espacios de reflexión interna les permiten una adecuada toma de decisiones. 
- Continuando con la misma línea sobre la hipótesis 2 entre la inteligencia interpersonal y la atmósfera en el aula podemos decir que son consistentes: pues, los estudiantes de la institución educativa 7038 Corazón de Jesús de Armatambo demostraron que hay una relación directa y relacionada entre las estadísticas Rho de Spearman. El valor es 0.996, es decir, cuanto mejor sea la relación interpersonal, mejor será el clima. En el entorno del aula, Paredes F. (2015) determina que el entorno de la atmósfera interpersonal, familiar e interpersonal del aula y el logro de habilidades de los estudiantes en la institución educativa Tupac Amaru que determina el entorno de Villa María del Triunfo. Paredes F. (2015) encontró resultados similares, descubrimos que existe una estrecha relación entre las relaciones interpersonales y el buen clima de aula entre los estudiantes.

- Asimismo, con respecto a la hipótesis 3, se obtuvo como resultado que existe relación significativa entre la dimensión manejo del estrés de la inteligencia emocional con un $39 \%$ y un nivel muy bueno de clima del aula esto indica que ambas variables están relacionadas significativamente y a su vez presentan una relación directa y correlacional, esto quiere decir que a mayores valores en la dimensión manejo del estrés, existirán un mejor clima de aula. Estos resultados son ratificados con los estudios de según Ugarriza y Pajares (2005), cuando el estudiante maneja situaciones provocadas por ciertos momentos agobiantes, en tal sentido maneja su estrés de forma conveniente. En ese sentido, el postulado de Goleman (1995), se relaciona con estos resultados, puesto que la inteligencia emocional se percibe cuando el estudiante examina sus emociones y maneja su estrés, desde su desenvolvimiento personal y en su convivencia 
- Según la hipótesis específica 4 , se obtuvo como resultado que existe relación significativa entre el buen clima del aula y la dimensión adaptabilidad de la inteligencia emocional es de un $39 \%$ esto indica que ambas variables están relacionadas significativamente, resultado similar encontró Matassini (2012) en su trabajo de investigación sobre la inteligencia emocional de los docentes y el clima organizacional en una institución educativa del Callao al concluir que existe una relación directa y positiva entre la dimensión adaptabilidad y la variable clima organizacional, a mayores valores en la dimensión adaptabilidad, existirán mejor clima de aula estos resultados con lo expuesto por Altamirano (2015) cuyo estudio llega a la conclusión que existe una relación entre ambas variables La adaptabilidad desde el postulado teórico de según Bar-On (1997), predispone hacía un conjunto de habilidades personales, emocionales y sociales para adaptarse y enfrentar a las demandas que influyen en la capacidad de un individuo para lograr confrontar las presiones del entorno y solucionar problemas.

- Finalmente, según la hipótesis específica 5 se obtuvo como resultado que existe relación significativa entre el clima del aula y la dimensión estado de ánimo general 4',7\% de la inteligencia emocional. Los estudios de Salazar (2015) coinciden con estos resultados, puesto que este estudioso determinó en su investigación la importancia para el rendimiento académico y desempeño del estudiante el desarrollo de la inteligencia emocional, principalmente en su estado de ánimo y motivación. El fundamento teórico de Cooper (1998), se relaciona con los resultados expuestos, puesto que, menciona que la inteligencia emocional es la capacidad de sentir, entender y aplicar eficazmente el poder y la agudeza de las emociones y estados de ánimo como fuente de energía humana. 


\section{Conclusiones}

Primera: Para la hipótesis general relación entre la inteligencia emocional y clima del aula de los estudiantes del sexto ciclo de una institución pública del distrito de Chorrillos se comprobó que existe una relación directa, alta y significativa al obtener un valor de 0.712 determinado por Pearson, es decir a mayor inteligencia emocional mejor clima del aula.

Segunda: Existe una relación positiva y significativa entre la inteligencia intrapersonal y el clima del aula de los estudiantes del sexto ciclo de una Institución Pública del distrito de Chorrillos, éstas se muestran en la relación alta con un índice de 986 según la correlación de Pearson, Fue significativa con valor menor a 0.00

Tercera: Existe una relación positiva y significativa entre la inteligencia interpersonal y el clima del aula de los estudiantes del sexto ciclo de una Institución Pública del distrito de Chorrillos., que se puede evidenciar en la correlación de Pearson obteniéndose un puntaje de 631, con una significatividad de 0.00 .

Cuarta: Existe una relación positiva y significativa entre el componente adaptabilidad y el clima de aula. En donde la correlación del componente adaptabilidad según la correlación de Pearson es de 462 teniendo una correlación poco significativa de 0.00 .

Quinta: Para la hipótesis entre el manejo del estrés y el clima del aula, existe una relación directa y significativa al obtener un valor de 0.634 determinado mediante el estadístico correlación de Pearson es decir a mayor manejo del estrés, mejor clima del aula.

Sexta: Existe una relación positiva y significativa entre el estado de ánimo y el clima de aula. Obteniéndose según la correlación de Pearson un 511 para inteligencia emocional y 622 para para clima de aula, fue significativa con valor menor a 0.00 , siendo a su vez un buen índice en comparación con la inteligencia emocional. 


\section{Sugerencias}

Primera: Comunicar y socializar cuales han sido los resultados de la investigación y pedir sean incluidos en el Proyecto Educativo Institucional y de esta manera sean plasmados en el FODA de la institución, y empezar trabajar sobre esta problemática.

Segunda: Mejorar las estrategias metodológicas fortaleciendo los aprendizajes a los docentes en inteligencia emocional y clima en el aula, de manera que pueda ser modelo y brinden un buen estado emocional a sus estudiantes, vivenciando esto durante el proceso de enseñanza aprendizaje. Cabe recalcar que todo partirá de la gestión que se desarrolle.

Tercera Implementar a partir del PEI programas de mejora del clima de aula, con talleres vivenciales en el desarrollo de habilidades sociales. Estos talleres permitirán que cada estudiante mejore estableciendo mejores relaciones al interior del aula.

Cuarta: Implementar 10 sesiones de clase. (Trabajados por el tutor.) en la que la temática sea trabajar la inteligencia emocional y cada estudiante pueda darse cuenta, cual inteligencia predomina en su pensamiento y acción.

Quinta: Establecer reuniones mensuales, conversatorios con los docentes tutores, en los que se les implemente en el conocimiento y práctica de la inteligencia emocional y manejo de conflictos, de manera que empoderados puedan manejar situaciones difíciles en el aula.

Sexta: Implementar los talleres del programa "Familias Fuertes" que involucra al padre e hijo en una serie de 7 sesiones en los que se trabajan aspectos como manejo de conflictos, descubriendo mis habilidades, etc. Involucrando una vez por semana al padre de familia y al termino del programa llamadas mensuales para ver que se apliquen lo trabajado en el programa. 


\section{REFERENCIAS BIBLIOGRAFICAS}

\section{REFERENCIAS}

Blondet. (2014). Tesis clima del aula y motivación académica de alumnos de quinto de secundaria de las instituciones educativas de Huacho. Universidad Cesar Vallejo, Perú.

Cáceres, Gutiérres, Briceño y Aranguren. (2015). El clima en el aula y el rendimiento escolar en la Enseñanza de la Física de la carrera de Educación-NURR-ULA, Trujillo- Lat. Am. J. Phys. Educ. Vol. 9, No. 3, Sept. 2015.

Casassus, J. (2007). Aprendizajes, emociones y clima de aula. Seminario internacional en gestión educativa. Recuperado de http://bibliotecadigital.academia.cl/handle/123456789/1694 Colores. (2015). Desarrollo de la competencia inteligencia emocional en una institución de educación básica del nivel de secundaria”. Universidad Tecnológica de Monterrey, México.

Escobedo. (2015). Relación entre inteligencia emocional y rendimiento académico de los alumnos del nivel básico de un colegio privado. Universidad Rafael Landivar, Guatemala.

Gardner,H. (1983). Frames of mind: The theory of multiple Intelligences. Nueva York: Basic Books. (traducción esp. 1987; 1994). Estructuras de la mente. La teoría de las múltiples inteligencias. Mexico Fondo de cultura Económica.

Goleman, D. (1996). Inteligencia emocional. España, Barcelona. Recuperado de http://www.hacienda.go.cr/cifh/sidovih/cursos/material_de_apoyo-F-C-90

CIFH/2MaterialdeapoyocursosCICAP/5InteligenciaEmocional/PracticaInteligEmocional.pdf Goleman, D. \& Cherniss, C. (2005). Inteligencia emocional en el trabajo. Cómo 
seleccionar y mejorar la inteligencia emocional en individuos, grupos y

organizaciones. Barcelona: Kairós

Guerreros. (2014). Clima social familiar, inteligencia emocional y rendimiento académico de los alumnos de quinto de secundaria de las instituciones educativas públicas de Ventanilla. Universidad Nacional Mayor de San Marcos, Perú.

Hernandez, M. (2015). Inteligencia emocional y percepción del clima del aula en alumnos de secundaria., (Trabajo de fin de master para optar el grado de Master en profesor de educación secundaria, especialidad Orientación educativa. Universidad de Valladolid - Valladolid España).

Maldonado. (2016). Tesis clima del aula escolar y estilos de enseñanza. Comuna de Quilpué,Chile.

Matassini, H. (2012). Relación entre inteligencia emocional y clima organizacional en los docentes de una institución educativa pública de La Perla-Callao. (Tesis para optar el grado de Maestro en educación Mención en Gestión Educativa). Universidad San Ignacio de Loyola. Lima-Perú.

Mayer, J.D. \&Salovey, P. (1990). “La inteligencia emocional Imaginación, la cognición y la personalidad”. México: Revista de Psicología, 52, 397-422.

Medina. (2017). Inteligencia emocional de los docentes y clima de aula en la escuela profesional de administración de negocios de la Universidad de San Juan Bautista filial Chincha. Universidad Nacional de Educación, Perú. 
Palomino. (2015). Estudio de correlación entre la inteligencia emocional y el rendimiento académico de los estudiantes de la facultad de Educación. Universidad Nacional Mayor de San Marcos, Perú.

Porcayo. (2015). Tesis inteligencia emocional en niños. Universidad Autónoma, México.

Tovar. (2019). Relación entre la inteligencia emocional y el rendimiento académico de los estudiantes del segundo año de la Escuela de Oficiales de la Policía Nacional del Perú. Universidad Nacional Mayor de San Marcos, Perú.

Ugarriza. N. I Pajares, L. (2003). Adaptación y estandarización del inventario de inteligencia emocional de Bar-On ICE:NA en niños y adolescentes: Manual Técnico. Lima: El libro amigo.

Vega. (2015). Clima del aula y su relación con los logros de aprendizajes en comunicación en los estudiantes del quinto grado de la I.E. San Juan - UGEL 01, 2016. Universidad Nacional de Educación - La Cantuta, Perú.

Vilchez. (2015). Influencia del programa de inteligencia emocional en el clima escolar de los estudiantes del tercer año "A” de secundaria de la I.E. 1283 Okinawa 2015. Universidad Nacional de Educación - La Cantuta, Perú. 
Anexos

ANEXO I

CUESTIONARIO

\section{INVENTARIO EMOCIONAL BarOn}

\section{INTRODUCCIÓN}

Este cuestionario contiene una serie de frases cortas que permite hacer una descripción de ti mismo(a). Para ello, debes indicar en qué medida cada una de las oraciones que aparecen a continuación es verdadera, de acuerdo a como te sientes, piensas o actúas la mayoría de las veces.

Hay cinco respuestas por cada frase.

1. Nunca es mi caso.

2. Pocas veces es mi caso.

3. A veces es mi caso.

4. Muchas veces es mi caso.

5. Siempre es mi caso.

\section{INSTRUCCIONES}

Lee cada una de las frases y selecciona UNA de las cinco alternativas, la que sea más apropiada para ti, seleccionando el número (del 1 al 5) que corresponde a la respuesta que escogiste según sea tu caso. Marca con un aspa el número. 
Si alguna de las frases no tiene que ver contigo, igualmente responde teniendo en cuenta cómo te sentirías, pensarías o actuarías si estuvieras en esa situación. Notarás que algunas frases no te proporcionan toda la información necesaria; aunque no estés seguro(a) selecciona la respuesta más adecuada para ti. No hay respuestas "correctas" o "incorrectas", ni respuestas "buenas" o "malas". Responde honesta y sinceramente de acuerdo a cómo eres. NO como te gustaría ser, NO como te gustaría que otro te viera. NO hay límite, pero por favor trabaja con rapidez y asegúrate de responder a TODAS las oraciones.

1. Para superar las dificultades que se me presentan actúo paso a paso.

2. Es difícil para mí disfrutar de la vida.

3. Prefiero un trabajo en el que se me diga casi todo lo que tengo que hacer.

4. Sé cómo enfrentar los problemas más desagradables.

5. Me agradan las personas que conozco.

6. Trato de valorar y darle el mejor sentido a mi vida.

7. Me resulta relativamente fácil expresar mis sentimientos.

8. Trato de ser realista, no me gusta fantasear ni soñar despierto(a).

9. Reconozco con facilidad mis emociones.

10. Soy incapaz de demostrar afecto.

11. Me siento seguro(a) de mí mismo(a) en la mayoría de situaciones.

12. Tengo la sensación que algo no está bien en mi cabeza.

13. Tengo problema para controlarme cuando me enojo.

14. Me resulta difícil comenzar cosas nuevas.

15. Cuando enfrento una situación difícil me gusta reunir toda la información posible que pueda sobre ella. 
16. Me gusta ayudar a la gente.

17. Me es difícil sonreír.

18. Soy incapaz de comprender cómo se sienten los demás.

19. Cuando trabajo con otro, tiendo a confiar más en sus ideas que en las mías.

20. Creo que puedo controlarme en situaciones muy difíciles.

21. Realmente no sé para que soy bueno(a).

22. No soy capaz de expresar mis ideas.

23. Me es difícil compartir mis sentimientos más íntimos con los demás.

24. No tengo confianza en mí mismo(a).

25. Creo que he perdido la cabeza.

26. Soy optimista en la mayoría de las cosas que hago.

27. Cuando comienzo a hablar me resulta difícil detenerme.

28. En general, me resulta difícil adaptarme.

29. Me gusta tener una visión general de un problema antes de intentar solucionarlo.

30. No me molesta aprovecharme de los demás, especialmente si se lo merecen.

31. Soy una persona bastante alegre y optimista.

32. Prefiero que otros tomen decisiones por mí.

33. Puedo manejar situaciones de estrés, sin ponerme demasiado nervioso(a).

34. Pienso bien de las personas.

35. Me es difícil entender como me siento.

36. He logrado muy poco en los últimos años.

37. Cuando estoy enojado(a) con alguien se lo puedo decir.

38. He tenido experiencias extrañas que no puedo explicar.

39. Me resulta fácil hacer amigos(as).

40. Me tengo mucho respeto. 
41. Hago cosas muy raras.

42. Soy impulsivo(a), y eso me trae problemas.

43. Me resulta difícil cambiar de opinión.

44. Soy bueno para comprender los sentimientos de las personas.

45. Lo primero que hago cuando tengo un problema es detenerme a pensar.

46. A la gente le resulta difícil confiar en mí.

47. Estoy contento(a) con mi vida.

48. Me resulta difícil tomar decisiones por mi mismo(a).

49. No puedo soportar el estrés.

50. En mi vida no hago nada malo.

51. No disfruto lo que hago.

52. Me resulta difícil expresar mis sentimientos más íntimos.

53. La gente no comprende mi manera de pensar.

54. Generalmente espero lo mejor.

55. Mis amigos me confían sus intimidades.

56. No me siento bien conmigo mismo(a).

57. Percibo cosas extrañas que los demás no ven.

58. La gente me dice que baje el tono de voz cuando discuto.

59. Me resulta fácil adaptarme a situaciones nuevas.

60. Cuando intento resolver un problema analizo todas las posibles soluciones y luego escojo la que considero mejor.

61. Me detendría y ayudaría a un niño que llora por encontrar a sus padres, aun cuando tuviese algo que hacer en ese momento.

62. Soy una persona divertida.

63. Soy consciente de cómo me siento. 
64. Siento que me resulta difícil controlar mi ansiedad.

65. Nada me perturba.

66. No me entusiasman mucho mis intereses.

67. Cuando estoy en desacuerdo con alguien soy capaz de decírselo.

68. Tengo tendencia a fantasear y perder contacto con lo que ocurre a mi alrededor.

69. Me es difícil llevarme con los demás.

70. Me resulta difícil aceptarme tal como soy.

71. Me siento como si estuviera separado(a) de mi cuerpo.

72. Me importa lo que puede sucederle a los demás.

73. Soy impaciente.

74. Puedo cambiar mis viejas costumbres.

75. Me resulta difícil escoger la mejor solución cuando tengo que resolver un problema.

76. Si pudiera violar la ley sin pagar las consecuencias, lo haría en determinadas situaciones.

77. Me deprimo.

78. Sé cómo mantener la calma en situaciones difíciles.

79. Nunca he mentido.

80. En general me siento motivado(a) para continuar adelante, incluso cuando las cosas se ponen difíciles.

81. Trato de continuar y desarrollar aquellas cosas que me divierten.

82. Me resulta difícil decir "no" aunque tenga el deseo de hacerlo.

83. Me dejo llevar por mi imaginación y mis fantasías.

84. Mis relaciones más cercanas significan mucho, tanto para mí como para mis amigos.

85. Me siento feliz con el tipo de persona que soy.

86. Tengo reacciones fuertes, intensas que son difíciles de controlar.

87. En general, me resulta difícil realizar cambios en mi vida cotidiana. 
88. Soy consciente de lo que me está pasando, aun cuando estoy alterado(a).

89. Para poder resolver una situación que se presenta, analizo todas las posibilidades existentes.

90. Soy capaz de respetar a los demás.

91. No estoy contento(a) con mi vida.

92. Prefiero seguir a otros a ser líder.

93. Me resulta difícil enfrentar las cosas desagradables de la vida.

94. Nunca he violado la ley.

95. Disfruto de las cosas que me interesan.

96. Me resulta relativamente fácil decirle a la gente lo que pienso.

97. Tiendo a exagerar.

98. Soy sensible a los sentimientos de las otras personas.

99. Mantengo buenas relaciones con los demás.

100. Estoy contento(a) con mi cuerpo.

101. Soy una persona muy extraña.

102. Soy impulsivo(a).

103. Me resulta difícil cambiar mis costumbres.

104. Considero que es muy importante ser un(a) ciudadano(a) que respeta la ley.

105. Disfruto mis vacaciones y los fines de semana.

106. En general tengo una actitud positiva para todo, aun cuando surgen problemas.

107. Tengo tendencia a depender de otros.

108. Creo en mi capacidad para manejar los problemas más difíciles.

109. No me siento avergonzado(a) por nada de lo que he hecho hasta ahora.

110. Trato de aprovechar al máximo las cosas que me gustan y me divierten.

111. Los demás piensan que no me hago valer, que me falta firmeza. 
112. Soy capaz de dejar de fantasear para volver a ponerme en contacto con la realidad.

113. Los demás opinan que soy una persona sociable.

114. Estoy contento(a) con la forma en que me veo.

115. Tengo pensamientos extraños que los demás no logran entender.

116. Me es difícil describir lo que siento.

117. Tengo mal carácter.

118. Por lo general, me trabo cuando pienso acerca de las diferentes maneras de resolver un problema.

119. Me es difícil ver sufrir a la gente.

120. Me gusta divertirme.

121. Me parece que necesito de los demás más de lo que ellos me necesitan.

122. Me pongo ansioso(a).

123. No tengo días malos.

124. Intento no herir los sentimientos de los demás.

125. No tengo una buena idea de lo que quiero en la vida.

126. Me es difícil hacer valer mis derechos.

127. Me es difícil ser realista.

128. No mantengo relación son mis amistades.

129. Haciendo un balance de mis puntos positivos y negativos me siento bien conmigo mismo(a).

130. Tengo una tendencia a explotar de cólera fácilmente.

131. Si me viera obligado(a) a dejar mi casa actual, me sería difícil adaptarme nuevamente.

132. En general, cuando comienzo algo nuevo tengo la sensación que voy a fracasar.

133. He respondido sincera y honestamente a las frases anteriores. 
Anexo II CUESTIONARIO SOBRE CLIMA DEL AULA (ESTUDIANTES) - ESCALA SES

Edad: Sexo: Año y Sección:

Estimado estudiante:

El objetivo de este cuestionario es recoger información sobre tu percepción del clima de aula. Lee con atención cada una de las preguntas y responde con la verdad. Marca con una (X) sobre la alternativa que corresponda a tu respuesta; solo así se obtendrá un diagnóstico real de la relación con tus profesores, para que así mejoren su rol dentro del aula y tú puedas aprender mejor. No dejes ninguna pregunta sin contestar.

TA: Totalmente de acuerdo A:
De acuerdo
I : Indeciso
D: En desacuerdo
TD: Totalmente en desacuerdo

Recuerda que es anónimo. 


\begin{tabular}{|c|c|c|c|c|c|}
\hline ITEM & $\begin{array}{l}\text { Totalmente } \\
\text { de acuerdo }\end{array}$ & $\begin{array}{l}\text { De } \\
\text { acuerdo }\end{array}$ & Indeciso & $\begin{array}{l}\text { En } \\
\text { desacuer } \\
\text { do }\end{array}$ & $\begin{array}{c}\text { Totalme } \\
\text { nte en } \\
\text { desacue } \\
\text { rdo }\end{array}$ \\
\hline $\begin{array}{l}\text { 1. En este colegio nuestros profesores nos animan a pensar en carreras } \\
\text { atrayentes y a menudo poco corrientes. }\end{array}$ & & & & & \\
\hline $\begin{array}{l}\text { 2. La mayoría de los profesores en este colegio están muy interesados en los } \\
\text { problemas personales de los alumnos. }\end{array}$ & & & & & \\
\hline $\begin{array}{l}\text { 3. En general los profesores de este colegio no son muy pacientes con los } \\
\text { alumnos. }\end{array}$ & & & & & \\
\hline $\begin{array}{l}\text { 4. La mayoría de mis profesores ponen una gran energía y entusiasmo en la } \\
\text { enseñanza. }\end{array}$ & & & & & \\
\hline $\begin{array}{l}\text { 5. La mayor parte de los profesores nos ayudan continuamente a ser muy } \\
\text { creativos en todo lo que hacemos. }\end{array}$ & & & & & \\
\hline $\begin{array}{l}\text { 6. Este es un colegio en el que existe una buena relación. Los profesores y } \\
\text { alumnos se preocupan unos de otros. }\end{array}$ & & & & & \\
\hline $\begin{array}{l}\text { 7. En este colegio me siento muy bien. Los profesores no tienen demasiadas } \\
\text { reglas desagradables a las que haya que } \\
\text { obedecer. }\end{array}$ & & & & & \\
\hline 8. En la mayoría de mis cursos creo que he aprendido mucho & & & & & \\
\hline
\end{tabular}




\begin{tabular}{|l|l|l|l|}
\hline $\begin{array}{l}\text { 9. En este colegio los profesores siempre están intentando hacer las cosas de } \\
\text { maneras nuevas y atrayentes. }\end{array}$ & & & \\
\hline $\begin{array}{l}\text { 10. Los profesores no parecen tener interés en conocer a sus alumnos. } \\
\text { profesores sin saber realmente las razones } \\
\text { por las que se les castiga. }\end{array}$ & & & \\
\hline
\end{tabular}




\begin{tabular}{|c|c|c|c|c|c|}
\hline ITEM & $\begin{array}{l}\text { Totalme } \\
\text { nte de } \\
\text { acuerdo }\end{array}$ & $\begin{array}{l}\text { De } \\
\text { acuer } \\
\text { do }\end{array}$ & $\begin{array}{l}\text { Indecis } \\
\text { o }\end{array}$ & $\begin{array}{l}\text { En } \\
\text { desacuer } \\
\text { do }\end{array}$ & $\begin{array}{l}\text { Total } \\
\text { me } \\
\text { nte en } \\
\text { desac } \\
\text { ue } \\
\text { rdo }\end{array}$ \\
\hline 12. La mayoría de mis clases están muy bien planificadas por mis profesores & & & & & \\
\hline $\begin{array}{l}\text { 13. En este colegio los profesores animan muy poco a los alumnos que quieren hacer } \\
\text { cosas de manera distinta. }\end{array}$ & & & & & \\
\hline $\begin{array}{l}\text { 14. En este colegio la mayoría de los profesores dedican mucho tiempo a ayudar a los } \\
\text { alumnos en su trabajo } \\
\text { personal y en sus problemas personales. }\end{array}$ & & & & & \\
\hline $\begin{array}{l}\text { 15. En este colegio existen demasiadas reglas y normas. Necesitas permiso para hacen } \\
\text { cualquier cosa. }\end{array}$ & & & & & \\
\hline $\begin{array}{l}\text { 16. La mayoría de mis profesores parecen estar muy interesados en lo que están } \\
\text { enseñando. }\end{array}$ & & & & & \\
\hline $\begin{array}{l}\text { 17. La mayor parte de mis profesores motivan mucho a los alumnos a que sean ellos } \\
\text { mismos y les permiten que } \\
\text { hagan cosas por sí solos. }\end{array}$ & & & & & \\
\hline
\end{tabular}




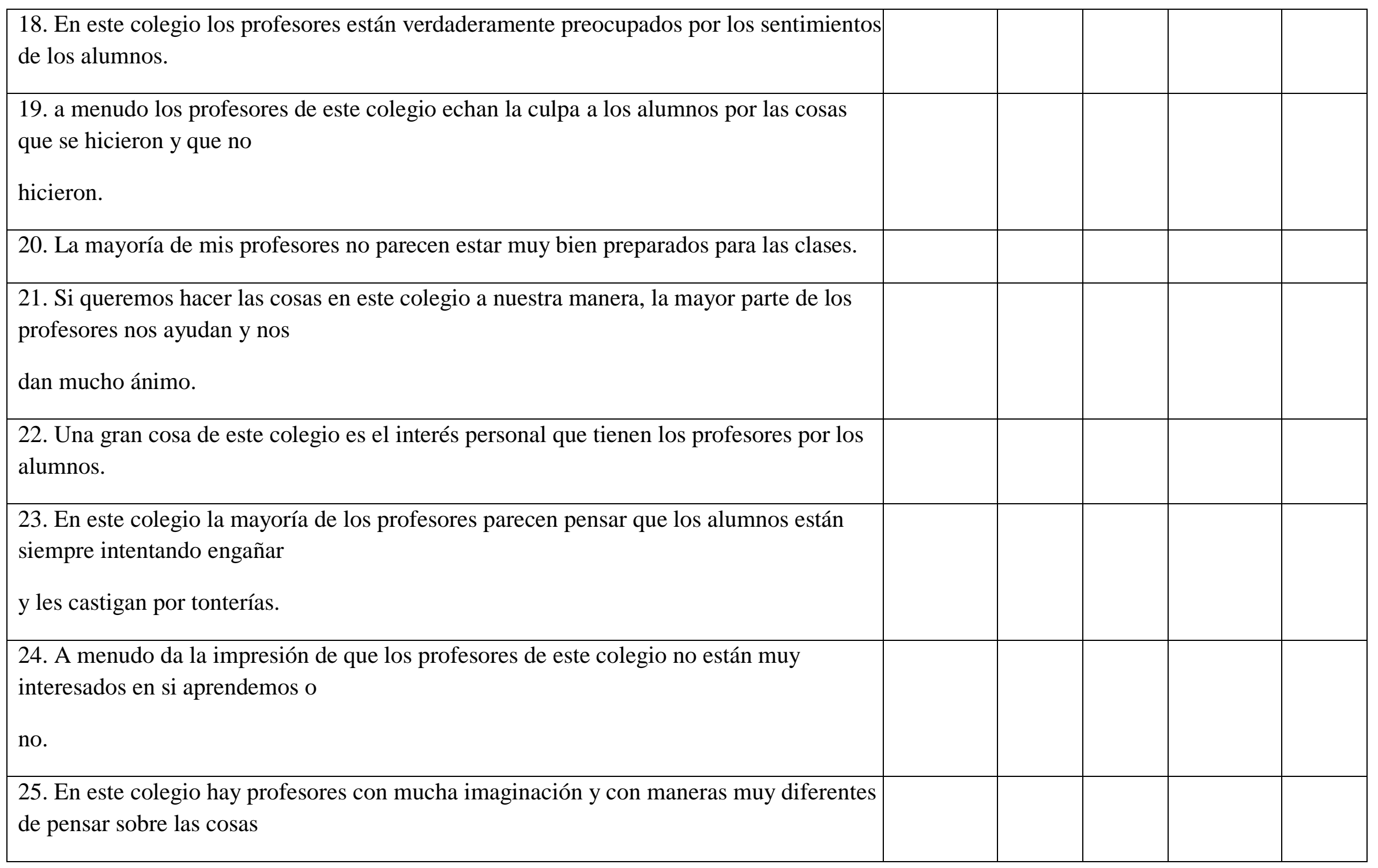


26. Además de estar preocupados por el trabajo escolar diario, la mayoría de los profesores están muy interesados

con los problemas personales de los alumnos.

27. Los profesores esperan de nosotros que obedezcamos demasiadas reglas y normas en este colegio.

28. La mayoría de mis profesores conocen su asignatura muy bien y son capaces de presentarla de una manera muy

interesante 
Anexo II1 MATRIZ DE CONSISTENCIA

TITULO: INTELIGENCIA EMOCIONAL Y EL CLIMA DEL AULA EN LOS ESTUDIANTES DEL SEXTO CICLO DE UNA INSTITUCIÓN EDUCATIVA PÚBLICA DEL DISTRITO DE CHORRILLOS.

\begin{tabular}{|c|c|c|c|c|c|}
\hline PROBLEMA & OBJETIVOS & HIPÓTESIS & $\begin{array}{l}\text { VARIABLES Y } \\
\text { SUBVARIABLES }\end{array}$ & $\begin{array}{l}\text { DIMENSIONES } \\
\text { VARIABLE } \\
\text { Inteligencia } \\
\text { Emocional }\end{array}$ & INDICADORES \\
\hline $\begin{array}{l}\text { Problema General: } \\
\text { ¿Qué relación existe } \\
\text { entre la inteligencia } \\
\text { emocional y el clima } \\
\text { del aula de los } \\
\text { estudiantes del } \\
\text { sexto ciclo de una } \\
\text { Institución Pública del } \\
\text { distrito de Chorrillos? }\end{array}$ & $\begin{array}{l}\text { Objetivo } \\
\text { General: } \\
\text { Determinar el } \\
\text { nivel de relación } \\
\text { entre } \\
\text { inteligencia la } \\
\text { emocional y el } \\
\text { clima del aula de } \\
\text { los estudiantes } \\
\text { del sexto ciclo } \\
\text { de } \\
\text { Institución una } \\
\text { Pública } \\
\text { distrito del } \\
\text { Chorrillos. }\end{array}$ & \begin{tabular}{l} 
Hipótesis General: \\
Existe una \\
relación positiva y \\
significativa entre la \\
inteligencia emocional \\
y el clima del aula \\
de los estudiantes del \\
sexto ciclo de una \\
Institución Pública del \\
distrito rarrillos. \\
\multicolumn{2}{c}{ Cho } \\
\end{tabular} & $\begin{array}{l}\text { Variable } 1 \\
\text { Inteligencia } \\
\text { Emocional. }\end{array}$ & - Interpersonal & $\begin{array}{l}\text { Autoconocimiento } \\
\text { Asertividad } \\
\text { Autoconcepto } \\
\text { Independencia } \\
\text { Autorrealización } \\
\text { Empatía } \\
\text { Relaciones interpersonales } \\
\text { Responsabilidad social. } \\
\text { Comprende sentimientos } \\
\text { de los demás. } \\
\text { Tolerancia al estrés } \\
\text { Control de impulsos } \\
\text { Responde adecuadamente } \\
\text { en eventos estresantes } \\
\text { Prueba de la realidad } \\
\text { Flexibilidad para } \\
\text { adaptarse a los cambios }\end{array}$ \\
\hline
\end{tabular}




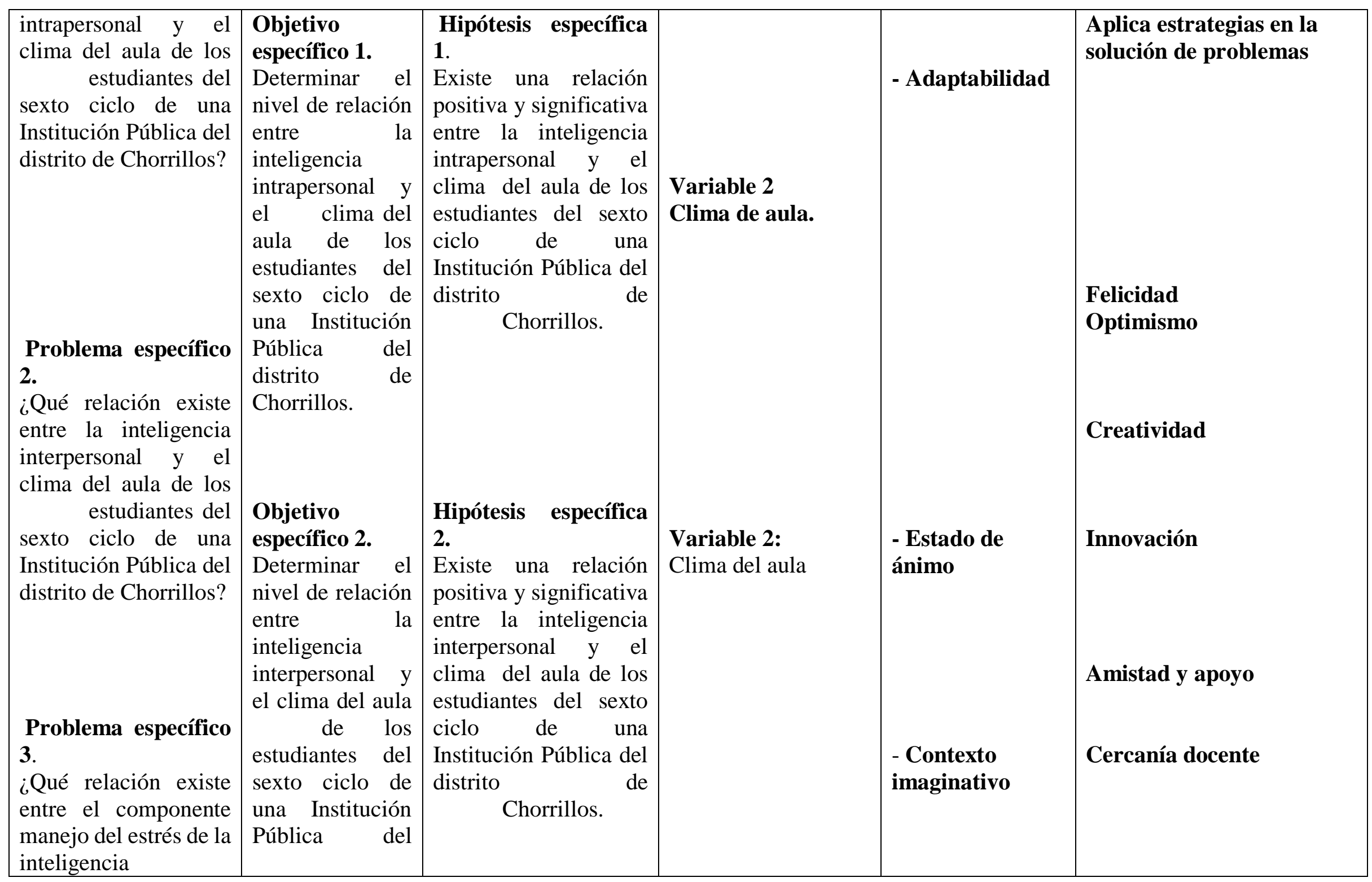




\begin{tabular}{|c|c|c|c|c|}
\hline 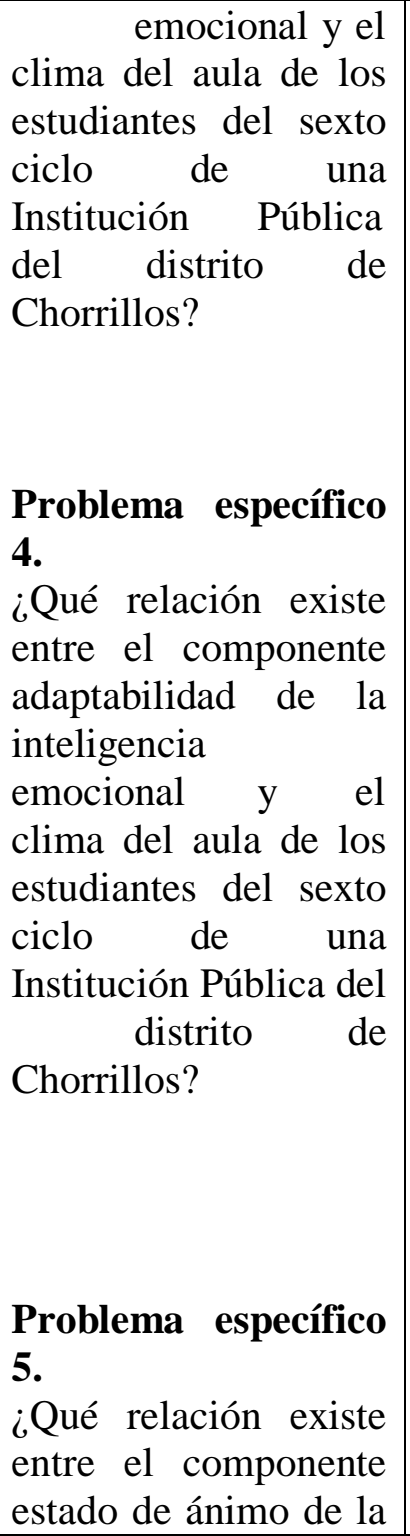 & 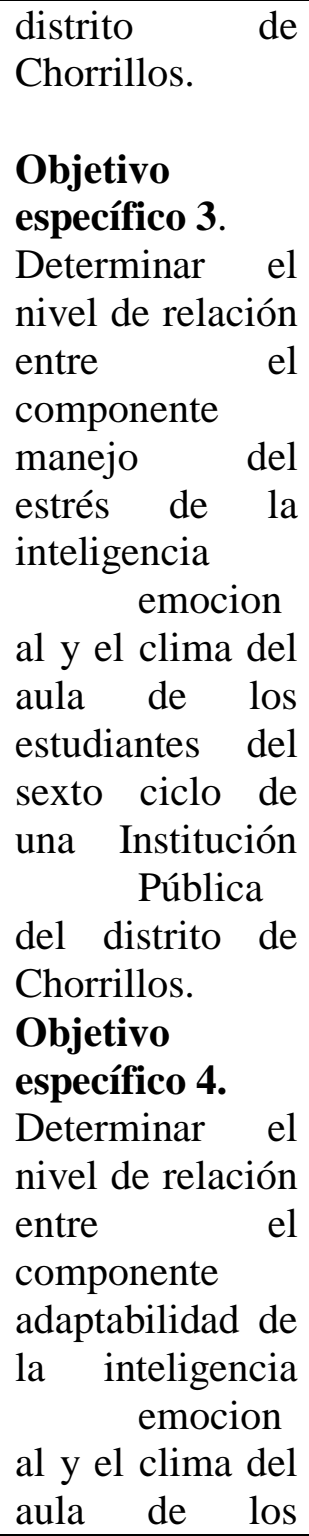 & \begin{tabular}{l} 
Hipótesis específica \\
3. \\
Existe una relación \\
positiva y significativa \\
entre el componente \\
manejo del estrés de la \\
inteligencia \\
emocional y el clima \\
del aula de los \\
estudiantes del sexto \\
ciclo de una \\
Institución \\
Pública del distrito de \\
Chorrillos. \\
\multicolumn{4}{c}{} \\
Hipótesis específica \\
4. \\
Existe una relación \\
positiva y significativa \\
entre el componente \\
adaptabilidad de la \\
inteligencia \\
emocional y el clima \\
del aula de los \\
estudiantes del sexto \\
ciclo de una \\
Institución
\end{tabular} & $\begin{array}{l}\text { - Contexto } \\
\text { interpersonal } \\
\\
\text { - Contexto } \\
\text { regulativo }\end{array}$ & \begin{tabular}{|l} 
Planificación \\
Dominio e interés
\end{tabular} \\
\hline
\end{tabular}




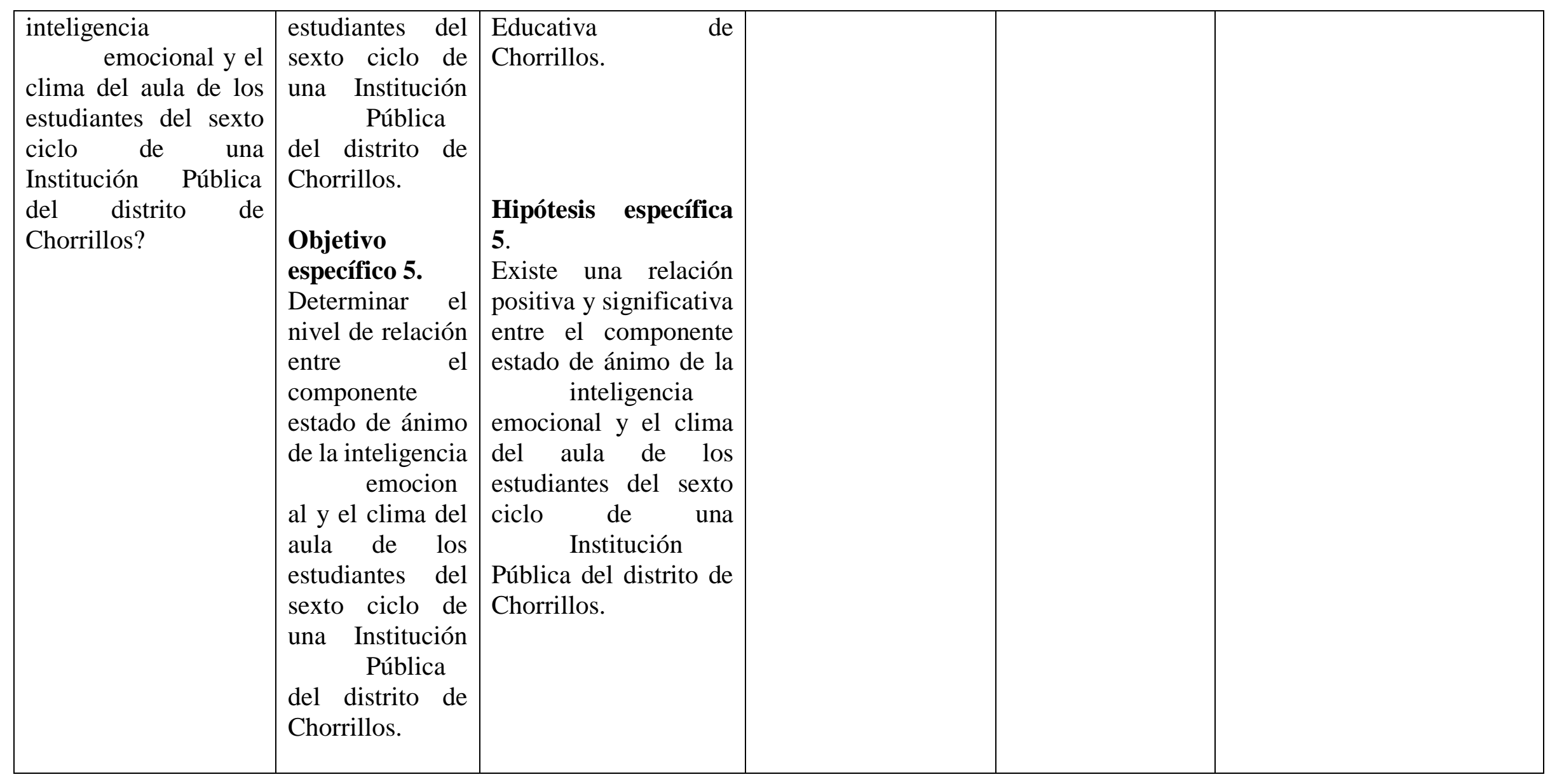

